RiCARDO AlVES MARTINS

\title{
TERMORREGULAÇÃO E DEPRESSÃO METABÓLICA EM ENDOTERMOS
}

Dissertação apresentada à Escola Politécnica da Universidade de São Paulo para obtenção do título de Mestre em Engenharia Elétrica.

- São Paulo 2009 


\section{TERMORREGULAÇÃO E DEPRESSÃO METABÓLICA EM ENDOTERMOS}

Dissertação apresentada à Escola Politécnica da Universidade de São Paulo para obtenção do título de Mestre em Engenharia Elétrica.

Área de Concentração:

Engenharia de Sistemas

Orientador:

Prof. Dr. José Guilherme de Souza Chauí Mattos Berlinck

- São Paulo - 
Este exemplar foi revisado e alterado em relação à versão original, sob responsabilidade única do autor e com a anuência de seu orientador.

São Paulo, 18 de Setembro de 2009.

Assinatura do autor

Assinatura do orientador

FICHA CATALOGRÁFICA

Martins, Ricardo Alves

Termorregulação e depressão metabólica em endotermos I

R.A. Martins. -- ed.rev. -- São Paulo, 2009.

$77 \mathrm{p}$.

Dissertação (Mestrado) - Escola Politécnica da Universidade de São Paulo. Departamento de Engenharia de Telecomunicações e Controle.

1. Biomatemática 2. Controle ótimo 3. Temperatura animal 4. Metabolismo animal I. Universidade de São Paulo. Escola Politécnica. Departamento de Engenharia de Telecomunicações e Controle II. $t$. 


\section{AGRADECIMENTOS}

À FAPESP pelo apoio para realização desta pesquisa.

Ao querido amigo ZéGui, incondicional em todas as horas. Menos durante o intervalo que reserva para tirar o sarro.

Ao prof. José Eduardo Bicudo, sempre disponível para uma boa conversa na qual eu sempre aprendo algo.

Ao sábio prof. Luiz Henrique Monteiro pelo apoio constante e pelas boas risadas.

Ao prof. Fuad Kassab Jr. por suas valiosas observações na qualificação.

Aos meus pais e sua fabulosa gastrolatria, generosos anfitriões da boa mesa sempre na expectativa de fazer-me provar mais um pedacinho.

Ao querido amigo Gustavo Bueno, inconformável como eu.

Aos queridos Ricardo Antas e Luciana Salazar por sua resistência motivadora e pelas boas conversas regadas a uísque.

À doce Ana Maria, plástico bolha para suportar a viagem. 
Para Pipoca e sua mãe Lady (que não mais termorregula). 
"Para contar, foi preciso fragmentar o todo em pedrinhas (calculi), e a cada uma dessas pedrinhas foi anexado um número. Será, portanto, que o fato de o mundo ser uma dispersão de partículas é conseqüência do nosso contar? Quer dizer então que não se trataria absolutamente de uma descoberta, mas sim de uma invenção? Por acaso não descobrimos no mundo aquilo que nós mesmos teríamos inserido nele? O mundo talvez seja calculável apenas porque nós o construímos para os nossos cálculos. Não são os números que são adequados ao mundo, mas o contrário: nós montamos o mundo de modo que se tornasse adequado ao nosso código numérico."

Por que as máquinas de escrever estalam? Em o Mundo Codificado.

Vilém Flusser

"A realidade da natureza acaba sendo estabelecida na esfera da argumentação humana"

O Golem: o que você deveria saber sobre ciência.

Harry Collins \& Trevor Pinch 


\section{RESUMO}

A depressão metabólica em aves e mamíferos, dada a alta demanda energética destes animais, se apresenta, geralmente, como resposta às condições de escassez de alimentos e baixas temperaturas. Desta forma, este projeto busca explorar, no campo teórico, como o sistema de termorregulação poderia atuar no sentido de maximizar as reservas energéticas minimizando os gastos metabólicos (depressão metabólica). Para tanto, fazemos uso de teorias da engenharia de controle que propiciam ferramental teórico para analisar como se dariam essas minimizações, ou seja, como o sistema nervoso atuaria estabelecendo um controle (set-point hipotalâmico) que minimizasse estes gastos à medida que se desse o processo de termorregulação.

Neste contexto, propomos um modelo básico de termorregulação que leva em conta temperatura corpórea, taxa metabólica e temperatura ambiente, no qual o set-point atua como um controle. Mostramos como este modelo de regulação térmica propicia, devido à sua configuração, significativa redução dos distúrbios causados por variações da temperatura ambiente. Através da teoria de controle ótimo, mostramos como o set-point hipotalâmico pode surgir como resultado da minimização de um funcional relacionado ao custo com a termorregulação. Além disso, fez-se uma análise de como a temperatura ambiente pode definir diferentes situações em termos de vantagens da depressão metabólica como mecanismo de minimização de gasto energético. Para este tipo de análise, propomos um índice de razão entre o custo metabólico constante e o obtido sob atuação do controlador durante o período em que se dá o processo. Após um período em depressão metabólica, os indivíduos devem voltar a sua condição de eutermia, e, em situações de baixa temperatura, o custo deste retorno pode suplantar as vantagens para um dado indivíduo. Assim, são analisadas as influencias da massa corpórea, onde se observa aumento do custo em decorrência da entrada em depressão metabólica por parte dos indivíduos de maior massa. Tal aumento de custo é acentuado nas situações de menor temperatura ambiente. Finalmente, uma análise relativa ao tempo para retorno à condição de eutermia é apresentada, sendo que os resultados vão ao encontro das evidencias atuais sobre a flexibilidade estratégica de muitos hibernantes. 


\section{ABSTRACT}

Metabolic depression of mammals and birds, animals of high metabolic demands, normally emerges as a response to food shortage and low ambient temperature. The main goal of this research is to explore, in a theoretical perspective, how the thermoregulatory system could extend the energy reserves of these endotherms decreasing metabolic costs under those environmental conditions. To approach the problem, we propose the use of control engineering theories to analyze the way the this minimization could occur, in other words, how the nervous system would act establishing a control (hypothalamic set-point) to minimize those costs during the thermoregulatory process.

In this context, we propose a basic thermoregulation model that takes into account body temperature, metabolic rate and environmental temperature, and in which the set-point acts as a control. We show how this model can significantly reduce disturbances generated by ambient temperature. Using optimal control theory, we show how the hypothalamic set-point can emerge as a result of a minimization process of a functional related to thermoregulation costs. Also, how ambient temperature can define different metabolic profiles is explored, in terms of metabolic depression and the necessary return to euthermic conditions. To quantify this analysis we propose an index, based on the ratio between a constant metabolic cost and the metabolic cost defined by the controller. After a period in metabolic depression individuals should return to their euthermic condition, and, in situations of low environmental temperature, it is shown that the cost to return can be larger than the advantages. In this way, analyzing body mass influences we observed increased metabolic depression cost in larger individuals. This cost is even higher under lower environmental temperature. Finally, the cost related to the time elapsed, until the euthermic state is reached again, is considered. These last results are in accordance with current conception about the flexibility in hibernation process. 


\section{SUMÁRIO}

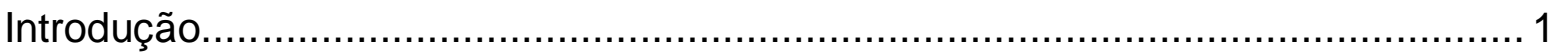

1. Regulação neuro-vegetativa da temperatura ................................................. 3

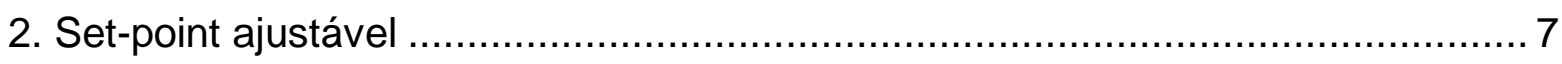

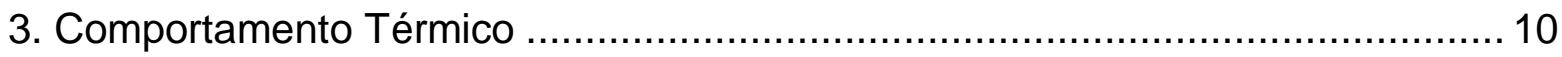

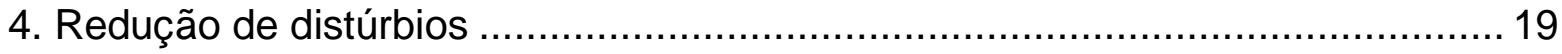

5. Abordagem através da teoria de controle ótimo …........................................ 23

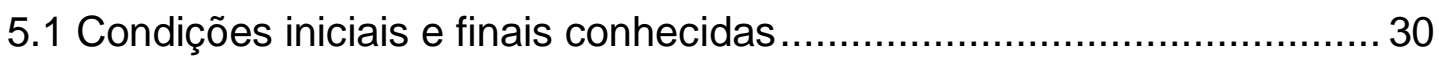

5.2 Condições iniciais conhecidas, finais desconhecidas e não

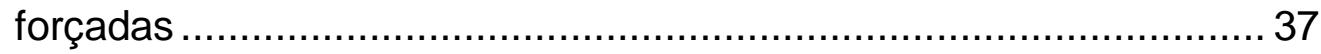

5.3 Condições iniciais conhecidas, finais alcançadas através da minimização de desempenho ........................................................ 41

6. Aplicações ao estudo da depressão metabólica ............................................... 55

6.1 Relações entre custo e massa corpórea ..................................................56

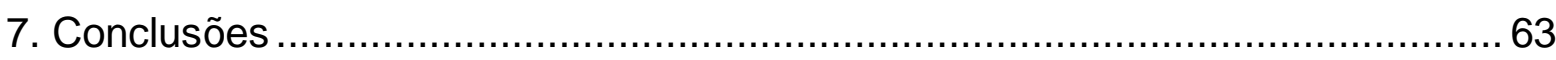

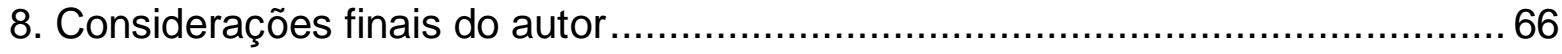

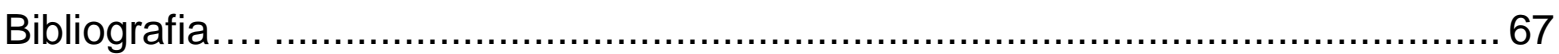




\section{INTRODUÇÃO}

A manutenção da vida está ligada com a possibilidade do organismo lidar com uma gama de situações ambientais que ora podem facilitar ora podem dificultar tal manutenção. Os exemplos mais evidentes dessa ligação são condições de privação alimentar, de privação de água, de excesso ou de falta de solutos, de extremos de temperatura (e.g., Schmidt-Nielsen, 1997; Withers, 1992). Não raro, essas condições se somam, como no inverno rigoroso quando tanto alimento quanto água se tornam de difícil obtenção concomitantemente a uma diminuição extrema na temperatura ambiente; ou como na zona entre-marés onde o acesso à água é extremamente variável ao longo do dia, em adição à exposição a temperaturas tanto muito altas quanto muito baixas. Dessa maneira, os organismos terminam por apresentar maneiras de passar, vivos, por essas situações, e essas maneiras podem, a grosso modo, ser comportamentais ou morfo-funcionais.

A migração de mamíferos é um bom exemplo de adaptação comportamental na qual a condição de privação, em vias de ocorrer, é evitada. O agrupamento de pingüins é, também, um outro exemplo de adaptação comportamental, sem que, no entanto, a condição do ambiente seja evitada. Em ambos os casos, a condição funcional dos organismos se mantém, basicamente, inalterada. Por outro lado, nem sempre tais soluções podem ser possíveis para outras espécies, e alterações funcionais podem se impor. Esses são, tipicamente, os casos de depressão metabólica, nos quais há uma diminuição nas taxas do organismo em geral, permitindo, temporalmente, a passagem da condição adversa até que uma situação mais favorável se faça presente (e.g., Schmidt-Nielsen, 1997; Guppy \& Withers, 1999; Geiser, 2004; Souza et al., 2004). Assim, entre outros exemplos, há a diapausa em insetos, a estivação em répteis e anfíbios, o torpor e a hibernação em aves e mamíferos. 
No caso particular de endotermos (aqui subentendidos como aves e mamíferos, somente ${ }^{1}$ ), os estados de depressão metabólica ocorrem, na maioria das vezes, em função da demanda energética elevada que esses animais têm, junto a condições ambientais de restrição alimentar e/ou frio intenso (Guppy \& Withers, 1999; Geiser, 2004; Westman \& Geiser, 2004). Existem, no entanto, outros fatores que podem estar ligados ao desencadeamento de estados hipometabólicos, como privação de água, hipóxia, etc. (e.g., Song \& Geiser, 1997; Schmid \& Speakman, 2000; Hochachka \& Somero, 2002).

Paralelo às questões de o que desencadeia os estados de depressão metabólica, está a problemática de como estes estados são atingidos e quais variáveis estão envolvidas em seu controle. Neste sentido, partimos do estudo geral do modelo de termorregulação, para mostrar como o set-point hipotalâmico pode surgir como um controle, resultado da minimização de um índice que reúna características que se deseje preservar ou minimizar, e que realizaria como conseqüência, aquilo que a literatura caracteriza por entrada em torpor (Westman \& Geiser, 2004; Geiser, 2004; Hainsworth, Collins \& Wolf, 1977).

Para isso, fazemos uso da teoria de controle ótimo, estabelecendo um ferramental teórico que permita uma análise quantitativa/qualitativa do sistema de termorregulação em questão, bem como dos custos envolvidos através dos índices que propomos. Cabe destacar ainda, que este trabalho não utiliza parâmetros reais, mas sim valores que buscam guardar certa proporção com os parâmetros reais de maneira a permitir a análise qualitativa de interesse.

Com os resultados deste trabalho, o que estamos sugerindo é que o set-point hipotalâmico seja um controle que surge como resultado de um processo de minimização, não um simples controle proporcional como propõem Hammel (1968) e Cabannac (1975) entre outros, que embora pareça justificar o fenômeno do ponto de vista térmico, ignora questões relacionadas ao metabolismo, a possíveis influencias de reservas energéticas e aos custos com a própria termorregulação.

\footnotetext{
${ }^{1}$ Pois vários outros grupos possuem exemplares ou exemplos de situações de endotermia, como em répteis, peixes, insetos.
} 
Porém, tão pouco deve ser visto de forma simplificada, como uma referência fixa, pré-determinada pelo sistema nervoso central.

Este trabalho é, assim, uma tentativa de juntar dois temas importantes que são, habitualmente, tratados de forma separada, questões relacionadas ao controle termorregulador e questões relacionadas aos custos da depressão metabólica.

\section{REGULAÇÃO NEURO-VEGETATIVA DA TEMPERATURA}

Um sistema regulado tem como característica principal, o aparecimento de ações ou respostas que se opõem às perturbações externas às quais este é submetido. São exemplos um pendulo com termo de forçamento, uma caixa d'água com bóia que controla sua vazão de entrada ou um corpo que controle seus fluxos de entrada e saída de energia. Este último representa, no caso de endotermos, tanto o controle de produção interna de energia metabólica, quanto o controle da perda ou ganho de energia para o ambiente. Assim, respostas de tremor (muscular) e não-tremor modulam ou controlam a termogênese, e a sudorese, associada ao controle vasomotor e de piloereção, modula a saída ou entrada de energia para ambiente.

Os sistemas podem ser classificados de acordo com a forma como respondem às perturbações, contínuas ou transientes. Nesta perspectiva, a melhor forma de estudá-los é perturbando-os, ou seja, a análise de qualquer sistema regulador deve estar baseada nas respostas que este sistema apresenta às diferentes entradas aplicadas. No caso do sistema termorregulatório, entradas sensoriais de frio e de calor (i.e., diminuição e aumento de temperatura) apresentam respostas autônomas ou comportamentais que seguem padrões bastante regulares. Habitualmente, os dados empíricos acerca da regulação da temperatura em endotermos são apresentados através destas respostas. Assim, há, por exemplo, a sugestão da existência, sob condições normais, de um intervalo de temperatura ambiente no qual a resposta metabólica de aumento/diminuição da taxa de produção (conversão) de energia está ausente frente às mudanças na temperatura ambiente. Sugere-se 
que, neste intervalo, a manutenção da temperatura se daria apenas através de respostas vasomotoras/piloeretoras, ou seja, respostas "sem demanda metabólica associada", mas basicamente, pelo controle sobre a taxa de transferência de energia entre o sistema e o entorno. A Figura 1.1-A ilustra o fenômeno, delimitando o que é conhecido como zona de termoneutralidade (TNZ - do inglês "thermoneutral zone") (Mercer, 2001). Em humanos, por exemplo, essa zona se encontra entre 33 e $35^{\circ} \mathrm{C}$ (Schmidit-Nielsen, 1997).

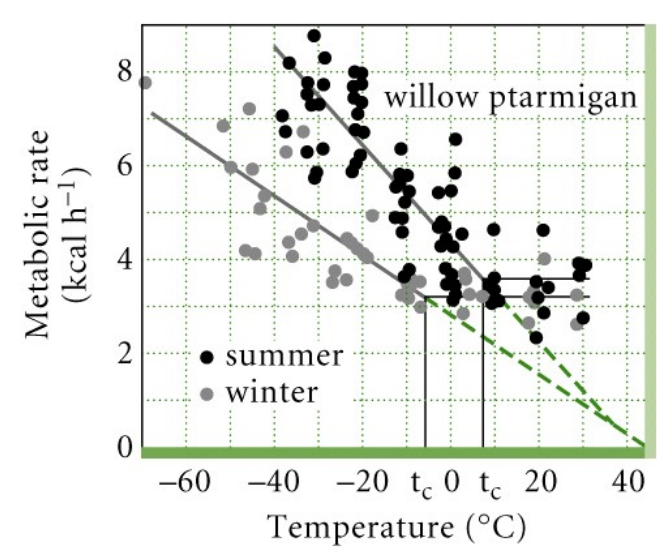

A

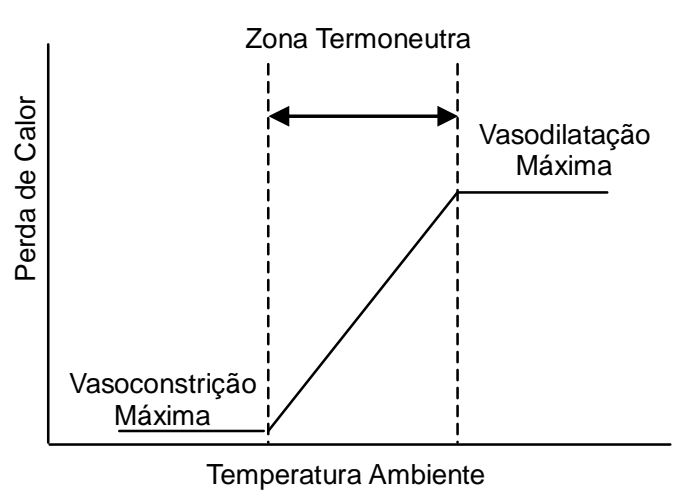

B

Fig. 1.1: Zona de termoneutralidade para um endotermo-homeotermo típico. (A) Relação entre a taxa metabólica (consumo de oxigênio) e temperatura ambiente (fonte:http://people.eku.edu/ritchisong/RITCHISO/Ptarmiganmetabolicrate.jpg) para a espécie de ave Willow ptarmigan. (B) Relação entre taxa de transferência de energia por diferença de temperatura e a temperatura ambiente. Adaptado de Mekjavic (2006). Ver texto para detalhes.

Tem sido dada atenção especial, atualmente, aos fatores ditos não-termais que influenciariam as respostas vasomotoras e, em conseqüência disso possíveis alargamentos/estreitamentos da zona de termoneutralidade (Romanovsky, 2002). O efeito destes fatores seria o de atenuar a vasoconstrição induzida pelas temperaturas mais baixas ou a vasodilatação induzida pelas temperaturas mais elevadas. Seres humanos podem, por exemplo, tirar ou colocar roupas, e animais podem voltar ao seu abrigo ou aproximar- se uns dos outros.

Uma vez que as repostas vasomotoras não sejam mais suficientes para manter a temperatura corpórea num certo valor, as respostas termorreguladoras vegetativas (i.e., sistema nervoso autônomo) de produção (termogênese) ou perda de energia 
são ativadas. Assim, temperaturas corpóreas que correspondem ao início destas respostas, definidas como limiares termo-efetores (thermoeffector threshold), marcariam o início das repostas termorreguladoras. A Figura 1.2 ilustra o que acabamos de descrever.

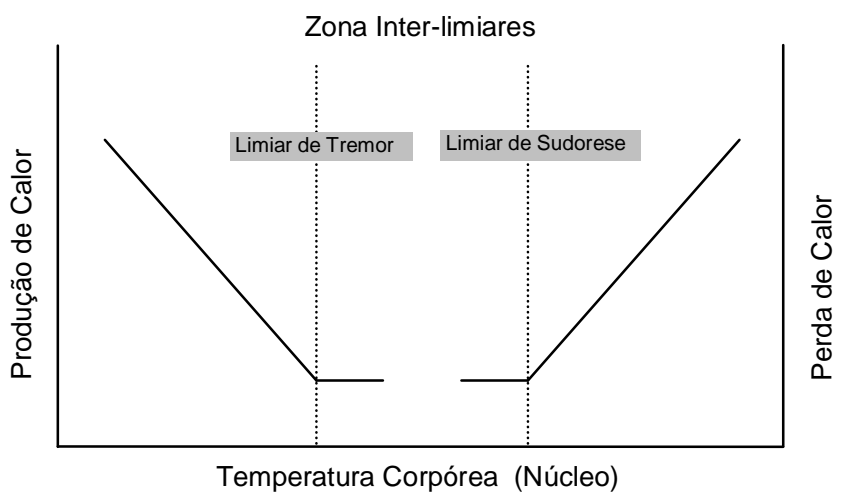

Fig. 1.2: Limiares de temperatura corpórea para resposta vegetativa de termorregulação metabólica. Podemos ver um intervalo de temperatura corpórea, similar à zona de termoneutralidade para a temperatura ambiente, no qual as respostas de produção ou perda de calor não estão presentes. Este intervalo é limitado pelos limiares termo-efetores de temperatura para os quais as respostas de tremor e de sudorese são ativadas. Como no caso da zona-termoneutra para temperatura ambiente, características comportamentais podem também alterar o comprimento deste intervalo. Adaptado de Mekjavic (2006).

Com base no padrão de respostas apresentadas nas Figuras 1.1 e 1.2, alguns pesquisadores (Kanosue, 1997; Mekjavic, 2006; Romanovsky, 2007) sugerem que a regulação da temperatura não poderia se dar em um nível preciso. Desta forma, vêem como inviável a possibilidade de existência de um set-point, como definido em termos da engenharia, posto que sob condições fisiológicas normais a temperatura corpórea flutuaria dentro da zona inter-limiares.

Há, contudo, críticas a essa interpretação. Ao representar as respostas termorregulatórias como explicado acima (ver Figura 1.2), o que se está fazendo é uma extrapolação na qual se deixa de evidenciar que tal padrão de resposta corresponde apenas a alguns casos e que, quando os resultados de um grupo são representados, esta suposta zona desaparece. Isto é sugerido a partir do experimento conduzindo pelo próprio Mekjavic (1991), cujos resultados são ilustrados na Figura 1.3. 


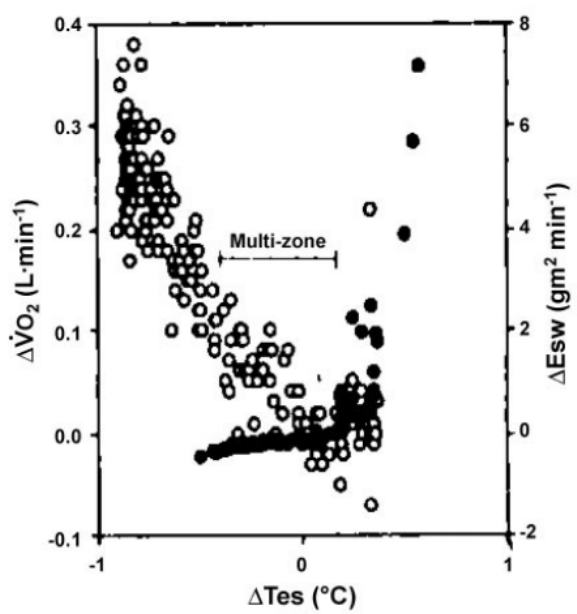

Fig. 1.3: Repostas termorregulatórias em função de temperatura esofagiana em um grupo de 9 indivíduos humanos, mostrando que tanto a termogênese $\Delta \dot{V} O_{2}$ (representada pelo consumo de oxigênio, ordenada esquerda - círculos vazios) quanto a perda evaporativa, $\Delta E s w$ (representada por taxa de suor, ordenada direita - círculos cheios) variam (se alteram) ao longo de toda a faixa de temperaturas esofagianas. A Figura ilustra como as respostas estão sobrepostos e que nenhuma, ou quase nenhuma, zona inter-limiares ou nula, existe. Note também como a termogênese $\Delta \dot{V}_{2}$ apresenta resposta linear frente às mudanças na temperatura esofagiana. Figura extraída de Mekjavic, 1991.

A constatação deste padrão termorregulatório em humanos, em conjunto com o fato de que tanto a temperatura esofagiana quanto a temperatura retal (comumente experimentos são conduzidos em função desta última, a qual se supõe ser mais fidedigna a uma temperatura central ("core")) não são a temperatura no cérebro, levou Cabannac a sugerir que se esta zona nula existe é de pouca relevância fisiológica e poderia significar, simplesmente, que o intervalo de regulação da temperatura é menos vital que, por exemplo, o de concentração de cálcio no sangue (Cabannac, 2006). A concentração calcêmica é sempre garantida em 10 mg/100 ml de sangue e a melhor maneira de explicar tal defesa é através de uma mecanismo de realimentação negativa onde $10 \mathrm{mg} / 100 \mathrm{ml}$ é dado como o set-point do sistema de regulação (Bonnier \& Cabanac, 1970; Talmage, 2000) .

Além disso, outras considerações devem ser feitas em prol da existência de um setpoint para regular a temperatura corpórea. Primeiramente, a existência de um setpoint, entendido como o valor a ser defendido pelo sistema de regulação da temperatura corpórea, não garante ou impõe a inexistência de flutuações ao seu redor. Mudanças estruturais no sistema, como capacitância ou condutância térmica, 
teoricamente expressos como simples alterações em ganhos, podem redefinir a forma como o sistema se estabiliza (ver discussão no item 4 mais abaixo).

Na mesma direção, o set-point envolvido no sistema termorregulatório não precisa ser uma constante fixa. Ao contrário, este poderia ser ajustado continuamente, como sugere originalmente Hammel (ver discussão abaixo), sob influencia de sinais periféricos e programações genéticas (Cabanac, 2006). Ainda, influencias estruturais como receptores de frio ou calor envolvidos na "leitura" das mudanças termais, pontos de disparo ou de desnaturação de proteínas, etc, são outras importantes fontes potenciais de mudança no set-point de temperatura. Evidências para este argumento seriam o aumento do valor de set-point durante a febre ou anapirexia (Cooper, 2002).

\section{SET-POINT AJUSTÁVEL}

Para humanos saudáveis, o set-point é dado, supostamente, em $37^{\circ} \mathrm{C}$ e temperatura corpórea é regulada em torno deste valor com variação de $1^{\circ} \mathrm{C}$, aproximadamente, durante o dia. As potenciais vantagens de tal valor não são ainda claras, principalmente quando se considera os valores apresentados por outros mamíferos eutérios, $36^{\circ} \mathrm{C}$ a $38^{\circ} \mathrm{C}$, por aves passariformes, $38^{\circ} \mathrm{C}$ a $43^{\circ} \mathrm{C}$ e por marsupiais, $35^{\circ} \mathrm{C}$ (Cooper, 2002).

Um dos modelos mais interessantes proposto para explicar a termorregulação está fundamentado na constatação que os set-points são ajustáveis(Hammel et al.,1963).. Segundo estes autores, o set-point termorregulatório pode ser ajustado com precisão sob a influência de sinais periféricos de temperatura. Mais ainda, este mecanismo teria propriedades antecipatórias porque o esfriamento da pele elevaria o set-point enquanto que o aquecimento da pele reduziria o set-point, antes que a temperatura ambiente pudesse modificar a temperatura no interior do organismo. 
Hammel e colegas sugerem, também, que a regulação da temperatura se daria através de um controle proporcional, e, assim, todas as respostas térmicas dadas pelo hipotálamo poderiam ser descritas por:

$R-R_{0}=\alpha_{r}\left(T_{h}-T_{\text {set }}\right) \quad$ (Hammel et al.,1963)

Sendo $R-R_{0}$ a resposta (tremor, sudorese, aumento ou diminuição de fluxo sangüíneo, etc.), $T_{h}$ a temperatura hipotalâmica, resultado do fechamento da alça de realimentação fig. 2.1, $T_{\text {set }}$, em seu conjunto, a referencia de temperatura hipotalâmica intrínseca, mais um termo temperatura-dependente proveniente dos receptores de frio e de calor da pele, associada a um "termo" diferente de zero quando o animal está acordado. Finalmente, $\alpha$, é um ganho que difere em magnitude para cada resposta, sendo positivo para as respostas de dissipação de energia térmica e negativo as respostas de conservação ou produção de energia térmica. Desta forma, os autores concluem que todos os fatores que influenciam a regulação da temperatura têm efeito sobre o set-point ou sobre o ganho $\alpha_{r}$, que nunca poderia ser nulo para homeotermos vivos e não anestesiados. A Figura 2.1 ilustra a representação esquemática do modelo como proposto por Hammel (1968). 


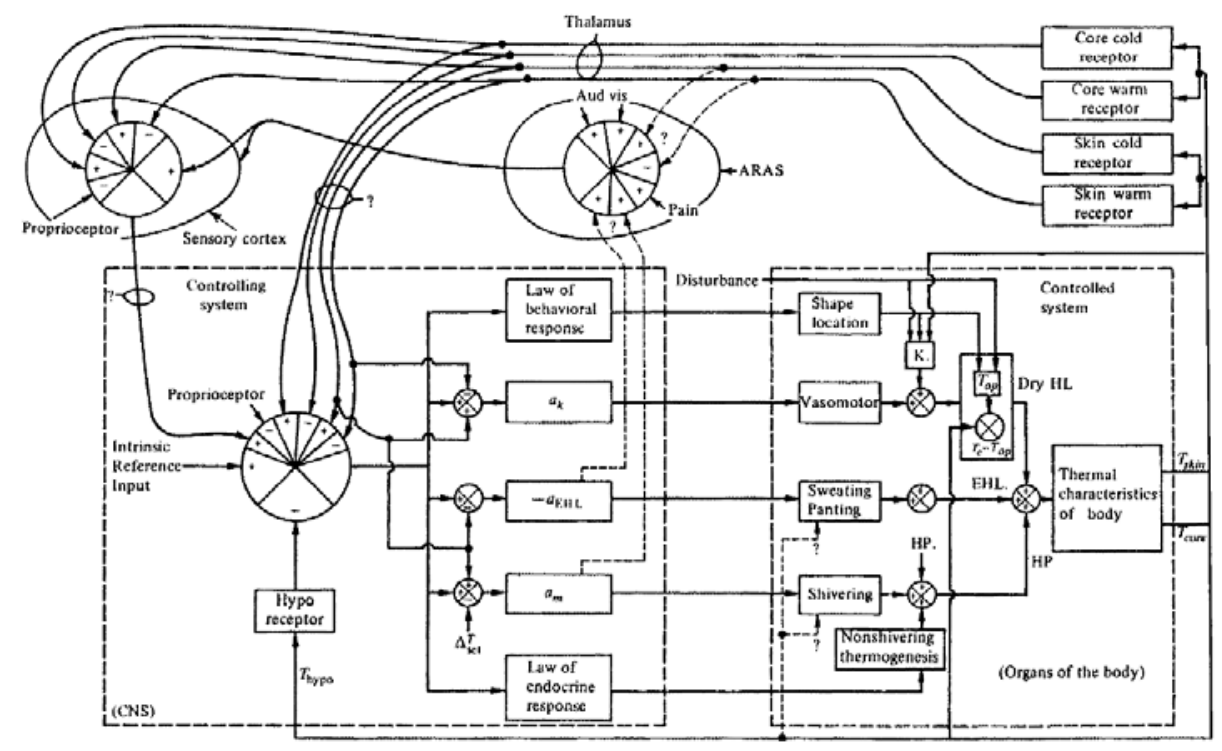

Fig. 2.1: Esquema do controle térmico em mamíferos (reproduzido de Hammel, 1968). Esta seria a representação do sistema de controle e da planta a ser controlada para a regulação da temperatura interna. Note que se tem $T_{\text {hypo }}$ como resultado do fechamento da alça de controle, a ser comparado com o set-point hipotalâmico, dado pela referencia e outras entradas (detalhes no texto), bem como a estrutura do controlador proporcional, onde $a_{k}$ é ganho ou fator de proporcionalidade para a transferência de calor não-evaporativo, $a_{m}$ é o fator de proporcionalidade para as respostas de tremor e $a_{E H L}$ é o fator de proporcionalidade para a perda de calor evaporativo ou sudorese. ARAS, sistema de ativação reticular ascendente; Aud vis, audiovisual; CNS, sistema nervoso central; EHL, Perda de calor evaporativo; HP, Produção de calor; HL, Perda de calor; $\mathrm{K}$, coeficiente para a transferência de calor nãoevaporativo; Tc, Temperatura central; Top, Temperatura operacional.

Sendo a temperatura corpórea uma variável regulada, na ausência de perturbações externas esta se estabiliza no valor de set-point do sistema. Este seria o valor defendido pelo sistema de termorregulação, ou seja, o valor ao qual a variável regulada é comparada a todo instante.

Outra característica que vale a pena ser destacada é que a regulação da temperatura corpórea, sendo dada através do controle da perda e produção de energia, evidencia o papel da taxa metabólica como resultado das demandas energéticas dos órgãos ou tecidos na produção energética. Este controle, neste estudo, é então resultado de um controlador integral (eq. 3.4, abaixo), onde o erro é dado como a diferença entre a temperatura de set-point e a temperatura corpórea. 


\section{COMPORTAMENTO TÉRMICO}

Dois pressupostos permitem a construção de um modelo de termorregulação. Um diz respeito a como a temperatura corpórea é dada a partir de um balanço que existe entre a energia recebida (ou produzida) por um organismo e a energia perdida (ou liberada) por este organismo. No caso de endotermos, a temperatura corpórea é ativamente regulada através do controle da energia produzida no organismo - metabolismo energético - e do controle da energia perdida para o ambiente pelos mecanismos de troca térmica de condução, convecção, radiação e sudorese. O outro pressuposto é o de que a geração energética dada pelo metabolismo é, numa ampla faixa, uma resposta linear frente às variações da temperatura ambiente, ver Figuras 1.1-A e 1.3.

Buscamos aqui, definir e explicitar as variáveis e estruturas envolvidas no processo termorregulação. Para tanto, analisamos inicialmente um modelo básico de termorregulação de aves e mamíferos (e.g., Cooper, 2002; Chaui-Berlinck et al., 2005). Resumidamente, a variação da temperatura corpórea é dada a partir da diferença entre as temperaturas ambiente, $T_{a}(t)\left({ }^{\circ} \mathrm{C}\right)$, e corpórea, $T_{b}(t)\left({ }^{\circ} \mathrm{C}\right)$, gerando perda de energia proporcional à condutância térmica ${ }^{2} \chi\left({ }^{\circ} \mathrm{C}^{-1} \mathrm{~s}^{-1}\right)$, para $\mathrm{o}$ ambiente. A diferença entre essa perda e a entrada pela taxa metabólica $M\left(J s^{-1}\right)$, proporcional a um coeficiente $h(\in] 0,1[)$ - representante da ineficiência no aproveitamento da produção metabólica -, resultam numa variação em $T_{b}(t)$, com taxa inversamente proporcional à massa corpórea $B(g)$, e capacitância térmica do organismo $C\left(\mathrm{~J} \mathrm{~g}^{-1}{ }^{\circ} \mathrm{C}^{-1}\right)$. Desta forma, o modelo inicial é dado por:

$\frac{d T_{b}(t)}{d t}=\frac{1}{B C}\left(h M(t)-\chi\left(T_{b}(t)-T_{a}\right)\right)$

Aplicando a transformada de Laplace e reescrevendo o modelo de troca térmica, equação 3.1, que caracteriza a variação da temperatura corpórea devido aos processos de produção e perda de energia na termogenese, temos:

\footnotetext{
${ }^{2}$ Representa um termo geral de condutância térmica para as trocas por condução, convecção, radiação e evaporação.
} 
$T_{b}(s)\left(1+\frac{1}{s} \frac{\chi}{B C}\right)=\frac{1}{s}\left(\frac{h}{B C} M(s)+\frac{\chi}{B C} T_{a}(s)\right)$

$T_{b}(s)=\left(\frac{h}{B C s+\chi}\right) M(s)+\left(\frac{\chi}{B C s+\chi}\right) T_{a}(s)$

Dividindo a equação 3.2 em partes e construindo os respectivos diagramas de blocos de forma a tentar capturar esquematicamente as relações entre as variáveis e os controles, segue a representação dos modelos em malha aberta:

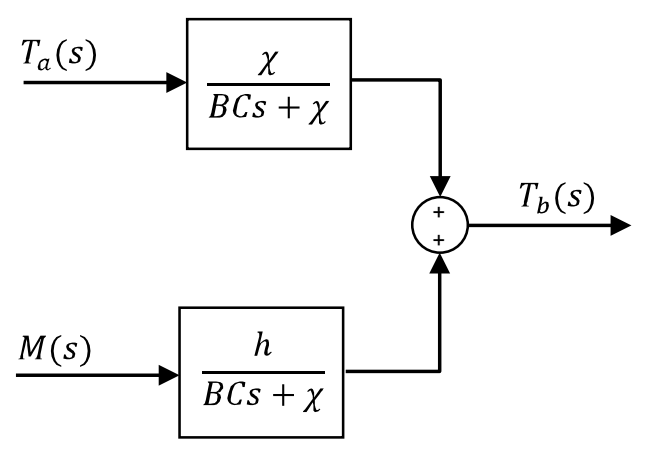

Fig. 3.1: Diagrama de blocos do modelo de variação da temperatura corpórea, equação 3.2. Vale destacar que o modelo representa um sistema em malha aberta e, desta forma, para uma dada produção de energia metabólica, variações na temperatura ambiente podem afetar de forma significativa a temperatura corpórea.

A função de transferência $G(s)=\frac{h}{B C s+\chi}$ modela, como uma mudança no metabolismo $M(t)$ afeta a temperatura corpórea, $T_{b}(t)$, enquanto a função de transferência $D(s)=\frac{\chi}{B C s+\chi}$ modela como as variações da temperatura ambiente afetam a temperatura corpórea.

A equação 3.2 representa o modelo de um sistema em malha aberta, no qual qualquer variação na temperatura ambiente ou na taxa metabólica causa variações na temperatura corpórea. Ou seja, uma vez definida a taxa metabólica, qualquer variação na temperatura ambiente causa variações na temperatura corpórea.

Segundo Khoo (1999), animais ectotermos/heterotermos não teriam o controle metabólico dado em função da temperatura corpórea, mas apenas em função da 
temperatura ambiente, ou seja, um sistema de trocas térmicas, como representado acima, bastaria para explicar os comportamentos térmicos destes animais.

Contudo, essa aproximação ou idéia de corpos inertes é fisiologicamente equivocada dado que a regulação térmica da grande maioria dos seres vivos difere muito disso. Alguns modelos tipo carga e descarga de capacitores como modelo de entrada e saída de energia do organismo, com produção metabólica que independe da temperatura ambiente, e perda por evaporação, parecem descrever bastante bem a dinâmica térmica animal (Hainsworth, 1995; Rodriguez-Gironés, 2002). Entretanto, tal modelagem não captura os aspectos de regulação/controle apresentados pelos organismos. Assim, mesmo quando a taxa metabólica não se presta à termorregulação, como sugere ser o caso de animais ectotermos, o comportamento do indivíduo/grupo acaba por tornar inválido o modelo de corpos inertes.

A partir de nosso segundo pressuposto, o da produção metabólica como sendo uma resposta linear frente às mudanças na temperatura ambiente, e da existência de um set-point de temperatura hipotalâmico, como sugerido por Hammel e colegas (1963), buscamos redefinir o controle de produção da energia metabólica como sendo o resultado do fechamento de uma alça de realimentação de estados, dado a partir de uma comparação entre a temperatura corpórea - que está sendo influenciada constantemente por mudanças na temperatura ambiente - e um setpoint pré-definido. Isso de forma a produzir as variações necessárias no metabolismo energético que compensem as perturbações causadas pela temperatura ambiente.

Em um sistema de malha fechada, a realimentação negativa faz com que mudanças na saída do sistema sejam compensadas por mudanças no sentido oposto, pelas ações de controle. Desta forma, a realimentação negativa é o atributo principal que permite os sistemas de controle em malha fechada a atuar como reguladores (Nise, 2003). Ou seja, sugerimos que a produção energética dada pelo metabolismo represente um controle obtido via realimentação de estados, no qual o controlador metabólico teria como entrada um erro proporcional decorrente das diferenças entre o set-point hipotalâmico fixo e a temperatura corpórea, $T_{b}(t)$. 
Mais adiante, iremos deixar de fixar um set-point previamente determinado para a comparação e buscar através de um processo de minimização obter uma temperatura corpórea que se mantenha fixa ou dentro de uma faixa, independente da temperatura ambiente.

Desta forma, a equação que define como se dá a variação do metabolismo energético é dada por:

$\frac{d M(t)}{d t}=K\left(T_{s}(t)-T_{b}(t)\right)$

Aplicando a transformada de Laplace à equação 3.3, ficamos com:

$$
M(s)=\frac{K}{s}\left(T_{s}(s)-T_{b}(s)\right)
$$

Ou seja, a entrada de controle metabólico para o sistema se dá através do erro entre a temperatura corpórea e a temperatura de set-point hipotalâmico, caracterizando, com isso, o fechamento da alça de realimentação.

Desta forma, para regular a temperatura corpórea em torno da temperatura de setpoint hipotalâmico, podemos utilizar uma arquitetura de realimentação de estados de maneira a controlar a resposta metabólica, $M(t)$, de produção de energia. Segue representação de blocos do esquema descrito, equações 3.2 e 3.4: 


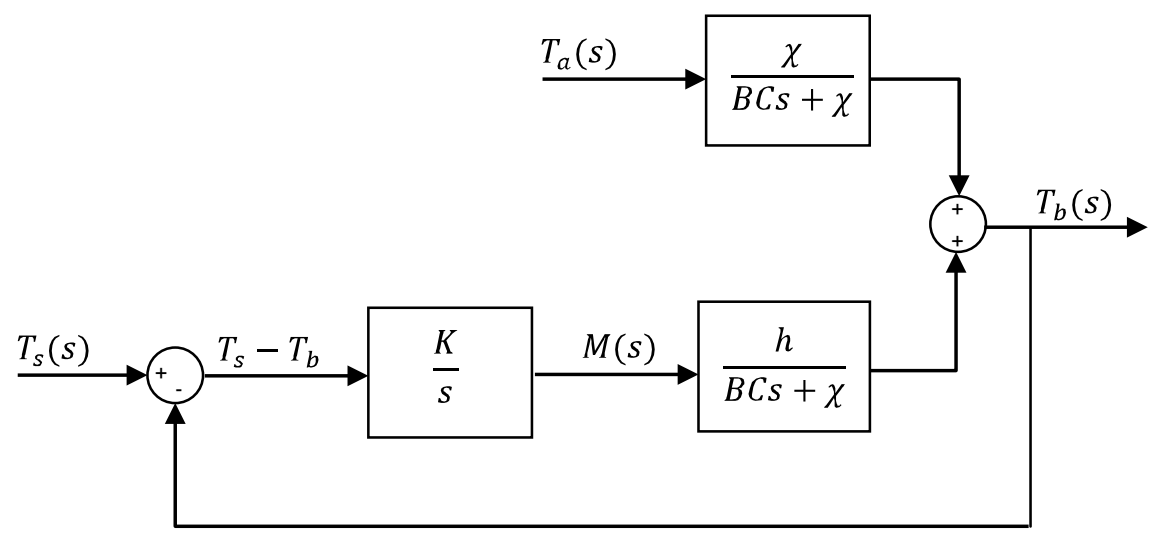

Fig. 3.2: Diagrama de blocos do modelo de variação da temperatura corpórea, equações 3.2 e 3.4. Modelo representa um sistema em malha fechada do processo de regulação da temperatura corpórea sobre influencia da temperatura ambiente.

Após algumas manipulações algébricas, podemos escrever:

$$
T_{b}(s)=\frac{K h}{B C s^{2}+\chi s+K h} T_{s}(s)+\frac{\chi s}{B C s^{2}+\chi s+K h} T_{a}(s)
$$

Assim, a equação 3.5 nos dá um modelo térmico sob influencia da temperatura ambiente. Primeiramente, preferimos estudar o modelo sem os efeitos da temperatura ambiente (o modelo completo será estudado na seqüência).

Isolando o controlador $C(s)=\frac{K}{s}$, a planta $G(s)=\frac{h}{B s+\chi}$ e a alça de realimentação do modelo de distúrbios, $D(s)=\frac{\chi}{B s+\chi}$, podemos analisar as respostas do modelo $G(s)$ frente ao controle da taxa metabólica.

Desta forma, ficamos com:

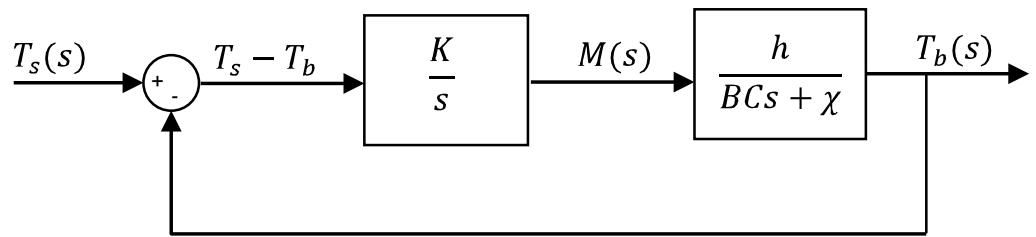

Fig. 3.3: Diagrama de blocos do modelo de variação da temperatura corpórea sem influencias da temperatura ambiente. 
Cuja função de transferência é:

$\frac{T_{b}(s)}{T_{s}(s)}=\frac{C(s) G(s)}{1+C(s) G(s)}=\frac{K h}{B C s^{2}+\chi s+K h}$

Ou seja:

$\left(B C s^{2}+\chi s+K h\right) T_{b}(s)=K h T_{s}(s)$

$T_{b}(s) s^{2}+\frac{\chi}{B C} T_{b}(s) s+\frac{K h}{B C} T_{b}(s)=\frac{K h}{B C} T_{s}(s)$

Aplicando a anti-transformada de Laplace:

$\ddot{T}_{b}(t)+\frac{\chi}{B C} \dot{T}_{b}(t)+\frac{K h}{B C} T_{b}(t)=\frac{K h}{B C} T_{s}(t)$

O equilíbrio é dado quando $\dot{T}_{b}(t)=0$ e $\ddot{T}_{b}(t)=0$, assim:

$T_{b}^{*}(t)=T_{s}(t)$

Cuja estabilidade pode ser estudada a partir do caso homogêneo, $T_{s}(t)=0$ :

$\ddot{T}_{b}(t)+\frac{\chi}{B C} \dot{T}_{b}(t)+\frac{K h}{B C} T_{b}(t)=0$

Neste caso, buscamos soluções da forma $T_{b}(t)=e^{\lambda t}$

Assim,

$\lambda^{2} e^{\lambda t}+\frac{\chi}{B C} \lambda e^{\lambda t}+\frac{K h}{B C} e^{\lambda t}=0$

Que tem como polinômio característico:

$\lambda^{2}+\frac{\chi}{B C} \lambda+\frac{K h}{B C}=0$

Cujas raízes são dadas por:

$\lambda=\frac{-\chi \pm \sqrt{\chi^{2}-4 K h B C}}{2 B C}$

A partir dos autovalores acima, e do fato de $\chi$, condutância térmica e $B C$, produto massa corpórea-capacitância, serem sempre maiores que zero, concluímos que o 
modelo termorregulatório simplificado, sem perturbação da temperatura ambiente é sempre estável.

Com isso, a forma como $T_{b}(t)$ se aproxima de $T_{s}(t)$ depende apenas do sinal de $\chi^{2}-4 K h B C$. E, assim são possíveis 3 casos:

Caso I : $\chi^{2}-4 K h B C>0$

Ou seja, $\chi>\sqrt{4 K h B C}$. Neste caso, a solução do sistema é dada nas formas abaixo. Para o caso homogêneo:

$T_{b}(t)=C_{1} e^{\frac{-\chi+\sqrt{\chi^{2}-4 K h B C}}{2 B C} t}+C_{2} e^{\frac{-\chi-\sqrt{\chi^{2}-4 K h B C}}{2 B C} t}$

Assim, $\lim _{t \rightarrow \infty} T_{b}(t)=0$

Devemos lembrar que as constantes $C_{1}$ e $C_{2}$ dependem apenas condições iniciais $\dot{T}_{b}(0)$ e $\ddot{T}_{b}(0)$.

Para o caso não-homogêneo, a solução de 3.6 é dada por:

$T_{b}(t)=C_{1} e^{\frac{-\chi+\sqrt{\chi^{2}-4 K h B C}}{2 B C} t}+C_{2} e^{\frac{-\chi-\sqrt{\chi^{2}-4 K h B C}}{2 B C} t}+T_{s}$

Onde $T_{s}$, representando o set-point hipotalâmico, é inicialmente constante. Ou seja:

$\lim _{t \rightarrow \infty} T_{b}(t)=T_{s}=$ Constante

Podemos, nesta situação, a partir da equação 3.7, concluir que animais de menor massa atingem equilíbrio térmico mais rapidamente (Figura 3.4). Este resultado é similar a resultados teóricos anteriores (Chaui-Berlinck et al., 2005) nos quais a dinâmica da temperatura corpórea de homeotermos era definida por suas diferentes 
massas, sugerindo efeitos de uma "inércia térmica", devido a maior produto massacapacitância.

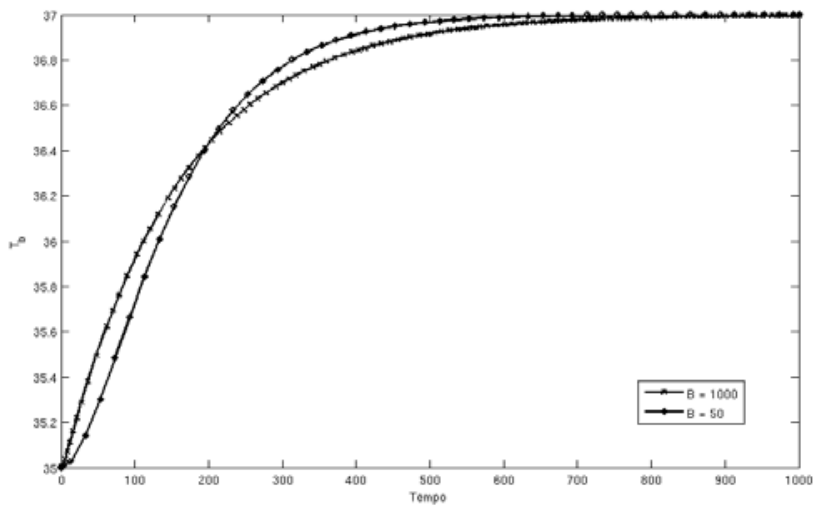

Fig. 3.4: Resultado de simulação da equação 3.7. Para os valores de $\chi=16, h=0.2, K=0.5$. Diferenças entre massas causa mudanças na velocidade com que o sistema atinge o equilíbrio.

Esta diferença se acentua no caso II, abaixo, onde a condutância térmica é reduzida (Figura 3.5). Tal cenário poderia indicar uma situação de baixa temperatura ambiente.

Caso II: $\chi^{2}-4 K h B C<0$

Ou seja, $\chi<\sqrt{4 K h B C}$. E, nesta situação, a solução da equação 3.6 , para o caso homogêneo é dada por:

$T_{b}(t)=C_{1} e^{\frac{-\chi}{2 B C} t} \cos \left(\frac{\sqrt{4 K h B C-\chi^{2}}}{2 B C} t\right)+C_{2} e^{\frac{-\chi}{2 B C} t} \operatorname{sen}\left(\frac{\sqrt{4 K h B C-\chi^{2}}}{2 B C} t\right)$

Aqui, podemos ver através da solução da equação diferencial, que animais com menor massa atingem equilíbrio mais rapidamente. Isso será importante observar quando a temperatura ambiente for considerada em nosso sistema, de forma a causar perturbações no modelo termorregulatório. 
Para o caso não-homogêneo:

$T_{b}(t)=C_{1} e^{\frac{-\chi}{2 B C} t} \cos \left(\frac{\sqrt{4 K h B C-\chi^{2}}}{2 B C} t\right)+C_{2} e^{\frac{-\chi}{2 B C} t} \operatorname{sen}\left(\frac{\sqrt{4 K h B C-\chi^{2}}}{2 B C} t\right)+T_{s}(t)$

Donde fica claro que $T_{b}(t) \rightarrow T_{s}(t)$ quando $t \rightarrow \infty$.

Esta solução geral da equação não-homogênea, equação 3.6, pode ser vista na Figura 3.5, com condições iniciais calculadas a partir de $T_{b}(0)=35$ e $\dot{T}_{b}(0)=0$. O set-point hipotalâmico $\left(T_{s}\right)$ é inicialmente constante.

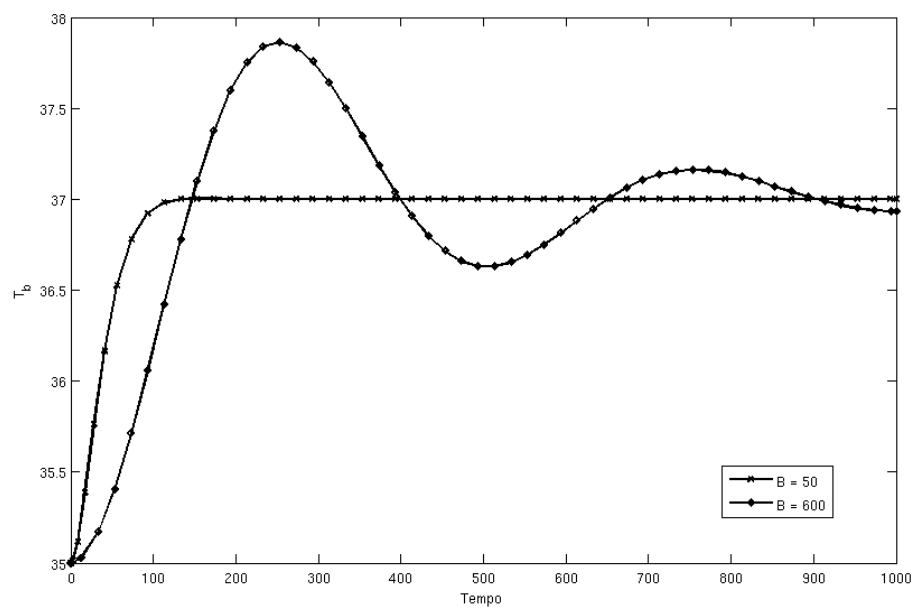

Fig. 3.5: Resultado de simulação da equação 3.7, no caso II. Para os valores de $\chi=4, h=$ $0.2, K=0.5$. Diferença entre massas causa mudanças na velocidade com que o sistema atinge o equilíbrio e na presença/ausência de sobre-sinal.

Caso III: $\chi^{2}-4 K h B C=0$

Esta terceira situação, também estável, vamos ignorar, pois, aparentemente não deve corresponder ao sistema físico em questão, pelo fato representar uma condição muito particular no espaço das constantes que modelam o sistema, ou seja, a condição $\chi^{2}=4 K h B C$ sugere uma condição analítica muito forte dada pela igualdade, mas não uma condição física real. 
Se caracterizarmos a temperatura ambiente como distúrbio na temperatura corpórea, poderíamos escrever, genericamente, o modelo térmico sob influencia da temperatura ambiente, equação 3.5, e estudar como estes distúrbios afetam $T_{b}(t)$.

\section{REDUÇÃO DE DISTÚRBIOS}

Um modelo genérico de malha fechada, com distúrbios $D(s)$ na saída pode ser representado da seguinte forma:

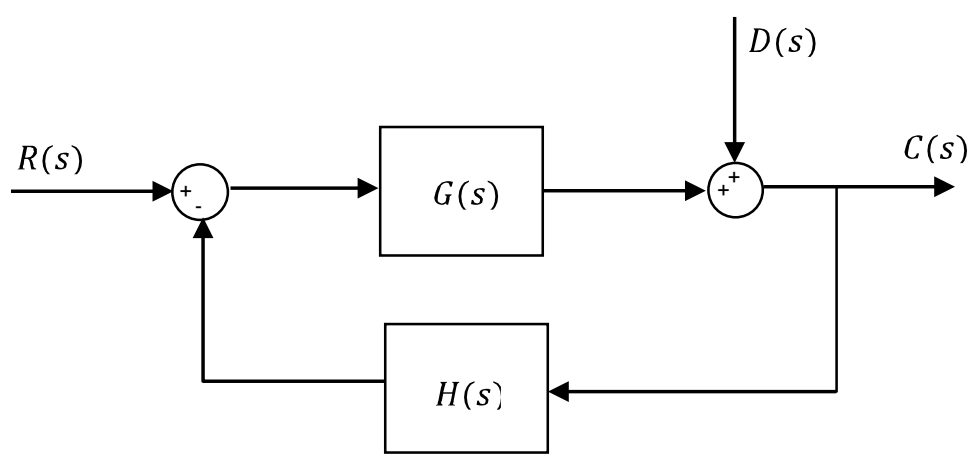

Fig. 4.1: Diagrama de um modelo genérico de malha fechada com distúrbios na saída.

Após algumas manipulações algébricas, o modelo representado na Figura 4.1 pode ser escrito como:

$C(s)=\frac{G(s)}{1+H(s) G(s)} R(s)+\frac{1}{1+H(s) G(s)} D(s)$

O modelo térmico de nosso interesse, sob influencia da temperatura ambiente, dado por 3.5 e esquematizado na Figura 3.2 representa, portanto, um modelo da forma 4.1. Vamos mostrar que este além de apresentar saída de temperatura corpórea que se estabiliza exatamente em seu set-point $T_{s}(s)$ quando este é fixado, também é capaz de minimizar eventuais distúrbios apresentados na saída, introduzidos por $T_{a}(s)$. 
Neste sentido, aplicando a transformada de Laplace à uma entrada de set-point fixa dada por $T_{s}$ e uma entrada de temperatura ambiente fixa dada por $T_{a}$, temos que:

$T_{s}(s)=\frac{T_{s}}{s}$ e $T_{a}(s)=\frac{T_{a}}{s}$

Que substituídos na equação 3.5, resulta:

$T_{b}(s)=\left(\frac{K h}{B C s^{2}+\chi s+K h}\right) \frac{T_{s}}{s}+\left(\frac{\chi s}{B C s^{2}+\chi s+K h}\right) \frac{T_{a}}{s}$

E assim, podemos calcular o erro entre o set-point $T_{s}(s)$ e a temperatura corpórea $T_{b}(s)$ da seguinte forma:

$E(s)=T_{s}(s)-T_{b}(s)$

$E(s)=\frac{T_{s}}{s}-\left(\frac{K h}{B C s^{2}+\chi s+K h}\right) \frac{T_{s}}{s}-\left(\frac{\chi s}{B C s^{2}+\chi s+K h}\right) \frac{T_{a}}{s}$

E, assim:

$E(s)=\left(\frac{B C s^{2}+\chi s}{B C s^{2}+\chi s+K h}\right) \frac{T_{s}}{s}-\left(\frac{\chi s}{B C s^{2}+\chi s+K h}\right) \frac{T_{a}}{s}$

Como as funções de transferência são estáveis, isso foi visto na seção anterior, podemos aplicar o teorema do valor final:

$e_{s s}=\lim _{s \rightarrow 0}[s E(s)]$

$e_{s s}=\lim _{s \rightarrow 0}\left[\left(\frac{B C s^{2}+\chi s}{B C s^{2}+\chi s+K h}\right) T_{s}-\left(\frac{\chi s}{B C s^{2}+\chi s+K h}\right) T_{a}\right]$

Que resulta em:

$e_{s s}=0$ 
E, assim, temos que o erro de estado estável é nulo para o modelo térmico 3.5, com set-point fixo.

Agora, para o caso de a temperatura ambiente $T_{a}(t)$ não ser fixa, podemos analisar da forma que se segue. Ainda a partir da equação 3.5:

$B C s^{2} T_{b}(s)+\chi s T_{b}(s)+K h T_{b}(s)=K h T_{s}(s)+\chi s T_{a}(s)$

Considerando condições iniciais nulas, aplicando a anti-transformada de Laplace, temos que:

$B C \ddot{T}_{b}(t)+\chi \dot{T}_{b}(t)+K h T_{b}(t)=K h T_{s}+\chi \dot{T}_{a}(t)$

Logo, no equilíbrio, ou seja, quando $\dot{T}_{b}(t)=0$ e $\ddot{T}_{b}(t)=0$, podemos escrever:

$K h T_{b}(t)=K h T_{s}+\chi \dot{T}_{a}(t)$

ou,

$T_{b}(t)=T_{s}+\frac{\chi}{K h} \dot{T}_{a}(t)$

Donde fica claro que se a temperatura ambiente for constante, num determinado intervalo de tempo, temos que $\dot{T}_{a}(t)=0$ e logo, $T_{b}(t)$ se estabiliza em $T_{s}$, constante. Porém, para o caso de consideramos as flutuações em $T_{a}(t)$, temos que através da redução da condutância térmica $\chi$ ou do aumento dos ganhos $K h$ pode o sistema 3.5 , reduzir a influencia da temperatura ambiente. 
Simulando o sistema 3.5, podemos ver (Figura 4.2) como a redução de $\chi$ afeta a temperatura corpórea sob influencia da temperatura ambiente. Simulamos para uma temperatura ambiente que oscila de forma senoidal, com média $20 \stackrel{\circ}{ } \mathrm{C}$ e amplitude $\pm 5^{\circ} \mathrm{C}$.

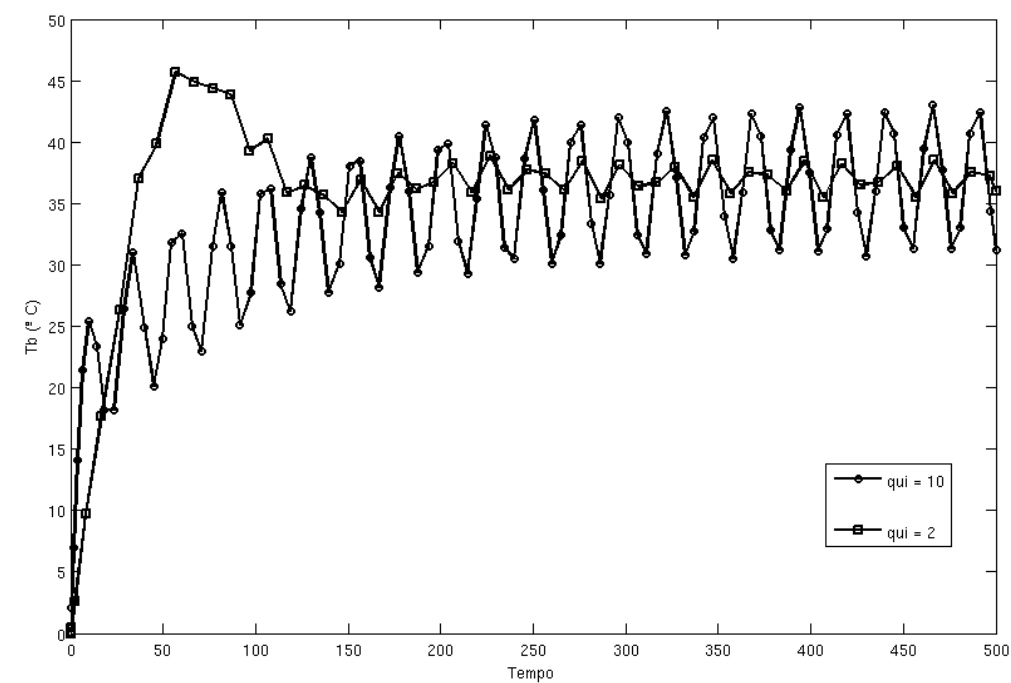

Fig 4.2: Temperatura corpórea sob influencia da temperatura ambiente com variação senoidal. Como se esperaria, redução na condutância térmica causa redução de distúrbios externos. Os valores utilizados na simulação são $B C=50, h=0.2, K=0.5$ e temperatura de set-point fixa $37^{\circ} \mathrm{C}$. O mesmo efeito seria esperado aumentando-se o produto dos ganhos $K h$.

A partir das seções 3 e 4 podemos concluir que o modelo do sistema de termorregulação de endotermos dado por 3.5, com set-point fixo é capaz de reduzir as perturbações em sua planta sugerindo uma aproximação ao comportamento térmico do endotermo homeotermo típico. Porém, esse comportamento termorregulatório, apesar de estar de acordo com o modelo proposto por Hammel, não leva em consideração nenhuma questão relacionada aos custos deste processo, ou mesmo seu papel em eventuais minimizações ou maximizações energéticas ou metabólicas. Desta forma o modelo 3.5 e mesmo o modelo proposto por Hammel são capazes de modelar e descrever o comportamento térmico de termorregulação de um homeotermo, com a introdução de um set-point, porém não contextualizam estes processos dentro da dinâmica de gastos metabólicos e energéticos. 
Neste sentido, buscaremos desenvolver através da teoria de controle ótimo uma análise de como o set-point poderia se apresentar como um controle, resultado de um processo de minimização, e atuar no sistema de forma a justificar tais minimizações. Com isso, uma análise dos custos inerentes ao processo de termorregulação, bem como seus desdobramentos podem ser desenvolvidos.

\section{ABORDAGEM ATRAVÉS DA TEORIA DE CONTROLE ÓTIMO}

Aplicar a teoria de controle ótimo surge na busca de ter indicações de como se daria uma possível minimização dos gastos energéticos no controle da temperatura corpórea.

Primeiramente, para buscar entender como, e se, a temperatura de set-point hipotalâmico poderia surgir no sistema, não sendo fixa ou pré-estabelecida, como nas seções 3 e 4, pelo sistema nervoso central, seja na forma de um controle diferencial ou integral, através de mais uma equação diferencial a ser acrescida ao nosso modelo, ou na forma de um controle proporcional como sugere Hammel (ver discussão nos itens 1 e 2) - mais parecido a um sistema de aquecimento central com termostato -, mas como resultado de um processo de minimização de variáveis no sistema. Para tanto, analisamos o sistema 3.1 e 3.3, modelo térmico e de resposta metabólica, frente às ferramentas da teoria de controle ótimo.

De uma forma geral, na teoria de controle ótimo (Smith, 1998) o que se busca é encontrar um controle ${ }^{3}, u(t) \subset \mathbb{R}^{m}$, que faça com que o sistema

$\dot{x}(t)=f(x(t), u(t), t)$

\footnotetext{
${ }^{3}$ No sentido da engenharia, controle ou histórico de controle são os valores de entrada do sistema no intervalo $\left[t_{i}, t_{f}\right]$.
} 
siga uma trajetória $x(t) \subset \mathbb{R}^{n}$, no espaço de estados, que minimize um funcional chamado medida de performance, da seguinte forma:

$J(u(t))=h\left(x\left(t_{f}\right), t_{f}\right)+\int_{t_{i}}^{t_{f}} g(x(t), u(t), t) d t$

Definindo uma função $\mathcal{H}(x(t), p(t), t)$ como:

$\mathcal{H}(x(t), u(t), p(t), t)=g(x(t), u(t), t)+p^{T}(t)[f(x(t), u(t), t)]$

$p(t):\left[t_{i}, t_{f}\right] \rightarrow \mathbb{R}^{n}$ são multiplicadores de Lagrange e estabelecem o coestado do sistema. A função $u(t)$ é aquela que faz com que o sistema 5.1 percorra uma trajetória no espaço de fases minimizando 5.2.

Da teoria de controle ótimo (Kirk, 1979), as condições necessárias, porém não suficientes, para que $u(t)$ seja a função (controle) que estamos buscando são dadas por:

$$
\left.\begin{array}{l}
\dot{x}(t)=\frac{\partial \mathcal{H}}{\partial p}(x(t), u(t), p(t), t) \\
\dot{p}(t)=-\frac{\partial \mathcal{H}}{\partial x}(x(t), u(t), p(t), t) \\
0=\frac{\partial \mathcal{H}}{\partial u}(x(t), u(t), p(t), t)
\end{array}\right\} \forall t \in\left[t_{i}, t_{f}\right]
$$

Cujas condições de fronteira são dadas por:

$$
\left[\frac{\partial h}{\partial x}\left(x\left(t_{f}\right), t_{f}\right)-p\left(t_{f}\right)\right]^{T} \delta x_{f}+\left[\mathcal{H}\left(x\left(t_{f}\right), u\left(t_{f}\right), p\left(t_{f}\right), t_{f}\right)+\frac{\partial h}{\partial t}\left(x\left(t_{f}\right), t_{f}\right)\right] \delta t_{f}=0 \quad 5.5
$$

Onde $\delta t_{f}$ é a variação do tempo para a condição de fronteira final de 5.1, ou seja, para a situação cujo tempo final de evolução do sistema é desconhecido, assim, se o tempo final é fixado então $\delta t_{f}=0$. Já $\delta x_{f}$ também representa uma variação que 
guarda o mesmo significado, porém relacionado ao estado final de 5.1, assim $\delta x_{f}=0$ quando o estado final $x\left(t_{f}\right)$ é conhecido.

Essa condição é importante, pois muitos problemas de controle ótimo requerem a solução de equações diferenciais com condições de contorno.

Como os sistemas de interesse normalmente relacionam várias variáveis, ou seja, de uma forma geral, a trajetória do sistema 5.1 representa um subconjunto do espaço $\mathbb{R}^{n}$, cuja dimensão é definida de acordo com o modelo de interesse, gostaríamos de ressaltar que para um tempo $t$ particular, $u(t)$ (ou $U(t)$ representa $o$ vetor de dimensão $m$, ou seja, $u(t) \in \mathbb{R}^{m} \forall t \in\left[t_{i}, t_{f}\right]$; da mesma forma, $\forall t \in\left[t_{i}, t_{f}\right]$, $x(t)$ (ou $X(t)$ ), o vetor de variáveis dependentes do sistema é de dimensão $n$, ou seja, $x(t) \in \mathbb{R}^{n}$.

Utilizaremos ambas as notações, maiúsculo ou minúsculo com o mesmo significado, o de representar vetores num subespaço de $\mathbb{R}^{k}$, a menos que se diga o contrário. Assim, por exemplo, como $X(t) \in \mathbb{R}^{n}$, devemos ter $X(t)=x(t)=\left(x_{1}(t), x_{2}(t), \ldots x_{n}(t)\right)^{T 4}$. Com isso, podemos reescrever o índice 5.2 na forma matricial, como:

$J(U(t))=X\left(t_{f}\right)^{T} H X\left(t_{f}\right)+\int_{t_{i}}^{t_{f}}\left(X(t)^{T} Q(t) X(t)+U(t)^{T} R(t) U(t)\right) d t$

Onde $H \in \mathcal{M}(n), Q(t) \in \mathcal{M}(n)$ e $R(t) \in \mathcal{M}(m)$ são matrizes que representam os pesos que são atribuídos às variáveis. Em todas as aplicações que se seguem tanto $Q(t)$ quanto $R(t)$ serão constantes, não função do tempo, como poderia eventualmente acontecer. Neste caso poderíamos empregar mesma análise que se segue.

Nesta direção, como o processo a ser controlado se dá através de um sistema linear, podemos representar suas equações de estado na forma matricial, assim

\footnotetext{
${ }^{4} \mathrm{O}$ símbolo de transposição aplicado ao vetor $x(t)$ significa que, a menos que se diga o contrário, estaremos sempre nos referindo a vetores coluna.
} 
retornando ao sistema de equações 3.1 - 3.3, que caracterizam o modelo térmico e de resposta metabólica de nosso estudo:

$\left(\begin{array}{c}\dot{T}_{b}(t) \\ \dot{M}(t)\end{array}\right)=\left(\begin{array}{cc}-\frac{\chi}{B C} & \frac{h}{B C} \\ -K & 0\end{array}\right)\left(\begin{array}{l}T_{b}(t) \\ M(t)\end{array}\right)+\left(\begin{array}{c}0 \\ K\end{array}\right) T_{s}(t)+\left(\begin{array}{c}\frac{\chi}{B C} \\ 0\end{array}\right) T_{a}$

Ou seja, temos um modelo matricial da forma:

$\dot{X}(t)=A X(t)+B U(t)+C T_{a}$

Onde $X(t) \subset \mathbb{R}^{2}$ é o vetor de variáveis dependentes, ou trajetória do sistema, e $U(t) \subset \mathbb{R}^{1}$ é o controle ou histórico de controle. Vale destacar que estamos considerando a entrada $T_{a}$, representando a temperatura ambiente, como sendo fixa. Na correspondência direta entre 5.7 e 5.8, temos que:

$X(t)=\left(\begin{array}{c}T_{b}(t) \\ M(t)\end{array}\right), \dot{X}(t)=\left(\begin{array}{c}\dot{T}_{b}(t) \\ \dot{M}(t)\end{array}\right), A=\left(\begin{array}{cc}-\frac{\chi}{B C} & \frac{h}{B C} \\ -K & 0\end{array}\right)$ é a matriz de coeficientes do sistema.

$U(t)=T_{S}(t), B=\left(\begin{array}{c}0 \\ K\end{array}\right), C=\left(\begin{array}{c}\frac{\chi}{B C} \\ 0\end{array}\right)$

Se definirmos um índice de desempenho, como em 5.2 da seguinte forma:

$J(u(t))=\int_{t_{i}}^{t_{f}} \frac{1}{2} T_{s}^{2}(t) d t$

Podemos atrelar ao índice 5.9 o seguinte significado físico: controlar o sistema 5.7 de forma que o esforço de controle seja conservado, ou seja, o sistema deve regular $T_{b}(t)$ de forma a produzir o mínimo dispêndio energético nessa tarefa. Cabe nesse ponto uma ressalva; obviamente, a partir de 5.9, fica fácil constatar que o esforço de controle mínimo é aquele dado por $T_{S}(t)=0$, ou seja, aquele cujo dispêndio energético com a termorregulação é completamente anulado; porém esta situação não representa a termorregulação de um endotermo vivo, como veremos mais 
adiante (seção 5.2). Assim, buscamos um controle que regule o sistema 5.7 de forma a atingir valores apropriados para a temperatura corpórea e taxa metabólica enquanto minimiza 5.9 .

Agora, como na comparação entre 5.2 e 5.9 , temos que $g(x(t), u(t), t)=\frac{1}{2} T_{s}{ }^{2}(t)$ e na comparação entre 5.1 e 5.7, temos que $f(x(t), u(t), t)=\left(\begin{array}{c}\frac{h}{B C} M(t)-\frac{\chi}{B C} T_{b}(t)+\frac{\chi}{B C} T_{a} \\ -K T_{b}(t)+K T_{s}(t)\end{array}\right)$; então podemos escrever o hamiltoniano 5.3 como:

$\mathcal{H}(x(t), u(t), p(t), t)=\frac{1}{2} T_{s}^{2}(t)+\left(\begin{array}{l}p_{1}(t) \\ p_{2}(t)\end{array}\right)^{T}\left(\begin{array}{c}\frac{h}{B C} M(t)-\frac{\chi}{B C} T_{b}(t)+\frac{\chi}{B C} T_{a} \\ -K T_{b}(t)+K T_{s}(t)\end{array}\right)$

$\mathcal{H}(x(t), u(t), p(t), t)=\frac{1}{2} T_{s}^{2}(t)+p_{1}(t) \frac{h}{B C} M(t)-p_{1}(t) \frac{\chi}{B C} T_{b}(t)+p_{1}(t) \frac{\chi}{B C} T_{a}-$ $p_{2}(t) K T_{b}(t)+p_{2}(t) K T_{s}(t)$

$\mathrm{E}$, neste caso, as condições necessárias de otimização que permitem ao sistema 5.7 realizar trajetórias no espaço de estados minimizando 5.9 são dadas por 5.4 aplicadas a 5.10:

$\left.\begin{array}{l}\dot{x}(t)=\left(\begin{array}{l}\dot{T}_{b}(t) \\ \dot{M}(t)\end{array}\right)=\left(\begin{array}{c}\frac{\partial \mathcal{H}}{\partial p_{1}} \\ \frac{\partial \mathcal{H}}{\partial p_{2}}\end{array}\right)=\left(\begin{array}{c}\frac{h}{B C} M(t)-\frac{\chi}{B C} T_{b}(t)+\frac{\chi}{B C} T_{a} \\ -K T_{b}(t)+K T_{s}(t)\end{array}\right) \\ \dot{p}(t)=\left(\begin{array}{l}\dot{p}_{1}(t) \\ \dot{p}_{2}(t)\end{array}\right)=-\left(\begin{array}{c}\frac{\partial \mathcal{H}}{\partial T_{b}} \\ \frac{\partial \mathcal{H}}{\partial M}\end{array}\right)=-\left(\begin{array}{c}-\frac{\chi}{B C} p_{1}(t)-K p_{2}(t) \\ \frac{h}{B C} p_{1}(t)\end{array}\right) \\ 0=\frac{\partial \mathcal{H}}{\partial u}=\frac{\partial \mathcal{H}}{\partial T_{s}}=T_{s}(t)+K p_{2}(t)\end{array}\right\} \forall t\left[t_{i}, t_{f}\right]$

De 5.11.3 temos que $T_{s}(t)=-K p_{2}(t)$. Substituindo essa relação em 5.11.1, podemos reescrever o sistema 5.11 como: 


$$
\left\{\begin{array}{c}
\dot{T}_{b}(t)=\frac{h}{B C} M(t)-\frac{\chi}{B C} T_{b}(t)+\frac{\chi}{B C} T_{a} \\
\dot{M}(t)=-K T_{b}(t)-K^{2} p_{2}(t) \\
\dot{p}_{1}(t)=\frac{\chi}{B C} p_{1}(t)+K p_{2}(t) \\
\dot{p}_{2}(t)=-\frac{h}{B C} p_{1}(t)
\end{array}\right.
$$

Desta forma construímos 5.12, um sistema de 4 equações diferenciais de primeira ordem, lineares, a coeficientes constantes, não-homogêneo (devido a entrada $T_{a}$ fixa), mas que pode através de uma simples mudança de coordenadas ser transformado em homogêneo.

$$
\begin{aligned}
& \lambda_{1}=\frac{-\chi C+\sqrt{\chi^{2} C^{2}-4 C h B K}}{2 B} \\
& \lambda_{2}=\frac{-\chi C-\sqrt{\chi^{2} C^{2}-4 C h B K}}{2 B} \\
& \lambda_{3}=\frac{\chi C+\sqrt{\chi^{2} C^{2}-4 C h B K}}{2 B} \\
& \lambda_{4}=\frac{\chi C-\sqrt{\chi^{2} C^{2}-4 C h B K}}{2 B}
\end{aligned}
$$

Os autovetores correspondentes:

$$
\begin{aligned}
& V_{\lambda_{1}}=\left(\begin{array}{c}
\frac{\chi C-\sqrt{\chi^{2} C^{2}-4 C h B K}}{2 K B} \\
1 \\
0 \\
0
\end{array}\right) \\
& V_{\lambda_{2}}=\left(\begin{array}{c}
\frac{\chi C+\sqrt{\chi^{2} C^{2}-4 C h B K}}{2 K B} \\
1 \\
0 \\
0
\end{array}\right) \\
& V_{\lambda_{3}}=\left(\begin{array}{c}
\frac{-\chi C+\sqrt{\chi^{2} C^{2}-4 C h B K}}{4 \chi C} \\
\frac{1 / 2\left(\chi C+\sqrt{\chi^{2} C^{2}-4 C h B K}\right)+K B h+\chi^{2} C}{2 \chi h C} \\
\frac{-\chi C-\sqrt{\chi^{2} C^{2}-4 C h B K}}{2 h C} \\
1
\end{array}\right)
\end{aligned}
$$




$$
V_{\lambda_{4}}=\left(\begin{array}{c}
\frac{-\chi C-\sqrt{\chi^{2} C^{2}-4 C h B K}}{4 \chi C} \\
\frac{1 / 2\left(\chi C-\sqrt{\chi^{2} C^{2}-4 C h B K}\right)+K B h+\chi^{2} C}{2 \chi h C} \\
\frac{-\chi C+\sqrt{\chi^{2} C^{2}-4 C h B K}}{2 h C} \\
1
\end{array}\right)
$$

$\left(\begin{array}{c}T_{b}(t) \\ M(t) \\ p_{1}(t) \\ p_{2}(t)\end{array}\right)=C_{1} V_{\lambda_{1}} e^{\lambda_{1} t}+C_{2} V_{\lambda_{2}} e^{\lambda_{2} t}+C_{3} V_{\lambda_{3}} e^{\lambda_{3} t}+C_{4} V_{\lambda_{4}} e^{\lambda_{4} t}+\left(\begin{array}{c}\frac{\chi}{B C} \\ 0 \\ 0 \\ 0\end{array}\right) T_{a}$

Pode-se provar através do teorema de Picard (Djairo, 2001) que o sistema 5.12, com condição inicial, apresenta solução única em torno do ponto inicial $\left(T_{b}(0), M(0), p_{1}(0), p_{2}(0)\right)=\left(T_{b_{0}}, M_{0}, p_{1_{0}}, p_{2_{0}}\right)$, e assim poderíamos encontrar $C_{1}, C_{2}, C_{3}$ e $C_{4}$; porém este não é o caso, pois não possuímos um problema de valor inicial, mas sim um problema de valor de contorno de dois pontos, dado não sabermos as condições de fronteira de $\mathrm{p}_{1}(\mathrm{t})$ ou $\mathrm{p}_{2}(\mathrm{t})$ para nenhum $t \in\left[\mathrm{t}_{\mathrm{i}}, \mathrm{t}_{\mathrm{f}}\right]$. As únicas condições de fronteira que possuímos são $T_{b}\left(t_{i}\right)$ e $M\left(t_{i}\right)^{5}$ que podem sugerir, simplesmente, o conhecimento de uma condição térmico-metabólica conhecida de antemão, no instante inicial.

Porém, da teoria de problemas de contorno para equações homogêneas (Boyce, 1979), pode-se mostrar que o problema 5.12 com condições de fronteira separadas $\left(T_{b}\left(t_{i}\right), M\left(t_{i}\right)\right)=\left(T_{b_{i}}, M_{i}\right)$ e $\left(T_{b}\left(t_{f}\right), M\left(t_{f}\right)\right)=\left(T_{b_{f}}, M_{f}\right)$ possui, no máximo, uma família infinita de soluções não-triviais. Como veremos, isso é muito importante, pois permitirá, em situações ambientais distintas, o uso do mesmo controlador ótimo, ou seja, da mesma solução 5.13, apenas particularizada para uma nova situação de temperatura ambiente.

Propomos, agora, a análise de algumas situações distintas e sua comparação.

\footnotetext{
${ }^{5}$ Sem perda de generalidade, de agora em diante, sempre que nos referirmos à $t_{i}$,estaremos considerando $t_{\mathrm{i}}=0$.
} 


\subsection{CONDIÇÕES INICIAIS E FINAIS CONHECIDAS}

A primeira situação de nosso interesse é aquela na qual as condições iniciais e finais do sistema são conhecidas. Cabe destacar, que nesta situação temos, portanto $\delta x_{f}=\delta t_{f}=0$ em 5.5 , pois não existe variação nas fronteiras, e isso faz com que, de fato, as únicas restrições necessárias ao cálculo das constantes de 5.13 sejam $\left(T_{b}\left(t_{i}\right), M\left(t_{i}\right)\right)$ e $\left(T_{b}\left(t_{f}\right), M\left(t_{f}\right)\right)$.

Neste caso, ao aplicamos as condições de contorno, estas impõem restrições às constantes arbitrárias $C_{1}, C_{2}, C_{3}$ e $C_{4}$. Assim, assumindo, por exemplo, $\left(T_{b}(0), M(0)\right)=\left(T_{b_{i}}, M_{i}\right)$, considerando o tempo de simulação como dado no item 3, $t_{f}=1000$ e, logo $\left(T_{b}(1000), M(1000)\right)=\left(T_{b_{f}}, M_{f}\right)$, podemos calculá-las.

Nesta direção, precisamos primeiramente relacionar os valores de $M_{i}$ à $T_{b_{i}}$ e igualmente $M_{f}$ à $T_{b_{f}}$ de forma a satisfazer a relação de equilíbrio térmico $M\left(t_{i}\right)$ $\chi\left(T_{b}\left(t_{i}\right)-T_{a}\right)=0$ e $M\left(t_{f}\right)-\chi\left(T_{b}\left(t_{f}\right)-T_{a}\right)=0$. Para efeito de ilustrar o que estamos dizendo e produzir simulações, vamos considerar, como no caso I do item 3 , $\chi=16, h=0.2, K=0.5, B=50, t_{i}=0$ e $t_{f}=1000$, para avaliar o comportamento do sistema térmico e metabólico em algumas situações de temperatura ambiente, $T_{a}=0^{\circ} \mathrm{C}, \quad T_{a}=10^{\circ} \mathrm{C}$ e $T_{a}=20^{\circ} \mathrm{C}$. Assim, considerando que a temperatura corpórea na condição final do processo de termorregulação deve se igualar a condição inicial que é conhecida $\left(T_{b}\left(t_{i}\right)=37\right)^{6}$ pode-se escrever então $T_{b}\left(t_{f}\right)=$ $T_{b}\left(t_{i}\right)=37$.

Conhecidas as condições de temperatura corpórea, a relação de equilíbrio térmico permite-nos estabelecer, também, a situação metabólica correspondente, que deve também idêntica nos instantes $t_{i}$ e $t_{f}$, ou seja, $M\left(t_{f}\right)=M\left(t_{i}\right)$, A seguinte tabela

\footnotetext{
${ }^{6}$ Sem perda de generalidade e para efeito de simulação computacional, estaremos considerando $T_{b}\left(t_{i}\right)=T_{b}\left(t_{f}\right)=37 \mathrm{em}$ todas as simulações desta subseção (4.1). Nas subseções seguintes continuamos considerando $T_{b}\left(t_{i}\right)=37$, porém $T_{b}\left(t_{f}\right)$ é desconhecido.
} 
define os valores de $M\left(t_{i}\right)$ e $M\left(t_{f}\right)$, nas 3 situação ambientais consideradas que utilizaremos.

\begin{tabular}{|l|c|c|c|}
\hline & $T_{a}=0{ }^{\circ} \mathrm{C}$ & $T_{a}=10^{\circ} \mathrm{C}$ & $T_{a}=20^{\circ} \mathrm{C}$ \\
\hline$M\left(t_{f}\right)=M\left(t_{i}\right)$ & 592 & 432 & 272 \\
\hline
\end{tabular}

Tabela 5.1: Valores de taxa metabólica calculados para $\chi=16$ nas condições de equilíbrio térmico.

Substituindo as condições de fronteira conhecidas na solução 5.13 obtemos o sistema de equações lineares 5.14 a seguir, e desta forma para cada valor de $T_{a}$, de $T_{b}\left(t_{i}\right), T_{b}\left(t_{f}\right), M\left(t_{i}\right)$ e $M\left(t_{f}\right)$ podemos recalcular facilmente os coeficientes desta solução. Assim, por exemplo, para $\mathrm{T}_{\mathrm{a}}=0^{\circ} \mathrm{C}$ devemos ter, de acordo com a tabela 5.1, $M\left(t_{\mathrm{f}}\right)=\mathrm{M}\left(\mathrm{t}_{\mathrm{i}}\right)=592 \mathrm{e}$, logo:

Para a condição inicial, $t_{i}=0,\left(T_{b}\left(t_{i}\right), M\left(t_{i}\right)\right)=(37,592)$ :

$$
\left(\begin{array}{c}
37 \\
592
\end{array}\right)-\left(\begin{array}{c}
\frac{\chi}{B C} \\
0
\end{array}\right) T_{a}=C_{1}\left(\begin{array}{l}
v_{\lambda_{1}}{ }^{1} \\
v_{\lambda_{1}}{ }^{2}
\end{array}\right)+C_{2}\left(\begin{array}{l}
v_{\lambda_{2}}{ }^{1} \\
v_{\lambda_{2}}{ }^{2}
\end{array}\right)+C_{3}\left(\begin{array}{l}
v_{\lambda_{3}}{ }^{1} \\
v_{\lambda_{3}}{ }^{2}
\end{array}\right)+C_{4}\left(\begin{array}{l}
v_{\lambda_{4}}{ }^{1} \\
v_{\lambda_{4}}{ }^{2}
\end{array}\right)
$$

Para a condição final, $\mathrm{t}_{\mathrm{f}}=1000,\left(T_{b}\left(t_{f}\right), M\left(t_{f}\right)\right)=(37,592)$ :

$$
\begin{aligned}
\left(\begin{array}{c}
37 \\
592
\end{array}\right)-\left(\begin{array}{c}
\frac{\chi}{B C} \\
0
\end{array}\right) & T_{a} \\
= & C_{1}\left(\begin{array}{c}
v_{\lambda_{1}}{ }^{1} \\
v_{\lambda_{1}}{ }^{2}
\end{array}\right) e^{\lambda_{1} t_{f}}+C_{2}\left(\begin{array}{l}
v_{\lambda_{2}}{ }^{1} \\
v_{\lambda_{2}}{ }^{2}
\end{array}\right) e^{\lambda_{2} t_{f}}+C_{3}\left(\begin{array}{l}
v_{\lambda_{3}}{ }^{1} \\
v_{\lambda_{3}}{ }^{2}
\end{array}\right) e^{\lambda_{3} t_{f}} \\
& +C_{4}\left(\begin{array}{c}
v_{\lambda_{4}}{ }^{1} \\
v_{\lambda_{4}}{ }^{2}
\end{array}\right) e^{\lambda_{4} t_{f}}
\end{aligned}
$$


Solucionando o sistema linear, 5.14, de 4 equações com 4 incógnitas, que possui solução única ${ }^{7}$ para cada valor de $T_{a}$ e M especificados pela Tabela 5.1, obtemos as constantes arbitrárias $C_{1}, C_{2}, C_{3}$ e $C_{4}$ dispostas na Tabela 5.2:

\begin{tabular}{|l|l|l|}
\hline$T_{a}=0{ }^{\circ} \mathrm{C}$ & $T_{a}=10^{\circ} \mathrm{C}$ & $T_{a}=20^{\circ} \mathrm{C}$ \\
\hline$C_{1}=30.0608$ & $C_{1}=21.7287 ;$ & $C_{1}=13.3966 ;$ \\
$C_{2}=6.9392 ;$ & $C_{2}=15.2713 ;$ & $C_{2}=23.6034 ;$ \\
$C_{3}=-3.1036 e-131 ;$ & $C_{3}=-2.2851 e-131 ;$ & $C_{3}=-1.4666 e-131 ;$ \\
$C_{4}=0.7587 ;$ & $C_{4}=0.6663 ;$ & $C_{4}=0.5740 ;$ \\
\hline
\end{tabular}

Tabela 5.2: Constantes arbitrárias $C_{1}, C_{2}, C_{3}$ e $C_{4}$, obtidas a partir do sistema de equações lineares 5.14 com $T_{b}\left(t_{i}\right)=T_{b}\left(t_{f}\right)=37$, nas 3 situações de $\mathrm{T}_{\mathbf{a}}\left(\mathrm{e} \mathrm{M}\left(\mathrm{t}_{\mathrm{i}}\right)=\mathrm{M}\left(\mathrm{t}_{\mathrm{f}}\right)\right.$ correspondente $)$ dadas pela Tabela 5.1

Fazendo uso destas constantes podemos, agora, simular o sistema 5.13 para as 3 condições calculadas. Segue representação gráfica de $T_{b}(t)$ que surge da minimização do índice 5.9:

\footnotetext{
${ }^{7}$ Um sistema de equações lineares como 5.14 possui solução única se e somente se o determinante da matriz de coeficientes do sistema homogêneo associado for não nulo (Hoffman \& Kunze, 1986).
} 

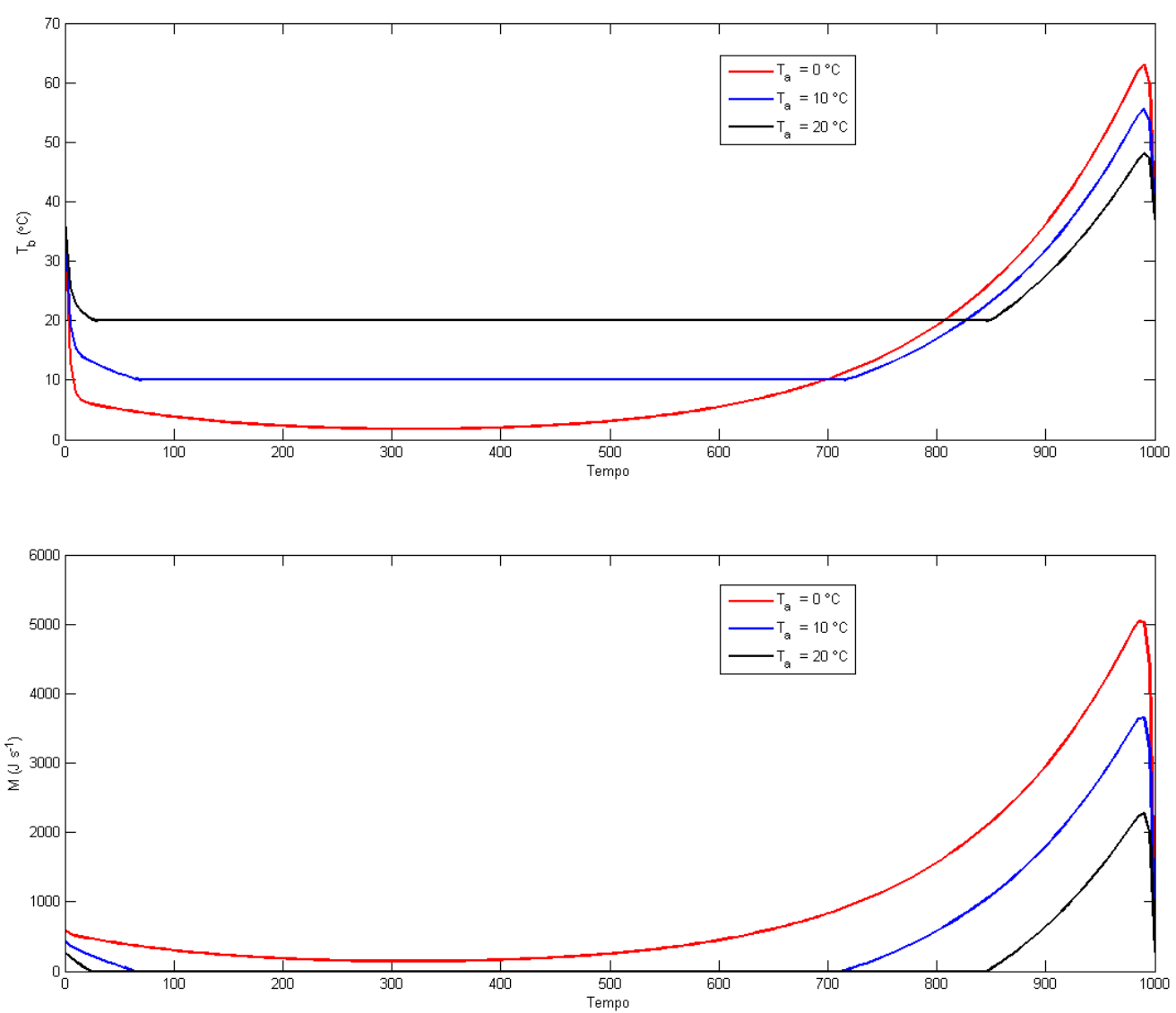

Fig. 5.1: Resultado de simulação de $T_{b}(t)$ e $M(t)$, em 5.13 para as 3 situações de temperatura ambiente $T_{a}$ para os valores $\chi=16, h=0.2, K=0.5$ e $B=50$. (A) Este é o trajeto ao longo do tempo realizado pela temperatura corpórea, quando o controlador ótimo busca minimizar o esforço de controle dado pelo índice 5.9. (B) Respectiva taxa metabólica, resultado da minimização do mesmo índice, nas 3 situação de temperatura ambiente. Devemos ressaltar que, nesta situação, as condições iniciais e finais do sistema são conhecidas, assim o controlador atua de forma a levar o sistema de uma condição à outra, minimizando 5.9; e, ainda que os valores para os quais o indivíduo deixa de apresentar gasto metabólico, em $B$, $(M(t)=0)$ coincidem exatamente, em $A$, com os valores para os quais $T_{b}(t)=T_{a}$. Mais detalhes no texto.

Dois pontos importantes devem ser ressaltados ao analisarmos a Figura 5.1. Notase que o comportamento de $\mathrm{T}_{\mathrm{b}}(\mathrm{t})$, assim calculado, não parece estar de acordo com dados empíricos, sobretudo na condição de $\mathrm{T}_{\mathrm{a}}=0{ }^{\circ} \mathrm{C}$, na qual $\mathrm{T}_{\mathrm{b}}(\mathrm{t})$ apresenta, em certo momento, valores que passam de $60^{\circ} \mathrm{C}$. Assim, em primeiro lugar, isso se deve ao fato de controlador ótimo estar minimizando o gasto energético com a própria termorregulação (índice 5.9). Isso permite a taxa metabólica atingir valores mínimos em certos intervalos (Figura 5.1 B) para as condições de $\mathrm{T}_{\mathrm{a}}$ maiores que 0 , porém na situação de menor temperatura ambiente, fatalmente, a taxa metabólica 
empregada deve sustentar a elevação de $\mathrm{T}_{\mathrm{b}}(\mathrm{t})$ de forma mais efetiva, inevitavelmente gerando maior gasto metabólico. Cabe observar, contudo, que no instante final, em todas as situações, os valores esperados são atingidos. Em segundo lugar, não impusemos nenhuma restrição ao controle $u(t)=T_{s}(t)$, ou à variável $\mathrm{T}_{\mathrm{b}}(\mathrm{t})$, no espaço de fases, ou seja, qualquer valor poderia ser assumido pois nossa idéia é exatamente buscar compreender como o comportamento térmico de um endotermo típico pode emergir e se sustentar em diversas condições de temperatura ambiente sem ser forçado matematicamente para tal. Porém, definimos um limitante inferior para $\mathrm{M}(\mathrm{t})$ como sendo 0 . Obviamente estamos cientes que em nenhuma situação real a taxa metabólica poderia ser zero para um indivíduo vivo, porém esse valor serve apenas para que não tenhamos nenhum resultado com taxas metabólicas negativas.

As repostas apresentadas na Figura 5.1 têm seus resultados traduzidos na tabela abaixo, com os valores do índice $\mathrm{J}(\mathrm{u}(\mathrm{t}))$ e com um índice que propomos, chamado índice relativo de área metabólica (IRAM), definido da seguinte maneira:

$$
\operatorname{IRAM}=\frac{\int_{t_{i}}^{t_{f}} M(t) d t}{M\left(t_{i}\right)\left(t_{f}-t_{i}\right)}
$$

Tal índice consiste numa razão entre a área da taxa metabólica empregada na termorregulação $\left(\int_{t_{i}}^{t_{f}} \mathrm{M}(\mathrm{t}) \mathrm{dt}\right)$ ao longo do tempo e a área da taxa metabólica se o indivíduo sustentasse o valor inicial (Tabela 5.1) ao longo do tempo, sem nenhuma alteração. Em outras palavras, o IRAM nos mostra o quanto se aumenta ou diminui, relativamente, o metabolismo total durante um período, devido à opção do controle ótimo, em relação a se manter, durante todo o período, com a mesma taxa metabólica inicial.

Índices de desempenho e de gasto metabólico relativo: 


\begin{tabular}{|c|c|c|c|}
\hline & $T_{a}=0{ }^{\circ} \mathrm{C}$ & $T_{a}=10^{\circ} \mathrm{C}$ & $T_{a}=20^{\circ} \mathrm{C}$ \\
\hline$J(u(t))$ & $2.561610^{7}$ & $1.388910^{7}$ & $5.808010^{6}$ \\
\hline$I R A M$ & 1.5893 & 0.9659 & 0.6017 \\
\hline
\end{tabular}

Tabela 5.3: Índice relativo de área metabólica IRAM e índice de custo com a termorregulação $\mathrm{J}(\mathrm{u}(\mathrm{t})$ ) referente à minimização do funcional 5.9. Ambos os índice coincidem com a informação apresentada, sugerindo que conforme a temperatura ambiente decresce tanto o esforço de controle necessário para sustentar a termorregulação, quanto à taxa metabólica necessária para o mesmo fim aumentam.

O IRAM na Tabela 5.3 nos sugere, ainda, que na situação $\mathrm{T}_{\mathrm{a}}=0{ }^{\circ} \mathrm{C}$, o fato de 0 individuo minimizar $\mathrm{J}(\mathrm{u}(\mathrm{t})$ ) força um gasto metabólico excessivo, em comparação, maior que o da situação onde nenhuma redução metabólica seja buscada (valor de IRAM maior que 1), isso devido à taxa metabólica requerida para voltar a condição inicial de eutermia ser muito elevada nessa condição ambiental (Figura 5.1 B).

Ou seja, nessa situação, se o indivíduo quer economizar com a termorregulação, ele vai gastar mais. Isso sugere que para um indivíduo com essa massa, a depressão metabólica não é vantajosa em situações mais baixas de temperatura ambiente.

Inevitavelmente, isso nos leva a seguinte pergunta: E, esse o indivíduo aumentar o tempo em que se encontra no estado hipometabólico? Será que a depressão metabólica continuaria não se apresentando como boa estratégia? Olhando para a definição IRAM ao aumentar-se o tempo total da simulação, podemos de antemão imaginar que este índice deve se reduzir, uma vez que a diferença $\left(t_{f}-t_{i}\right)$ aumenta no denominador, justificando, desta maneira, a depressão metabólica. Porém um pergunta que ainda resta é a seguinte é possível que isso aconteça de forma a não aumentar o índice $J(u(t))$, que representa desempenho com a termorregulação?

Para responder a essa pergunta simulamos novamente o modelo dobrando o tempo de simulação. Os resultados são apresentados na Figura 5.1.1, abaixo. 

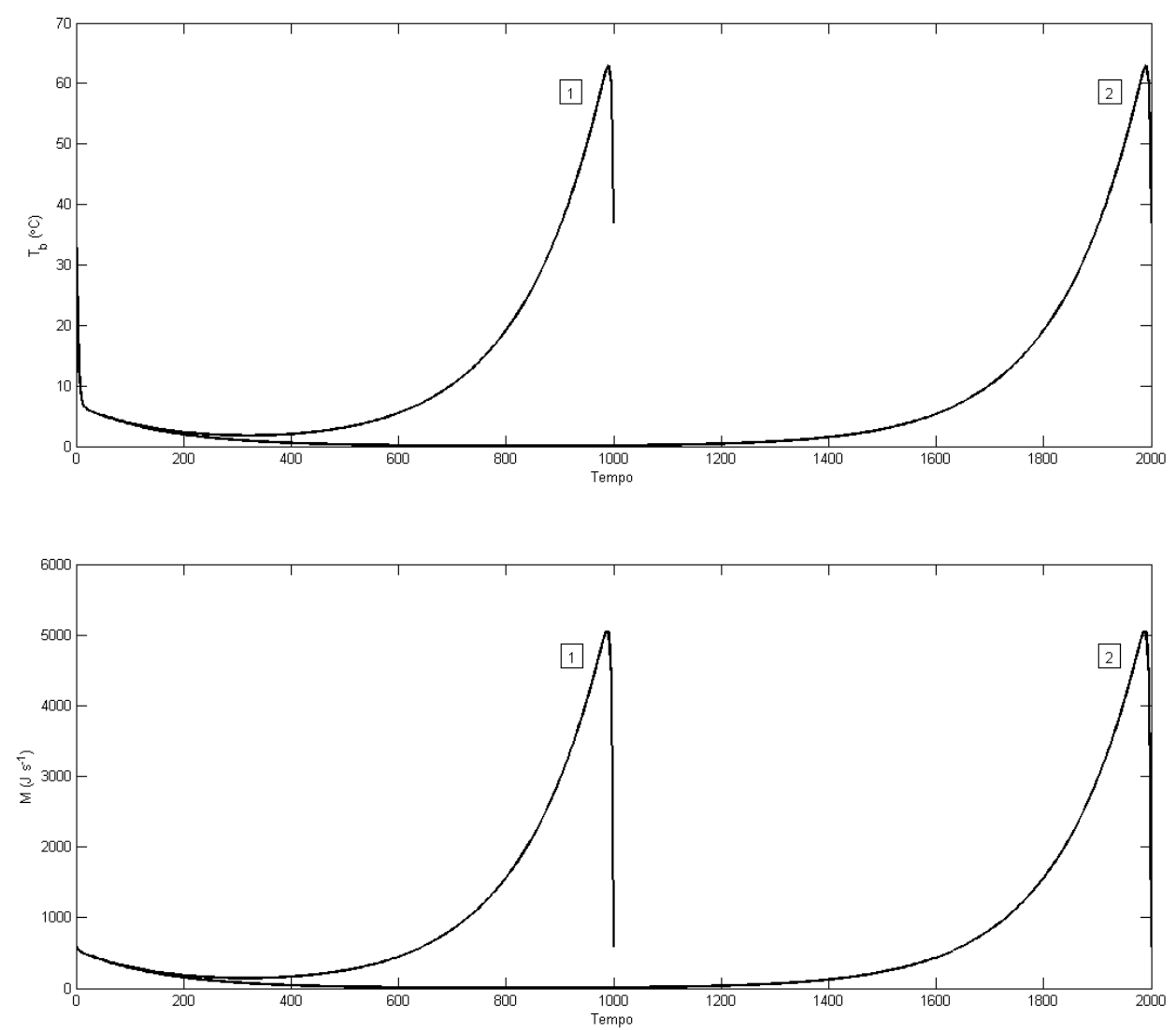

B

Fig. 5.1.1: Resultado de simulação de $T_{b}(t)$ e $\mathrm{M}(\mathrm{t})$, de 5.13 para $T_{a}=0{ }^{\circ} \mathrm{C}, \chi=16, h=0.2$, $K=0.5$ e $B=50$. (A) Este é o trajeto ao longo do tempo realizado pela temperatura corpórea, nas situações (1) $t_{f}=1000$ e (2) $t_{f}=2000$. (B) Respectiva taxa metabólica, para mesmos tempos finais de simulação. Podemos perceber, que ambas as variáveis preservam suas formas, apenas distendendo-se no tempo, isso implicará numa redução em IRAM. Como previsto, o indivíduo aumenta seu intervalo no estado hipometabólico.

Como podemos observar a partir da Figura 5.1.1 B, o fato de a taxa metabólica representar uma transformação que estende $\mathrm{M}(\mathrm{t})$ ao longo do tempo, IRAM deve reduzir-se pela metade, uma vez que o tempo final dobrou. Realmente IRAM= 0.7974 na situação (2) da Figura 5.1.1 B, em contraste com IRAM = 1.5893, apresentado na Tabela 5.3 para $\mathrm{T}_{\mathrm{a}}=0^{\circ} \mathrm{C}$. Agora, para esta mesma situação o índice $J(u(t))$ calculado se mantém, como havíamos calculado anteriormente e apresentado na mesma tabela, o que sinaliza a viabilidade desta estratégia para redução do custo metabólico.

Obviamente, à estratégia de maximizar o intervalo de depressão metabólica estão associados outros riscos não considerados aqui, como aumento do risco de 
predação, e de "rupturas fisiológicas" que discutimos melhor na seção 6; no entanto, gostaríamos de destacar que os resultados desta seção parecem ser de grande relevância, por marcar uma diferença fundamental entre os custos associados aos estados de depressão metabólica, como sendo, fortemente, influenciados pela opção de maximizar ou minimizar o tempo em que o indivíduo se encontra em tais estados. Este resultado parece estar de acordo com o reconhecimento da flexibilidade na estratégia por parte de muitos hibernantes (Humphries et al., 2003).

\subsection{CONDIÇÕES INICIAIS CONHECIDAS, FINAIS DESCONHECIDAS E NÃO FORÇADAS}

Diferentemente da situação anterior, não vamos definir uma situação final de estado para o sistema 5.12, nem vamos forçar nenhuma situação desejada, apenas vamos supor o tempo final $t_{f}=1000$. Desta forma, procederemos com o cálculo do controlador ótimo como anteriormente, porém desta vez fazendo uso de das condições 5.5. A partir deste estudo, nos passos que seguem, ao invés de definirmos uma situação final, vamos tentar alcançá-la forçado ganhos a um índice de desempenho da forma 5.6, ligeiramente distinto de 5.9, porém que guarda o mesmo significado.

Considerando, o fato de conhecermos $t_{f}$, temos que a variação $\delta t_{f}=0$, e do fato de desconhecermos o estado final $\left(\mathrm{T}_{\mathrm{b}}\left(\mathrm{t}_{\mathrm{f}}\right), \mathrm{M}\left(\mathrm{t}_{\mathrm{f}}\right)\right)$ temos que $\delta \mathrm{x}_{\mathrm{f}}$ pode assumir valores arbitrários em 5.5. Ou seja, para que

$\left[\frac{\partial \mathrm{h}}{\partial \mathrm{x}}\left(\mathrm{x}\left(\mathrm{t}_{\mathrm{f}}\right), \mathrm{t}_{\mathrm{f}}\right)-\mathrm{p}\left(\mathrm{t}_{\mathrm{f}}\right)\right]^{\mathrm{T}} \delta \mathrm{x}_{\mathrm{f}}=0$

com $\delta \mathrm{x}_{\mathrm{f}}$ arbitrário, devemos ter necessariamente:

$\frac{\partial \mathrm{h}}{\partial \mathrm{x}}\left(\mathrm{x}\left(\mathrm{t}_{\mathrm{f}}\right), \mathrm{t}_{\mathrm{f}}\right)-\mathrm{p}\left(\mathrm{t}_{\mathrm{f}}\right)=0$

Em termos do sistema 5.7 em questão, $x(t)=\left(\begin{array}{c}T_{b}(t) \\ M(t)\end{array}\right)$ e $p(t)=\left(\begin{array}{l}p_{1}(t) \\ p_{2}(t)\end{array}\right)$ e, logo: 
$\frac{\partial \mathrm{h}}{\partial \mathrm{T}_{\mathrm{b}}}\left(\left(\mathrm{T}_{\mathrm{b}}\left(\mathrm{t}_{\mathrm{f}}\right), \mathrm{M}(\mathrm{t})\right), \mathrm{t}_{\mathrm{f}}\right)-\mathrm{p}_{1}\left(\mathrm{t}_{\mathrm{f}}\right)=0$

$\frac{\partial \mathrm{h}}{\partial \mathrm{M}}\left(\left(\mathrm{T}_{\mathrm{b}}\left(\mathrm{t}_{\mathrm{f}}\right), \mathrm{M}(\mathrm{t})\right), \mathrm{t}_{\mathrm{f}}\right)-\mathrm{p}_{2}\left(\mathrm{t}_{\mathrm{f}}\right)=0$

Inicialmente utilizando-se o funcional 5.9 como medida de desempenho, temos que $h\left(x\left(t_{f}\right), t_{f}\right)=0$, e assim, ficamos com:

$p_{1}\left(t_{f}\right)=0$

$p_{2}\left(t_{f}\right)=0$

Com estas condições nosso problema passa a ser o mesmo sistema de equações 5.12 uma vez que não modificamos o índice 5.9, porém, agora, sujeito às condições $\left(\mathrm{T}_{\mathrm{b}}(0), \mathrm{M}(0)\right)=(37,272)^{8}$ e $\left(\mathrm{p}_{1}\left(\mathrm{t}_{\mathrm{f}}\right), \mathrm{p}_{2}\left(\mathrm{t}_{\mathrm{f}}\right)\right)=(0,0)$.

De 5.11.2 temos que:

$\dot{p}_{1}(t)=\frac{\chi}{B C} p_{1}(t)+K p_{2}(t)$

$\dot{p}_{2}(t)=-\frac{h}{B C} p_{1}(t)$

Cuja solução tem a forma dada por:

$\left(\begin{array}{l}p_{1}(t) \\ p_{2}(t)\end{array}\right)=C_{1} V_{\lambda_{1}} e^{\lambda_{1} t}+C_{2} V_{\lambda_{2}} e^{\lambda_{2} t}$

Com autovalores na forma:

$\lambda_{1}=\frac{\chi \mathrm{C}+\sqrt{\chi^{2} \mathrm{C}^{2}-4 \mathrm{ChBK}}}{2 \mathrm{~B}} \quad \lambda_{2}=\frac{\chi \mathrm{C}-\sqrt{\chi^{2} \mathrm{C}^{2}-4 \mathrm{ChBK}}}{2 \mathrm{~B}}$

\footnotetext{
${ }^{8} \mathrm{~T}_{\mathrm{b}}(0)=37$ como anteriormente e $\mathrm{M}(0)=272$ parte da tabela 5.1 para a situação de $\mathrm{T}_{\mathrm{a}}=20{ }^{\circ} \mathrm{C}$ que
} estamos considerando nessa seção. 
e, autovetores associados:

$$
\mathrm{V}_{\lambda_{1}}=\left(\begin{array}{c}
\frac{\chi \mathrm{C}+\sqrt{\chi^{2} \mathrm{C}^{2}-4 \mathrm{ChBK}}}{2 \mathrm{hC}} \\
1
\end{array}\right) \quad \mathrm{V}_{\lambda_{2}}=\left(\begin{array}{c}
\frac{-\chi \mathrm{C}+\sqrt{\chi^{2} \mathrm{C}^{2}-4 \mathrm{ChBK}}}{2 \mathrm{hC}} \\
1
\end{array}\right)
$$

Agora, como $\left(\mathrm{p}_{1}\left(\mathrm{t}_{\mathrm{f}}\right), \mathrm{p}_{2}\left(\mathrm{t}_{\mathrm{f}}\right)\right)=(0,0)$ a única solução possível é a trivial. Para verificarmos isso, basta substituir essa condição de fronteira em 5.16, assim:

$\left(\begin{array}{l}0 \\ 0\end{array}\right)=C_{1} V_{\lambda_{1}} e^{\lambda_{1} t_{f}}+C_{2} V_{\lambda_{2}} e^{\lambda_{2} t_{f}}$

O que implica $C_{1}=C_{2}=0$. $E$, $\operatorname{logo} p_{1}(t)=0$ e $p_{2}(t)=0$ são as únicas soluções possíveis para 5.16 , sujeito à $\left(\mathrm{p}_{1}\left(\mathrm{t}_{\mathrm{f}}\right), \mathrm{p}_{2}\left(\mathrm{t}_{\mathrm{f}}\right)\right)=(0,0)$.

Assim, como o controlador ótimo $\mathrm{T}_{S}(\mathrm{t})$ em 5.11 .3 é escrito em função de $\mathrm{p}_{2}(\mathrm{t})$, temos que:

$\mathrm{T}_{\mathrm{S}}(\mathrm{t})=-\mathrm{Kp}_{2}(\mathrm{t})=0 \Rightarrow \mathrm{T}_{\mathrm{S}}(\mathrm{t})=0, \forall \mathrm{t} \in\left[\mathrm{t}_{\mathrm{i}}, \mathrm{t}_{\mathrm{f}}\right]$

Desta maneira, o sistema 5.12, que soluciona o problema de estabelecer um controlador ótimo que faz com que 5.7 minimize 5.9, com completo desconhecimento de $\mathrm{T}_{\mathrm{b}}\left(\mathrm{t}_{\mathrm{f}}\right)$ e $\mathrm{M}\left(\mathrm{t}_{\mathrm{f}}\right)$ na condição final, se reduz ao problema de valor inicial:

$$
\left\{\begin{array}{c}
\dot{\mathrm{T}}_{\mathrm{b}}(\mathrm{t})=\frac{\mathrm{h}}{\mathrm{BC}} \mathrm{M}(\mathrm{t})-\frac{\chi}{B C} \mathrm{~T}_{\mathrm{b}}(\mathrm{t})+\frac{\chi}{B C} \mathrm{~T}_{\mathrm{a}} \\
\dot{\mathrm{M}}(\mathrm{t})=-\mathrm{KT}_{\mathrm{b}}(\mathrm{t}) \\
\mathrm{T}_{\mathrm{b}}(0)=37, \mathrm{M}(0)=272
\end{array}\right.
$$

Uma rápida análise é capaz de revelar o ponto de equilíbrio do sistema 5.17. De uma forma geral, os pontos de equilíbrio ou singularidades são os pontos que 
representam as soluções estacionárias (Monteiro, 2006) do sistema, ou seja, as soluções encontradas quando $\dot{\mathrm{x}}(\mathrm{t})=0$. Pelo fato de o sistema 5.12 se tratar de um sistema linear, este apresenta um único ponto de equilíbrio, dado então quando $\left(\dot{\mathrm{T}}_{\mathrm{b}}(\mathrm{t}), \dot{\mathrm{M}}(\mathrm{t})\right)=(0,0)$ e, nesta condição o ponto de equilíbrio é dado em:

$\left(T_{b}^{*}(t), M^{*}(t)\right)=\left(0,-\frac{\chi}{h} T_{a}\right)$

É fácil observar a partir do sistema 5.16 que o fato de os co-estados $\mathrm{p}_{1}(\mathrm{t})$ ou $\mathrm{p}_{2}(\mathrm{t})$ não influenciarem a dinâmica dos estados $\mathrm{T}_{\mathrm{b}}(\mathrm{t})$ ou $\mathrm{M}(\mathrm{t})$ implica que estes estados tendem aos seus equilíbrios após certo tempo, dada a estabilidade do sistema 5.17, facilmente observável. O que significa que este sistema abandonado em qualquer condição tende sempre ao equilíbrio $\left(0,-\frac{\chi}{h} T_{a}\right)$ conforme $t \rightarrow \infty$. Obviamente, $\mathrm{M}^{*}\left(\mathrm{t}_{\mathrm{f}}\right)=-\frac{\chi}{\mathrm{h}} \mathrm{T}_{\mathrm{a}}$ não guarda um sentido físico, é apenas o resultado analítico da análise da situação em questão, onde o controlador resultante é dado como $\mathrm{T}_{\mathrm{S}}(\mathrm{t})=0$.

Em contrapartida, esse resultado será de nosso interesse, e preservará sentido físico, ao levarmos em consideração que a taxa metabólica $\mathrm{M}(\mathrm{t})$ de todos os seres vivos tem um limite inferior, dado por zero, na situação de morte. Simulando o sistema 5.17, temos que a temperatura corpórea pára, exatamente, quando essa se iguala à temperatura ambiente, posto que a taxa metabólica é nula, ou seja, um corpo inerte, independentemente de sua massa, condutância ou capacitância térmica que deixa de termorregular, ficaria sob influencia da temperatura ambiente, e tenderia após certo tempo se igualar à ela. Este resultado pode ser visto na Figura 5.2 . 
$J(u(t))=\frac{1}{2}\left(T_{b}\left(t_{f}\right)-T_{b}\left(t_{i}\right)\right)^{2}+\frac{1}{2}\left(M\left(t_{f}\right)-M\left(t_{i}\right)\right)^{2}+\int_{t_{i}}^{t_{f}} \frac{1}{2} T_{s}{ }^{2}(t) d t$

No qual, $T_{b}\left(t_{f}\right)$ e $M\left(t_{f}\right)$ são desconhecidos e serão forçados, enquanto $T_{b}\left(t_{i}\right)$ e $M\left(t_{i}\right)$ não.

Como na situação anterior, o fato de conhecermos $t_{f}$, nos garante que $\delta t_{f}=0$, e do fato de não forçarmos uma situação final para $T_{b}(t)$ e $M(t)$, temos que $\delta x_{f}$ pode assumir valores arbitrários em 5.5. Assim, para que tenhamos:

$\left[\frac{\partial h}{\partial x}\left(x\left(t_{f}\right), t_{f}\right)-p\left(t_{f}\right)\right]^{T} \delta x_{f}=0$

Devemos ter necessariamente:

$\frac{\partial \mathrm{h}}{\partial \mathrm{x}}\left(\mathrm{x}\left(\mathrm{t}_{\mathrm{f}}\right), \mathrm{t}_{\mathrm{f}}\right)-\mathrm{p}\left(\mathrm{t}_{\mathrm{f}}\right)=0$

Mais uma vez 5.15 define nossa condição de fronteira. Porém agora, como nosso índice de desempenho é dado pelo funcional 5.18 , com $\mathrm{h}\left(\mathrm{x}\left(\mathrm{t}_{\mathrm{f}}\right), \mathrm{t}_{\mathrm{f}}\right) \neq 0$, temos que:

$\left(T_{b}\left(t_{f}\right)-T_{b}\left(t_{i}\right)\right)-p_{1}\left(t_{f}\right)=0$
$\left(M\left(t_{f}\right)-M\left(t_{i}\right)\right)-p_{2}\left(t_{f}\right)=0$

Olhando para a forma geral do hamiltoniano, 5.3 , vemos que $h\left(x\left(t_{f}\right), t_{f}\right)$ não faz diferença em sua formulação. Assim, o problema de controle ótimo que minimiza o índice 5.18 possui a mesma solução 5.13 , porém com diferentes condições de fronteira dadas por 5.19. Ou seja, agora para encontrar as constantes arbitrárias $\mathrm{C}_{1}, \mathrm{C}_{2}, \mathrm{C}_{3}$ e $\mathrm{C}_{4}$ que particularizam a solução, dentro da família infinita de soluções 5.13, devemos considerar o sistema 5.20 de equações lineares.

Fazendo $\mathrm{t}_{\mathrm{i}}=0$. Por exemplo, para $T_{a}=0{ }^{\circ} \mathrm{C}$, a Tabela 5.1 nos fornece a condição metabólica inicial, assim $\left(\mathrm{T}_{\mathrm{b}}(0), \mathrm{M}(0)\right)=(37,592)$ : 
$\left(\begin{array}{c}37 \\ 592\end{array}\right)-\left(\begin{array}{c}\frac{\chi}{B C} \\ 0\end{array}\right) T_{a}=C_{1}\left(\begin{array}{l}v_{\lambda_{1}}{ }^{1} \\ v_{\lambda_{1}}{ }^{2}\end{array}\right)+C_{2}\left(\begin{array}{c}v_{\lambda_{2}}{ }^{1} \\ v_{\lambda_{2}}{ }^{2}\end{array}\right)+C_{3}\left(\begin{array}{l}v_{\lambda_{3}}{ }^{1} \\ v_{\lambda_{3}}{ }^{2}\end{array}\right)+C_{4}\left(\begin{array}{l}v_{\lambda_{4}}{ }^{1} \\ v_{\lambda_{4}}{ }^{2}\end{array}\right)$

Fazendo $t_{f}=1000$. Para a condição de fronteira dada por 5.19:

$$
\begin{gathered}
\left(\begin{array}{c}
\mathrm{T}_{\mathrm{b}}(1000)-\mathrm{p}_{1}(1000) \\
\mathrm{M}(1000)-\mathrm{p}_{2}(1000)
\end{array}\right)=\left(\begin{array}{c}
37 \\
592
\end{array}\right) \\
C_{1}\left(\begin{array}{c}
v_{\lambda_{1}}{ }^{1} \\
v_{\lambda_{1}}{ }^{2}
\end{array}\right) e^{\lambda_{1} t_{f}}+C_{2}\left(\begin{array}{l}
v_{\lambda_{2}}{ }^{1} \\
v_{\lambda_{2}}{ }^{2}
\end{array}\right) e^{\lambda_{2} t_{f}}+C_{3}\left(\begin{array}{c}
v_{\lambda_{3}}{ }^{1} \\
v_{\lambda_{3}}{ }^{2}
\end{array}\right) e^{\lambda_{3} t_{f}}+C_{4}\left(\begin{array}{c}
v_{\lambda_{4}}{ }^{1} \\
v_{\lambda_{4}}{ }^{2}
\end{array}\right) e^{\lambda_{4} t_{f}}+\left(\begin{array}{c}
\frac{\chi}{B C} \\
0
\end{array}\right) T_{a} \\
-\left[C_{1}\left(\begin{array}{c}
v_{\lambda_{1}}{ }^{3} \\
v_{\lambda_{1}}{ }^{4}
\end{array}\right) e^{\lambda_{1} t_{f}}+C_{2}\left(\begin{array}{c}
v_{\lambda_{2}}{ }^{3} \\
v_{\lambda_{2}}{ }^{4}
\end{array}\right) e^{\lambda_{2} t_{f}}+C_{3}\left(\begin{array}{c}
v_{\lambda_{3}}{ }^{3} \\
v_{\lambda_{3}}{ }^{4}
\end{array}\right) e^{\lambda_{3} t_{f}}\right. \\
\left.+C_{4}\left(\begin{array}{c}
v_{\lambda_{4}}{ }^{3} \\
v_{\lambda_{4}}{ }^{4}
\end{array}\right) e^{\lambda_{4} t_{f}}\right]=\left(\begin{array}{c}
37 \\
592
\end{array}\right)
\end{gathered}
$$

Desta forma, solucionando o sistema de equações lineares 5.20, obtemos para cada valor de temperatura ambiente $T_{a}$ diferentes valores de $C_{1}, C_{2}, C_{3}$ e $C_{4}$. Procedendo assim, para três diferentes valores de temperatura ambiente, a saber, $\mathrm{T}_{\mathrm{a}}=0^{\circ} \mathrm{C}$, $\mathrm{T}_{\mathrm{a}}=10^{\circ} \mathrm{C}$ e $\mathrm{T}_{\mathrm{a}}=20^{\circ} \mathrm{C}$ e fazendo uso da Tabela 5.1 que nos fornece a taxa metabólica inicial correspondente, construímos a Tabela 5.4:

\begin{tabular}{|l|l|l|}
\hline \multicolumn{1}{|c|}{$T_{a}=0{ }^{\circ} \mathrm{C}$} & \multicolumn{1}{|c|}{$T_{a}=10^{\circ} \mathrm{C}$} & \multicolumn{1}{c|}{$T_{a}=20^{\circ} \mathrm{C}$} \\
\hline$C_{1}=30.0608$ & $C_{1}=21.7287$ & $C_{1}=13.3966$ \\
$C_{2}=6.9392$ & $C_{2}=15.2713$ & $C_{2}=23.6034$ \\
$C_{3}=-4.6871 e-135$ & $C_{3}=-7.2532 e-135$ & $C_{3}=-9.8194 e-135$ \\
$C_{4}=0.0765$ & $C_{4}=0.1591$ & $C_{4}=0.2418$ \\
\hline
\end{tabular}

Tabela 5.4: Constantes arbitrárias $\mathrm{C}_{1}, \mathrm{C}_{2}, \mathrm{C}_{3}$ e $\mathrm{C}_{4}$, obtidas a partir do sistema de equações lineares 5.20 com $T_{b}\left(t_{i}\right)=37$, nas 3 situações de $T_{\mathbf{a}}$ (e $M\left(t_{i}\right)$ correspondente, dadas pela Tabela 5.1).

Substituindo as constantes $C_{1}, C_{2}, C_{3}$ e $C_{4}$, na solução 5.13 , construímos a solução particular para cada $T_{a}$ de interesse, que minimiza 5.18. Os diferentes valores de $T_{b}(t)$, obtidos desta forma são mostrados na Figura 5.3 A, enquanto $M(t)$ em $5.3 B$. Cabe relembrar que $T_{b}\left(t_{i}\right)=37$ para todas as situações. 

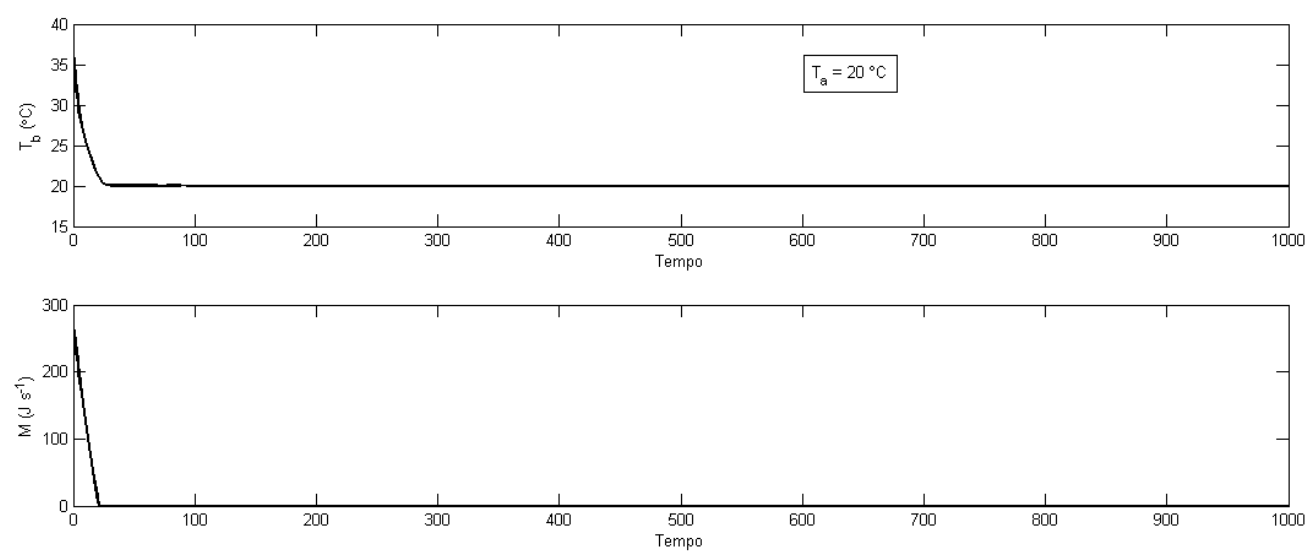

Fig. 5.2: Simulação do sistema 5.17, com restrição das variáveis no espaço de estados, mais particularmente da taxa metabólica, que atinge seu limite inferior $M(t)=0$ numa possível situação final de reserva energética, para um indivíduo que deixa de termorregular. Os valores empregados para as constantes são os mesmos que na seção anterior, valores $\chi=16, h=$ $0.2, \mathrm{~K}=0.5$ e $\mathrm{B}=50$.

Agora, sugerimos uma pequena mudança no funcional que caracteriza o índice de desempenho 5.9 .

\subsection{CONDIÇÕES INICIAIS CONHECIDAS, FINAIS ALCANÇADAS ATRAVÉS DA}

\section{MINIMIZAÇÃO DE DESEMPENHO}

Propomos, agora, uma pequena mudança no índice de desempenho 5.9. Esta mudança tem o intuito de verificar se é possível fazer com que o sistema termorregulatório 5.7 atinja os valores esperados de temperatura corpórea e taxa metabólica sem forçar estes valores como condições de fronteira do sistema per se, como se ele "soubesse" qual deveria ser seu estado final - como fizemos na subseção 5.1-, mas sim que o controlador force o sistema para que ele retorne, após certo tempo, aos mesmos valores $\mathrm{T}_{\mathrm{b}}\left(\mathrm{t}_{\mathrm{i}}\right)$ e $\mathrm{M}\left(\mathrm{t}_{\mathrm{i}}\right)$, como resultado da otimização de um funcional da forma 5.6, dado por: 

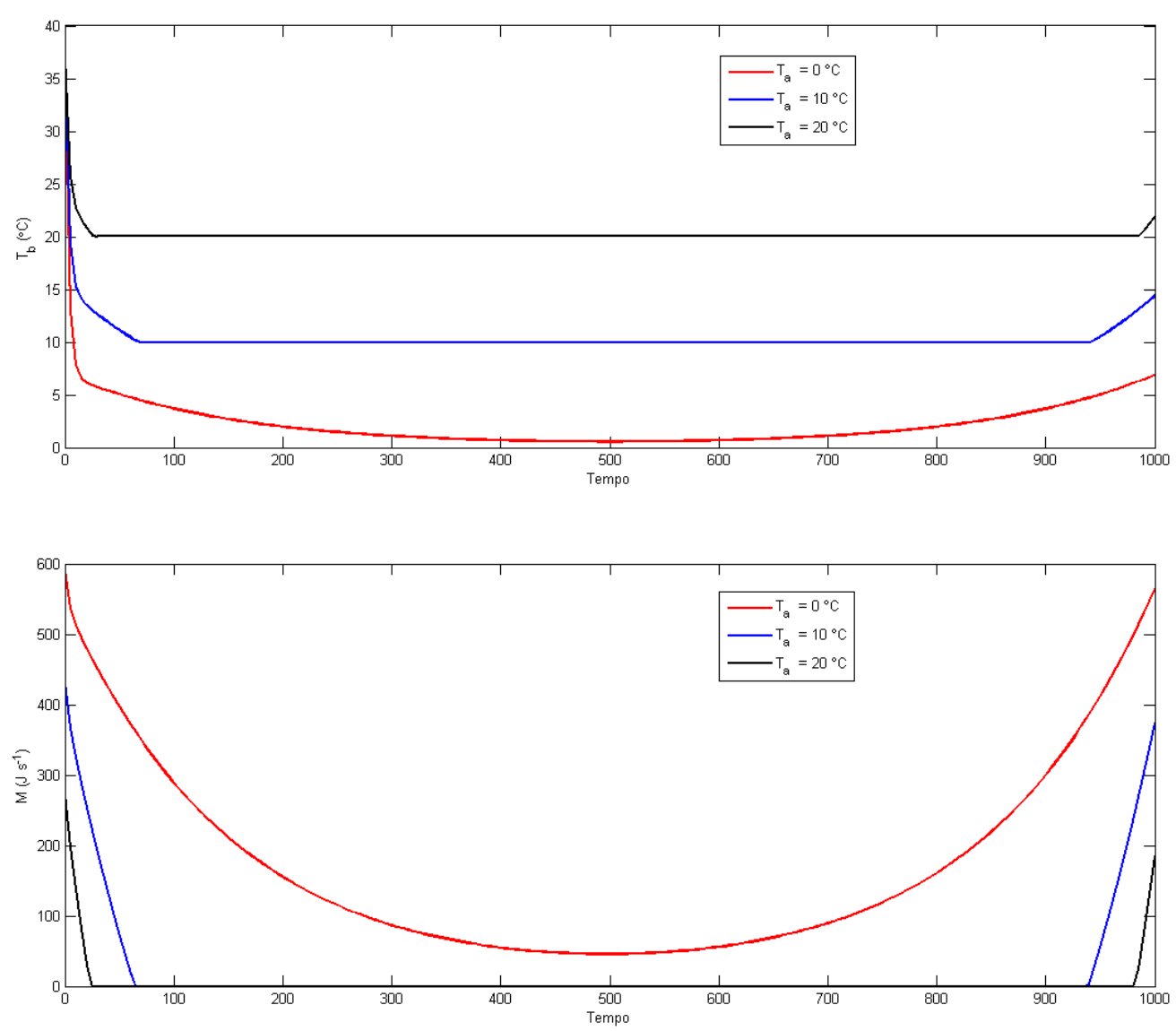

Fig. 5.3: Resultados de simulação de $T_{b}(t)$ e $\mathrm{M}(\mathrm{t})$, para as 3 situações de temperatura ambiente, com as constantes calculadas na Tabela 5.4, e os valores $\chi=16, h=0.2, K=0.5$ e $B=50$. Estes são os trajetos resultantes quando o controlador ótimo busca minimizar o esforço de controle dado pelo índice 5.18 , nos quais $T_{b}\left(t_{i}\right)$ e $M\left(t_{i}\right)$ são conhecidos e $T_{b}\left(t_{f}\right)$ e $M\left(t_{f}\right)$ buscam alcançá-los. (A) Este é o trajeto ao longo do tempo realizado pela temperatura corpórea, pode-se facilmente observar que os valor final de temperatura corpórea é inferior ao valor inicial. (B) Respectiva taxa metabólica, resultado da minimização, nas 3 situação de temperatura ambiente. Da mesma maneira, $M\left(t_{f}\right)$ é inferior a $M\left(t_{i}\right)$. Mais detalhes no texto.

Comparando-se os valores finais de $\mathrm{T}_{\mathrm{b}}(\mathrm{t})$ e $\mathrm{M}(\mathrm{t})$ apresentados na Figura $5.3 \mathrm{com}$ aqueles apresentados na Figura 5.1, percebemos que para nenhuma situação de temperatura ambiente, a temperatura corpórea $\mathrm{T}_{\mathrm{b}}(\mathrm{t})$ ou a taxa metabólica $\mathrm{M}(\mathrm{t})$ puderam voltar aos seus valores iniciais esperados, dentro do período de simulação, ficando todos abaixo de $25^{\circ} \mathrm{C}$ no instante final.

Como anteriormente construímos a Tabela 5.5 que resume os resultados de interesse para nossa análise da minimização. 


\begin{tabular}{|c|c|c|c|}
\hline & $T_{a}=0{ }^{\circ} \mathrm{C}$ & $T_{a}=10^{\circ} \mathrm{C}$ & $T_{a}=20^{\circ} \mathrm{C}$ \\
\hline$J(u(t))$ & $1.558610^{4}$ & $6.744310^{4}$ & $1.556710^{5}$ \\
\hline$I R A M$ & 0.2932 & 0.0523 & 0.0167 \\
\hline
\end{tabular}

Tabela 5.5: Índice relativo de área metabólica (IRAM) e índice de custo com a termorregulação J(u(t)) referente à minimização do funcional 5.18, que estabelece essa. Mais uma vez, conforme a temperatura ambiente decresce tanto o esforço de controle $\mathrm{J}(\mathrm{u}(\mathrm{t})$ ) necessário para sustentar a termorregulação, quanto a taxa metabólica necessária para o mesmo fim aumentam.

Faz-se importante compararmos os resultados apresentados na Tabela 5.5 com àqueles apresentados na Tabela 5.3. Primeiramente o índice de desempenho $J(u(t))$, nas condições atuais desta seção (valores finais de $T_{b}(t)$ e $M(t)$ desconhecidos, porém forçados), os valores apresentados, para todas as situações de temperatura ambiente consideradas são significativamente menores que nas condições da seção 3.1, apresentados na Tabela 5.3. Cabe destacar que essa redução é o reflexo de o sistema não atingir os valores de $T_{b}(t)$ e $M(t)$ esperados, para nenhuma das situações de $T_{a}$ (ver os valores finais $T_{b}\left(t_{f}\right)$ e $M\left(t_{f}\right)$ na Figura 5.3 A e B e comparar com a Figura 5.1 A e B). Outro resultado relevante que deve ser considerado é o índice relativo de área metabólica (IRAM) que para as 3 condições de $\mathrm{T}_{\mathrm{a}}$, também apresenta valores significativamente inferiores quando comparados à Tabela 5.3, porém um diferença importante deve ser notada quando $\mathrm{T}_{\mathrm{a}}=0{ }^{\circ} \mathrm{C}$, IRAM $=0.2932$ sugere que se $\mathrm{o}$ indivíduo, com essa massa, não voltar aos valores iniciais $T_{b}\left(t_{i}\right)$ e $M\left(t_{i}\right)$ ao final de algum tempo, então a depressão metabólica forçada pela minimização com a termorregulação está justificada também nessa situação ambiental, diferentemente do que acontecia na seção 3.1 (ver Tabela 5.3), onde as condições finais a serem alcançadas induziam um aumento da taxa metabólica que parecia inviabilizar a depressão metabólica como possível fator de minimização energético.

Nesta direção, a comparação entre os resultados nos sugere que uma alteração no índice de desempenho 5.18, no sentido de aumentar seu peso, enfatizando um forçamento no estado final das variáveis de estado $\mathrm{T}_{\mathrm{b}}(\mathrm{t})$ e $\mathrm{M}(\mathrm{t})$, deve aproximar os 
resultados obtidos e apresentados na Tabela 5.5 (e Figura 5.3) dos resultados obtidos na seção 5.1, e apresentados na Tabela 5.3 (e Figura 5.1). Assim, propomos, a partir de 5.18, o seguinte índice de desempenho, introduzindo as constantes $\mathrm{f}_{1}, \mathrm{f}_{2} \in \mathbb{R}^{+}$:

$J(u(t))=f_{1}\left(T_{b}\left(t_{f}\right)-T_{b}\left(t_{i}\right)\right)^{2}+f_{2}\left(M\left(t_{f}\right)-M\left(t_{i}\right)\right)^{2}+\int_{t_{i}}^{t_{f}} \frac{1}{2} T_{s}{ }^{2}(t) d t$

Embora as constantes $f_{1}$ e $f_{2}$ pudessem ser distintas, vamos considerá-las inicialmente iguais.

De posse de 5.21, podemos recalcular as condições de fronteira dadas por 5.5. Mais uma vez temos $\delta t_{f}=0$, uma vez que consideramos conhecer $t_{f} \mathrm{e}$, ao contrário, como desconhecemos a situação final de $T_{b}(t)$ e $M(t)$, temos $\delta x_{f}$ assumindo valores arbitrários. Assim, as condições de fronteira são:

$$
\begin{aligned}
& 2 f_{1}\left(T_{b}\left(t_{f}\right)-T_{b}\left(t_{i}\right)\right)-p_{1}\left(t_{f}\right)=0 \\
& 2 f_{2}\left(M\left(t_{f}\right)-M\left(t_{i}\right)\right)-p_{2}\left(t_{f}\right)=0
\end{aligned}
$$

As constantes arbitrárias são dadas para a solução 5.13 , que mais uma vez não altera, pois $\mathrm{h}\left(\mathrm{x}\left(\mathrm{t}_{\mathrm{f}}\right), \mathrm{t}_{\mathrm{f}}\right)=\mathrm{f}_{1}\left(\mathrm{~T}_{\mathrm{b}}\left(\mathrm{t}_{\mathrm{f}}\right)-T_{b}\left(t_{i}\right)\right)^{2}+\mathrm{f}_{2}\left(\mathrm{M}\left(\mathrm{t}_{\mathrm{f}}\right)-M\left(t_{i}\right)\right)^{2}$ não altera a formulação do hamiltoniano do sistema.

Para as mesmas 3 situações de $T_{a}$ analisadas anteriormente, com os valores iniciais de taxa metabólica dados pela Tabela 5.1 e para valores $f_{1}$ e $f_{2}$ dados por $f_{1}=f_{2}=$ $10,10^{4}, 10^{5}, 10^{8}$ podemos encontrar as constantes arbitrárias $C_{1}, C_{2}, C_{3}$ e $C_{4}$ que particularizam a solução, considerando o sistema 5.23 de equações lineares.

Fazendo $t_{i}=0$, a condição inicial de temperatura corpórea $T_{b}(0)=37$, e a Tabela 5.1 fornecendo os valores da condição metabólica inicial para cada temperatura ambiente considerada, podemos escrever: 
$\left(\begin{array}{l}T_{b}(0) \\ M(0)\end{array}\right)-\left(\begin{array}{c}\frac{\chi}{B C} \\ 0\end{array}\right) T_{a}=C_{1}\left(\begin{array}{l}v_{\lambda_{1}}{ }^{1} \\ v_{\lambda_{1}}{ }^{2}\end{array}\right)+C_{2}\left(\begin{array}{l}v_{\lambda_{2}}{ }^{1} \\ v_{\lambda_{2}}{ }^{2}\end{array}\right)+C_{3}\left(\begin{array}{l}v_{\lambda_{3}}{ }^{1} \\ v_{\lambda_{3}}{ }^{2}\end{array}\right)+C_{4}\left(\begin{array}{l}v_{\lambda_{4}}{ }^{1} \\ v_{\lambda_{4}}{ }^{2}\end{array}\right)$

Em contrapartida, fazendo $t_{f}=1000$. Para a condição de fronteira dada por 5.22:

$\left(\begin{array}{l}2 f_{1} T_{b}(1000)-p_{1}(1000) \\ 2 f_{2} M(1000)-p_{2}(1000)\end{array}\right)=\left(\begin{array}{l}2 f_{1} T_{b}(0) \\ 2 f_{2} M(0)\end{array}\right)$

Ou seja:

$$
\begin{aligned}
\left(\begin{array}{cc}
2 f_{1} & 0 \\
0 & 2 f_{2}
\end{array}\right)\left[C_{1}\left(\begin{array}{c}
v_{\lambda_{1}}{ }^{1} \\
v_{\lambda_{1}}{ }^{2}
\end{array}\right) e^{\lambda_{1} t_{f}}+C_{2}\left(\begin{array}{c}
v_{\lambda_{2}}{ }^{1} \\
v_{\lambda_{2}}{ }^{2}
\end{array}\right) e^{\lambda_{2} t_{f}}+C_{3}\left(\begin{array}{c}
v_{\lambda_{3}}{ }^{1} \\
v_{\lambda_{3}}{ }^{2}
\end{array}\right) e^{\lambda_{3} t_{f}}\right. \\
\left.+C_{4}\left(\begin{array}{c}
v_{\lambda_{4}}{ }^{1} \\
v_{\lambda_{4}}{ }^{2}
\end{array}\right) e^{\lambda_{4} t_{f}}+\left(\begin{array}{c}
\frac{\chi}{B C} \\
0
\end{array}\right) T_{a}\right] \\
-\left[C_{1}\left(\begin{array}{c}
v_{\lambda_{1}}{ }^{3} \\
v_{\lambda_{1}}{ }^{4}
\end{array}\right) e^{\lambda_{1} t_{f}}+C_{2}\left(\begin{array}{c}
v_{\lambda_{2}}{ }^{3} \\
v_{\lambda_{2}}{ }^{4}
\end{array}\right) e^{\lambda_{2} t_{f}}+C_{3}\left(\begin{array}{c}
v_{\lambda_{3}}{ }^{3} \\
v_{\lambda_{3}}{ }^{4}
\end{array}\right) e^{\lambda_{3} t_{f}}\right. \\
\left.+C_{4}\left(\begin{array}{c}
v_{\lambda_{4}}{ }^{3} \\
v_{\lambda_{4}}{ }^{4}
\end{array}\right) e^{\lambda_{4} t_{f}}\right]=\left(\begin{array}{c}
2 f_{1} T_{b}(0) \\
2 f_{2} M(0)
\end{array}\right)
\end{aligned}
$$

Solucionando o sistema de equações lineares 5.23 para as diferentes situações de $T_{a}$ (com taxa metabólica inicial correspondente) e de $f_{1,2}$ obtemos os diferentes valores para as constantes $C_{1}, C_{2}, C_{3}$ e $C_{4}$, que particularizam soluções em 5.13 . Em cada situação apresentamos os diferentes valores de $T_{b}(t)$ e $M(t)$ obtidos nas Figuras 5.4 a 5.6. Como anteriormente, as constantes empregadas em todas as situações que seguem são dadas por $\chi=16, \mathrm{~h}=0.2, \mathrm{~K}=0.5$ e $\mathrm{B}=50$.

Observe que para as 3 condições de temperatura ambiental, na situação onde o forçamento $f_{1}=f_{2}=10^{8}$ é considerado, os resultados obtidos de $T_{b}(t)$ e $M(t)$ se igualam exatamente aos da subseção 5.1, onde conhecíamos as condições de fronteira $T_{b}\left(t_{f}\right)$ e $\mathrm{M}\left(t_{f}\right)$, ou seja, o índice dado por 5.21 força o mesmo comportamento. E, vamos a partir do cálculo de $J(u(t))$ e IRAM analisar os custos inerentes ao processo para as distintas situações ambientais e de forçamento; estes resultados estão analisados e expressos de agora em diante e seus resultados numéricos sumarizados nas Tabelas 5.6, 5.8 e 5.10 . 
Para $T_{a}=0{ }^{\circ} \mathrm{C}$ e para cada $f_{1}=f_{2}=10,10^{4}, 10^{5}, 10^{8}$ os distintos resultados de $T_{b}(t)$ e $M(t)$ podem ser vistos nas Figuras 5.4 A e B, abaixo.
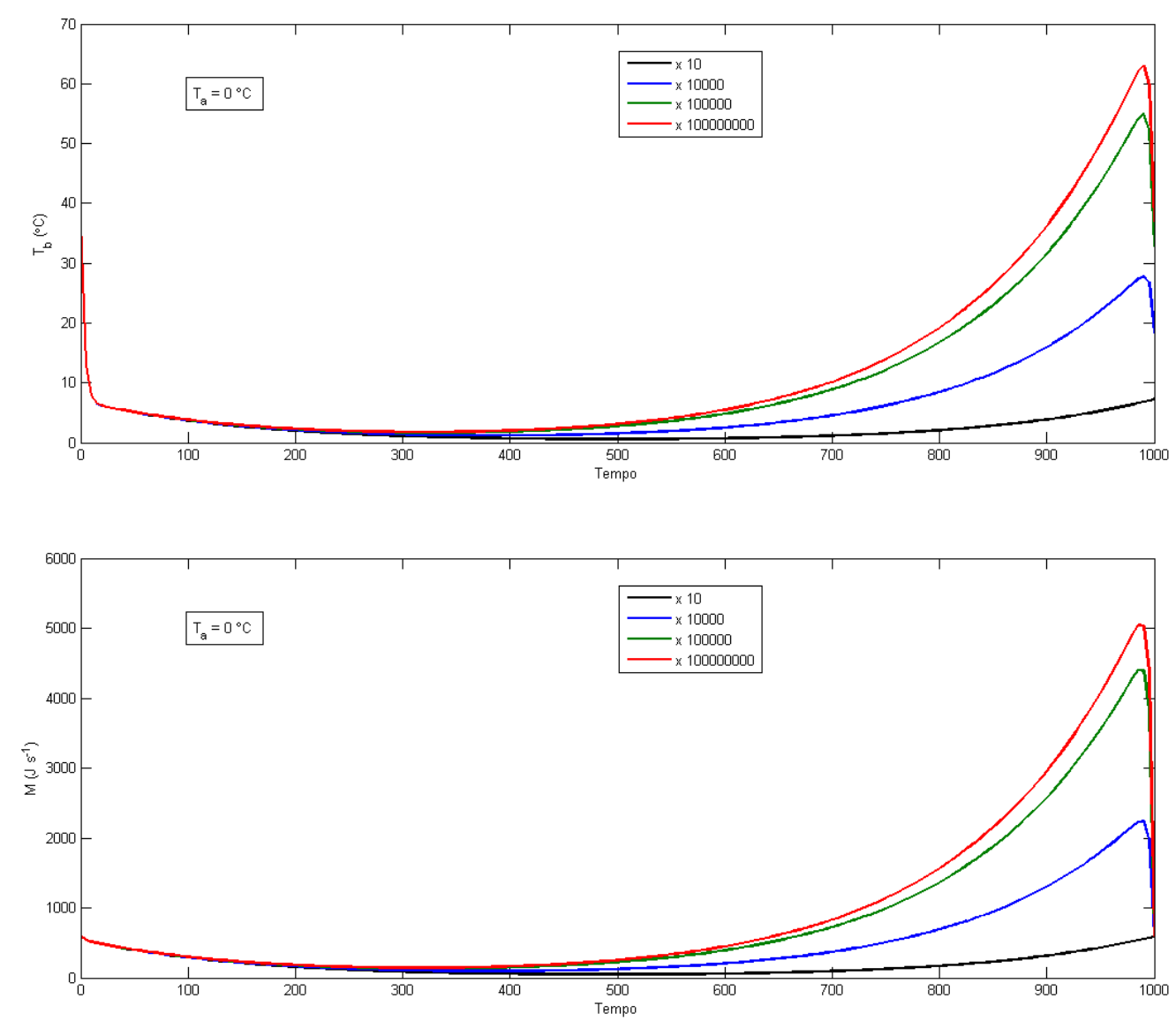

Fig. 5.4: Resultados da simulação de $T_{b}(t)$ e $\mathrm{M}(\mathrm{t})$ dados pela solução 5.13, com constantes calculadas a partir do sistema 5.23, na situação de temperatura ambiente $\mathrm{T}_{\mathrm{a}}=0{ }^{\circ} \mathrm{C}$. As trajetórias apresentadas são resultado da minimização do índice 5.21, com diversos forçamentos $f_{1}=f_{2}=10,10^{4}, 10^{5}, 10^{8}$. (A) Apenas para o forçamento $f_{1}=f_{2}=10^{8}, T_{b}\left(t_{f}\right)$ retorna o valor dado por $\mathrm{T}_{\mathrm{b}}\left(\mathrm{t}_{\mathrm{i}}\right)$ (B) Idem para a taxa metabólica neste grau forçamento. Segue análise frente aos resultados sumarizados na Tabela 5.6 .

Comparar os valores finais de $\mathrm{T}_{\mathrm{b}}(\mathrm{t})$ e $\mathrm{M}(\mathrm{t})$ na situação de $f_{1}=f_{2}=10$ na Figura 5.4 A e B com as mesmas variáveis na Figura 5.3 A e B, e perceber a proximidade entre esses graus de forçamento. Comparar agora, na situação de $f_{1}=f_{2}=10^{8}$ a Figura 5.4 A e B com os resultados obtidos na seção 5.1 e apresentados na Figura 5.1 A e $B$ apenas para $T_{a}=0{ }^{\circ} \mathrm{C}$. Esse forçamento aproxima os valores de $\mathrm{T}_{\mathrm{b}}\left(\mathrm{t}_{\mathrm{f}}\right)$ e $\mathrm{M}\left(\mathrm{t}_{\mathrm{f}}\right) \mathrm{de}$ $\mathrm{T}_{\mathrm{b}}\left(\mathrm{t}_{\mathrm{i}}\right)$ e $\mathrm{M}\left(\mathrm{t}_{\mathrm{i}}\right)$. Assim, pode-se observar facilmente a partir da Figura 5.4 que à 
medida que $f_{1,2}$ se intensificam no sentido de forçar a minimização de condições finais no índice 5.21, os valores de $T_{b}(t)$ e $M(t)$ tendem aos valores de $T_{b}(t)$ e $M(t)$ para $\forall t \in\left[t_{i}, t_{f}\right]$ quando as condições finais eram conhecidas na seção 5.1. Isso é reforçado pelos resultados apresentados na Tabela 5.6.

De posse dos resultados obtidos podemos montar a Tabela 5.6 e comparar cada situação simulada frente aos índices que viemos utilizando.

\begin{tabular}{|c|c|c|}
\hline$f_{1,2}$ & $J(u(t))$ & IRAM \\
\hline 10 & $1.696310^{4}$ & 0.3005 \\
\hline $10^{4}$ & $3.592710^{6}$ & 0.7831 \\
\hline $10^{5}$ & $1.880410^{7}$ & 1.4048 \\
\hline $10^{8}$ & $2.560710^{7}$ & 1.5891 \\
\hline
\end{tabular}

Tabela 5.6: Î́ndice de custo com a termorregulação $\mathrm{J}(\mathrm{u}(\mathrm{t}))$ e índice relativo de área metabólica (IRAM) referentes à minimização do funcional 5.21 quando $\mathrm{T}_{\mathrm{a}}=0^{\circ} \mathrm{C}$. De uma forma geral, pode-se perceber que conforme $\mathrm{o}$ forçamento $\mathrm{f}_{1,2}$ se intensifica ambos os índices possuem seus valores aumentados, resultado do aumento de $\mathrm{T}_{\mathrm{b}}(\mathrm{t})$ e $\mathrm{M}(\mathrm{t})$, como pode ser visto nas Figuras $5.5 \mathrm{~A}$ e B.

A partir da Tabela 5.6 podemos perceber que à medida que $\mathrm{f}_{1,2}$ aumenta os índices $\mathrm{J}(\mathrm{u}(\mathrm{t}))$ e IRAM assumem valores cada vez mais próximos $^{9}$ dos valores apresentados na Tabela 5.3 para a situação de temperatura ambiente $T_{a}=0{ }^{\circ} \mathrm{C}$.

Como havíamos constatado anteriormente e discutido na seção 5.1 frente aos resultados da Tabela 5.3 para $T_{a}=0{ }^{\circ} \mathrm{C}$, o custo da redução e retorno ao estado inicial de eutermia não se justifica para um indivíduo de massa $B=50$. Isso foi concluído a partir de IRAM por apresentar valor maior que 1 para a situação estudada. Porém, podemos concluir a partir dos dados apresentados na Tabela 5.6, fazendo uso do mesmo índice, que se o indivíduo não for forçado a retornar à sua condição térmica e metabólica inicial, outro cenário pode se apresentar, pois a redução da taxa metabólica, resultado da minimização do gasto com a

\footnotetext{
${ }^{9}$ No caso de $\mathrm{f}_{1,2}=10^{8}$, os valores devem ser considerados idênticos, a pequena diferença se deve meramente a aproximações numéricas.
} 
termorregulação, passa a ser justificada, uma vez que a relação entre custo metabólico de realizar essa minimização (reduzir e voltar subir) e o de manter a taxa metabólica na condição inicial é reduzida. Isso pode ser visto na Tabela 5.6, onde a região que separa a viabilidade da inviabilidade da redução está entre $f_{1,2}=10^{4} \mathrm{e}$ $f_{1,2}=10^{5}$. Trata-se de um intervalo bastante largo, e mais divisões poderiam ser feitas para descobrir com exatidão onde se dá a mudança, bem como a temperatura corpórea e taxa metabólica que são sustentadas neste caso, porém preferimos seguir analisando a outras situações de temperatura ambiente. Essa decisão ficará clara na seguinte seção quando analisamos estes índices frente a diferentes massas corpóreas.

Apenas gostaríamos de reforçar que, para essa temperatura ambiente, o controlador $T_{s}(t)$ (set-point hipotalâmico) buscar igualar $T_{b}\left(t_{f}\right)$ a $T_{b}\left(t_{i}\right)$ e $M\left(t_{f}\right)$ a $M\left(t_{i}\right)$ não é adequado para uma indivíduo com essas características. Vamos agora prosseguir nossa análise frente às outras situações de temperatura ambiente estudadas.

Para $T_{a}=10^{\circ} \mathrm{C}$ e para cada $f_{1}=f_{2}=10,10^{4}, 10^{5}, 10^{8}$ os distintos resultados de $T_{b}(t)$ e $M(t)$ podem ser vistos nas Figuras 5.5 A e B, abaixo. 

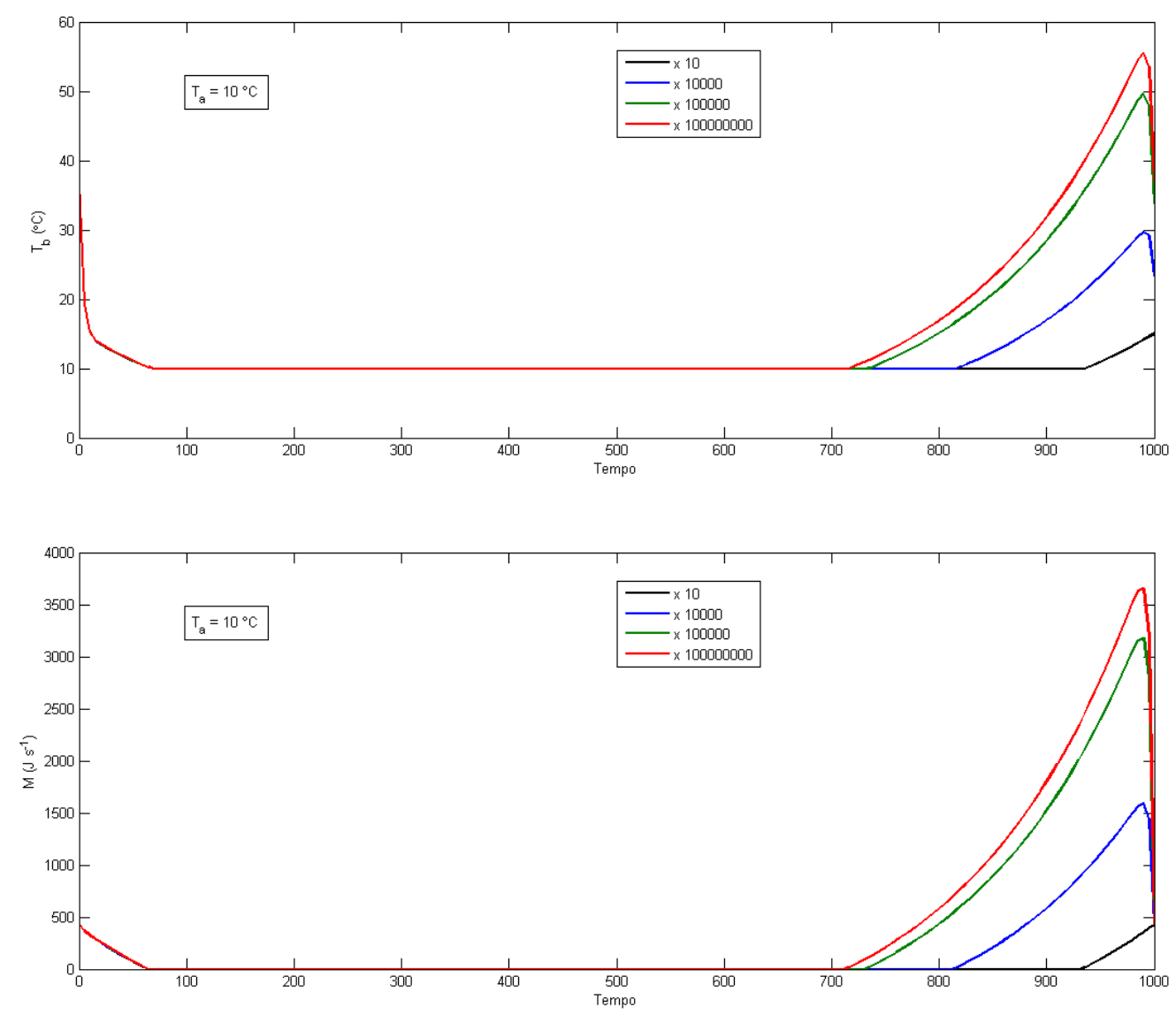

Fig. 5.5: Resultados da simulação de $T_{b}(t)$ e $\mathrm{M}(\mathrm{t})$ dados pela solução 5.13 , com constantes calculadas a partir do sistema 5.23, na situação de temperatura ambiente $T_{a}=10^{\circ} \mathrm{C}$. As trajetórias apresentadas são resultado da minimização do índice 5.21, com diversos forçamentos $f_{1}=f_{2}=10,10^{4}, 10^{5}, 10^{8}$. (A) Apenas para o forçamento $f_{1}=f_{2}=10^{8}, T_{b}\left(t_{f}\right)$ retorna o valor dado por $\mathrm{T}_{\mathrm{b}}\left(\mathrm{t}_{\mathrm{i}}\right)$. (B) Idem para a taxa metabólica neste grau forçamento.

Como anteriormente, podemos perceber a partir da Figura 5.5, que o aumento de $f_{1,2}$ força uma aproximação entre os valores de $\mathrm{T}_{\mathrm{b}}(\mathrm{t})$ e $\mathrm{M}(\mathrm{t}) \forall t \in\left[t_{i}, t_{f}\right]$ apresentados aqui e aqueles apresentados na Figura 5.1 quando as condições finais eram conhecidas (seção 5.1). Isso é reforçado pelos resultados apresentados na Tabela 5.7. 


\begin{tabular}{|c|c|c|}
\hline$f_{1,2}$ & $J(u(t))$ & IRAM \\
\hline 10 & $7.345510^{4}$ & 0.0589 \\
\hline $10^{4}$ & $1.990410^{6}$ & 0.3311 \\
\hline $10^{5}$ & $1.020610^{7}$ & 0.8115 \\
\hline $10^{8}$ & $1.388510^{7}$ & 0.9657 \\
\hline
\end{tabular}

Tabela 5.7: Índice de custo com a termorregulação $\mathrm{J}(\mathrm{u}(\mathrm{t}))$ e índice relativo de área metabólica (IRAM) referentes à minimização do funcional 5.21 quando $T_{a}=10^{\circ} \mathrm{C}$. Fica evidente que os aumentos de $\mathrm{f}_{1,2}$ forçam aumentos a ambos os índices e, mais que $f_{1,2}=10^{8}$ corresponde aos valores de $T_{b}\left(t_{f}\right)$ e $M\left(t_{f}\right)$ que se igualam $T_{b}\left(t_{i}\right)$ e $M\left(t_{i}\right)$.

Como na situação anterior, a Tabela 5.7 permite-nos perceber como os índices $J(u(t))$ e IRAM são induzidos por aumentos em $\mathrm{f}_{1,2}$. Comparar os resultados para $\mathrm{f}_{1,2}=10^{8}$ nesta tabela coma Tabela 5.3 para a situação de temperatura ambiente $T_{a}=10^{\circ} \mathrm{C}$. Os valores coincidem, sugerindo que $T_{b}(t)$ e $M(t)$ se igualam nas duas situações. Cabe também comparar os valores de IRAM apresentados aqui com aqueles apresentados na Tabela $5.6\left(T_{a}=0^{\circ} \mathrm{C}\right)$; mostrando que um aumento significativo do custo metabólico se dá na temperatura ambiente mais baixa.

E, finalmente para $T_{a}=20^{\circ} \mathrm{C}$ e para os distintos forçamentos $f_{1}=f_{2}=10,10^{4}, 10^{5}, 10^{8}$, cujos influencias sobre $T_{b}(t)$ e $M(t)$ podem ser vistos nas Figuras 5.6 A e B, abaixo. 

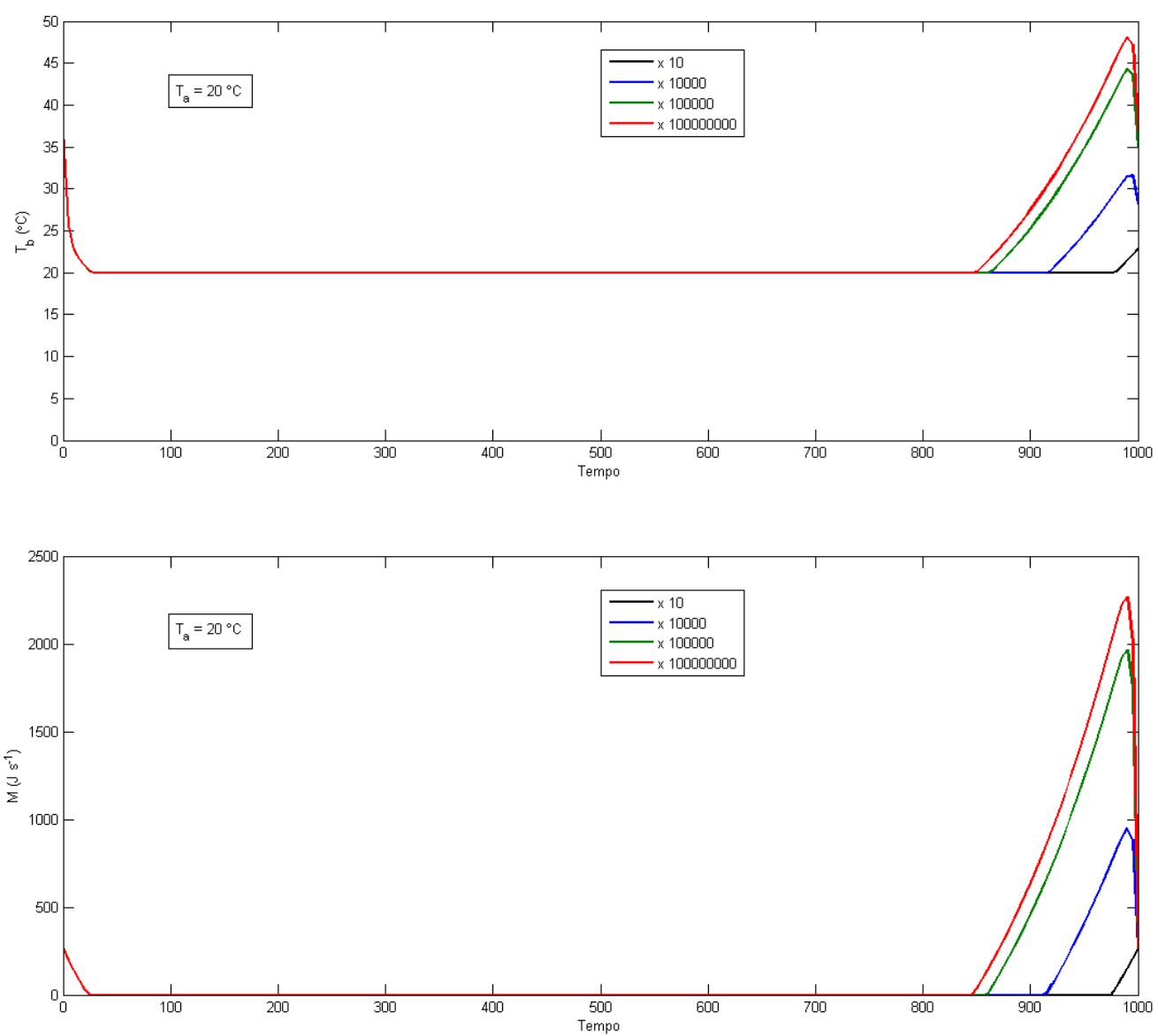

Fig. 5.6: Resultados da simulação de $T_{b}(t)$ e $M(t)$ dados pela solução 5.13, com constantes calculadas a partir do sistema 5.23 , na situação de temperatura ambiente $T_{a}=20^{\circ} \mathrm{C}$. As trajetórias apresentadas são resultado da minimização do índice 5.21, com diversos forçamentos $f_{1}=f_{2}=10,10^{4}, 10^{5}, 10^{8}$. (A) Apenas para o forçamento $f_{1}=f_{2}=10^{8}, T_{b}\left(t_{f}\right)$ retorna o valor dado por $T_{b}\left(t_{i}\right)$ (B) Idem para a taxa metabólica neste grau forçamento.

Como anteriormente, podemos perceber a partir da Figura 5.6, que o aumento de $f_{1,2}$ força uma aproximação entre os valores de $\mathrm{T}_{\mathrm{b}}(\mathrm{t})$ e $\mathrm{M}(\mathrm{t}) \quad \forall t \in\left[t_{i}, t_{f}\right]$ apresentados aqui e aqueles apresentados na Figura 5.1 quando as condições finais eram conhecidas (seção 5.1). Isso é reforçado pelos resultados apresentados na Tabela 5.7. 


\begin{tabular}{|c|c|c|}
\hline$f_{1,2}$ & $J(u(t))$ & IRAM \\
\hline 10 & $1.696010^{5}$ & 0.0223 \\
\hline $10^{4}$ & $9.413910^{5}$ & 0.1645 \\
\hline $10^{5}$ & $4.299110^{6}$ & 0.4877 \\
\hline $10^{8}$ & $5.806110^{6}$ & 0.6016 \\
\hline
\end{tabular}

Tabela 5.8: Índice de custo com a termorregulação $\mathrm{J}(\mathrm{u}(\mathrm{t})$ ) e índice relativo de área metabólica (IRAM) referentes à minimização do funcional 5.21 quando $T_{a}=10^{\circ} \mathrm{C}$. Fica evidente que os aumentos de $\mathrm{f}_{1,2}$ forçam aumentos a ambos os índices e, mais que $\mathrm{f}_{1,2}=10^{8}$ corresponde aos valores de $\mathrm{T}_{\mathrm{b}}\left(\mathrm{t}_{\mathrm{f}}\right)$ e $\mathrm{M}\left(\mathrm{t}_{\mathrm{f}}\right)$ que se igualam $\mathrm{T}_{\mathrm{b}}\left(\mathrm{t}_{\mathrm{i}}\right)$ e $\mathrm{M}\left(\mathrm{t}_{\mathrm{i}}\right)$.

Voltamos, aqui, a enfatizar as diferenças entre os resultados obtidos nas subseções 5.1 e 5.3. Em 5.1, definidas as condições iniciais e finais do sistema 5.7, o controlador ótimo $T_{s}(t)$ leva o sistema de uma condição à outra, minimizando um índice de desempenho, ou seja, de antemão características pré-definidas do sistema particularizavam uma solução, ou trajetória no espaço de estados $\left[T_{b}(t) \times\right.$ $M(t)$ ]. Já em 5.3, o mesmo valor é atingindo como resultado da minimização de um índice que força uma situação final para as variáveis dependentes $\left(T_{b}(t)\right.$ e $\left.M(t)\right)$. Como exemplo de uma situação final, poderíamos considerar referências estruturais celulares de manutenção de tecidos e órgãos, como uma temperatura adequada de funcionamento. E, como vimos ao longo da seção 5.3, essas referências não são as mesmas para todas as situações de temperatura ambiente.

Buscaremos, agora, efetuar as mesmas análises empregadas nesta seção ao estudo termorregulatório de endotermos com distintas massas corpóreas. 


\section{APLICAÇÕES AO ESTUdO DA DEPRESSÃO METABÓLICA}

Os estados de depressão metabólica em endotermos são, de uma maneira não suficientemente rigorosa e consensual, usualmente divididos em 3 tipos: hibernação, torpor, hipotermia facultativa (Schmidt-Nielsen, 1997; Guppy \& Withers, 1999; Geiser, 2004). A hibernação tende a ser caracterizada por uma depressão metabólica profunda, com redução na demanda energética para menos que $2 \%$ dos níveis de repouso, com intensa queda na temperatura corpórea e duração prolongada. O torpor é um evento diário, geralmente restrito à fase de não-atividade do animal, com diminuição da demanda energética não tão intensa quanto a da hibernação, o mesmo ocorrendo para a temperatura corpórea. A hipotermia facultativa é um tipo de depressão metabólica que ocorre em alguns animais que, habitualmente, não apresentam tal condição. Por outro lado, vêm sendo cada vez mais relatados os casos de associação entre restrição calórica e diminuição na temperatura corpórea e taxa metabólica em mamíferos e aves, o que poderá vir a caracterizar, num futuro não distante, um quadro no qual todos os endotermos se encaixem (Graf et al., 1989; Jansky, 1995; Lane et al., 1996; Freeman et al., 2004; Heldmaier et al., 2004). Cabe ainda lembrar que a hibernação ocorre "em surtos", isto é, o longo período de hibernação contém vários eventos mais curtos de entrada e saída do estado de depressão metabólica, cada uma dessas entradas sendo designada como um episódio de torpor ${ }^{10}$.

Estudos mostram que a eutermia logo após o torpor apresenta-se como que uma privação de sono não-REM (Berger \& Phillips, 1995; Berger, 1998; Heller \& Ruby, 2004), indicando uma diminuição no processo homeostático de manutenção de sinapses (estabilização dinâmica não-utilitária) no sistema nervoso central devido à queda na temperatura do órgão. Assim, um primeiro problema que podemos apontar quanto ao estado hipometabólico é a integridade funcional do sistema nervoso. Outros fenômenos candidatos a problemas são a diminuição na proliferação linfocitária, a desidratação e desbalanços iônicos, o estresse oxidativo. Finalmente, há, ainda, o comprometimento sensório e motor, os quais aumentam,

10 "torpor bout". 
entre outros, o risco de predação (ver a extensa revisão sobre o assunto em Humphries et al., 2003).

Dessa maneira, o panorama geral é que a entrada em depressão metabólica leva a uma grande "ruptura fisiológica" (Guppy \& Withers 1999) e custos operacionais no retorno. Portanto, mesmo mamíferos no hibernáculo irão se beneficiar por não entrar no estado hipometabólico (French, 2000).

\subsection{RELAÇÕES ENTRE CUSTO E MASSA CORPÓREA}

Dentro do quadro acima delineado faz-se, portanto, importante o estudo da associação que existe entre a demanda energética nos estados de hipometabolismo frente a diferentes massas corpóreas. Somente mais recentemente vêm se encontrando estudos com tal foco, e poucos desses têm uma abordagem teórica.

Aplicar a teoria de controle ótimo surge, nesta direção, com a idéia de estabelecer um ferramental teórico-analítico que permita analisar como se dá uma possível minimização dos gastos energéticos com a depressão metabólica, ou seja, como o sistema nervoso atuaria estabelecendo um controle (set-point hipotalâmico) que minimizasse estes gastos à medida que se desse o processo de termorregulação. Para tanto, definimos uma medida, chamada índice de desempenho, dado por 5.21, que se caracteriza como um funcional relacionado ao gasto com a termorregulação ao longo do tempo e que permite, através dos pesos $f_{1}$ e $f_{2}$, um balanço entre temperatura corpórea e taxa metabólica. Através da teoria de controle ótimo, buscamos encontrar um controle para o sistema que minimizasse tal índice. Seguiremos com as idéias desenvolvidas na seção 5, estendendo-as ao estudo de indivíduos com diferentes relações massa - condutância térmica. Faremos também, diferentemente da seção anterior, uma dissociação entre os forçamentos $f_{1}$ e $f_{2}$ atribuindo-Ihes distintos valores, de forma a simular o comportamento térmico de indivíduos que não priorizam ambas variáreis do mesmo modo. 
Vamos analisar uma relação linear entre massa corpórea e condutância térmica para outros dois valores de massa, a saber, $B=10$, de forma a caracterizar um individuo bastante menor do que àquele que estudado na seção 5 e $B=100$ caracterizando um indivíduo bastante maior. Assim, a relação linear entre as variáveis é dada pela equação 6.1:

$\chi=K B$

Tendo como referencia os valores de $\chi=16$ e $B=50$ utilizados na seção anterior, podemos extrair o valor da constante $K$ para estabelecer à quais valores de condutância térmica correspondem às massas de nosso interesse atual, $B=10 \mathrm{e}$ $B=100$. Assim da equação. 6.1:

$K=\frac{\chi}{B}=\frac{16}{50}=0.32$

$\mathrm{E}$, logo os valores de $\chi$ que correspondem à indivíduos de massas $B=10 \mathrm{e}$ $B=100$ dados pela relação 6.1 são:

\begin{tabular}{|l|l|}
\hline$B=10$ & $B=100$ \\
\hline$\chi=0.3210=3.2$ & $\chi=0.32100=32$ \\
\hline
\end{tabular}

Tabela 6.1: Condutâncias correspondentes a outros valores de massa, numa relação linear.

De posse destes valores, podemos relacionar os valores de $M_{i}$ à $T_{b_{i}}$, como fizemos anteriormente, para satisfazer a condição de equilíbrio térmico

$M\left(t_{i}\right)-\chi\left(T_{b}\left(t_{i}\right)-T_{a}\right)=0$

Posto isso, faremos uso das condutâncias correspondentes dadas pela Tabela 6.1 para construir aos indivíduos de cada massa corpórea, em diferentes situações de temperatura ambiente, baseado nas condições de equilíbrio térmico inicial e final, expressas em 6.2, os valores de taxa metabólica nestas situações. Mais uma vez, estamos considerando que a temperatura corpórea na condição final do processo 
de termorregulação deve se igualar a condição inicial dada por $\left(T_{b}\left(t_{i}\right)=37\right)$ para simular uma situação de retorno ao estado de eutermia. Para que isso aconteça, ou seja, para que tenhamos $T_{b}\left(t_{f}\right)=T_{b}\left(t_{i}\right)=37$ devemos, como vimos na seção 5.3 forçar $\mathrm{f}_{1}=\mathrm{f}_{2}=10^{8}$. Construímos, assim, a Tabela 6.2, abaixo.

\begin{tabular}{|c|c|c|c|}
\hline & $T_{a}=0{ }^{\circ} \mathrm{C}$ & $T_{a}=10{ }^{\circ} \mathrm{C}$ & $T_{a}=20^{\circ} \mathrm{C}$ \\
\hline$\chi=3.2$ & 118,4 & 86,4 & 54,4 \\
\hline$\chi=32$ & 1184 & 864 & 544 \\
\hline
\end{tabular}

Tabela 6.2: Valores de taxa metabólica $\mathrm{M}\left(\mathrm{t}_{\mathrm{f}}\right)=\mathrm{M}\left(\mathrm{t}_{\mathrm{i}}\right)$ calculados para $\chi=3.2$ e $\chi=32$ nas situações de equilíbrio térmico, em diferentes condições temperatura ambiente.

Fazendo uso dos valores calculados na Tabela 6.2 e do forçamento dado por $\mathrm{f}_{1}=\mathrm{f}_{2}=10^{8}$, procedemos com o cálculo do controlador ótimo, $T_{s}(t)$ (set-point hipotalâmico), que minimiza o índice de desempenho, dado pelo funcional 5.21. Assim, como fizemos na seção 5.3, substituindo as condições de fronteira de taxa metabólica, expressas na Tabela 6.2, e de temperatura corpórea $\left(T_{b}\left(t_{i}\right)=37\right)$, na solução 5.13 obtemos o sistema de equações lineares da forma 5.23, que solucionado juntamente à 5.22, apresenta-nos as constantes $C_{1}, C_{2}, C_{3}$ e $C_{4}$ que particularizam a solução 5.13. Desta maneira, construímos a solução particular para cada $\mathrm{T}_{\mathrm{a}}$ de interesse.

Os resultados de taxa metabólica e temperatura corpórea são apresentados na Figura 6.1 A e B e Figura 6.2 A e B. 
Para $B=10:$
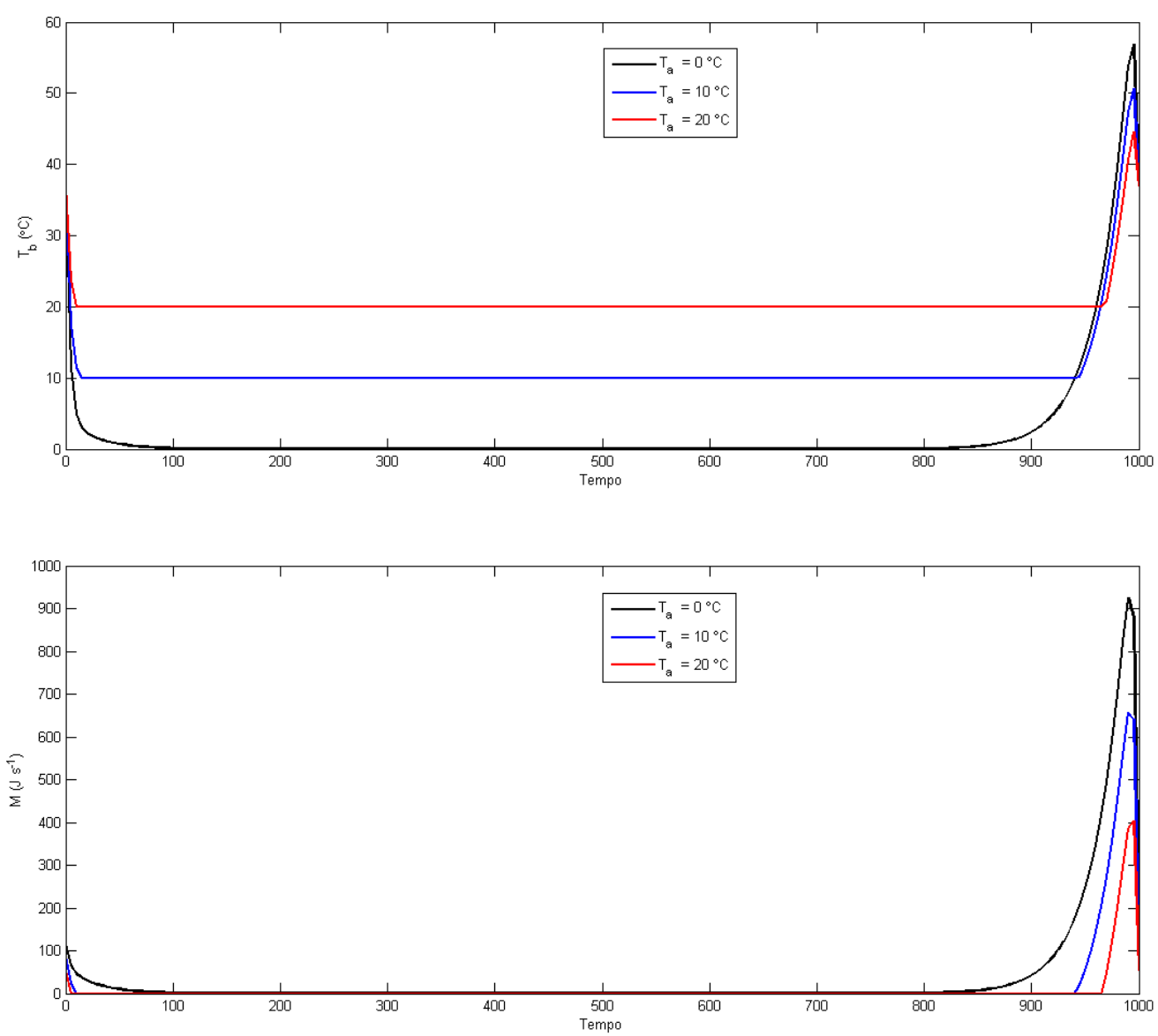

Fig. 6.1: Resultado de simulação de $T_{b}(t)$ e $\mathrm{M}(\mathrm{t})$, em 5.13 para as 3 situações de temperatura ambiente $T_{a}$ para os valores $\chi=3.2, h=0.2, K=0.5$ e $B=10$. (A) Este é o trajeto ao longo do tempo realizado pela temperatura corpórea, quando o controlador ótimo busca minimizar o esforço de controle dado pelo índice 5.9. (B) Respectiva taxa metabólica, resultado da minimização do mesmo índice, nas 3 situação de temperatura ambiente. Devemos ressaltar que, nesta situação, as condições iniciais e finais do sistema são conhecidas (dadas pela Tabela 6.2), assim o controlador atua de forma a levar o sistema de uma condição à outra, minimizando 5.9 . 

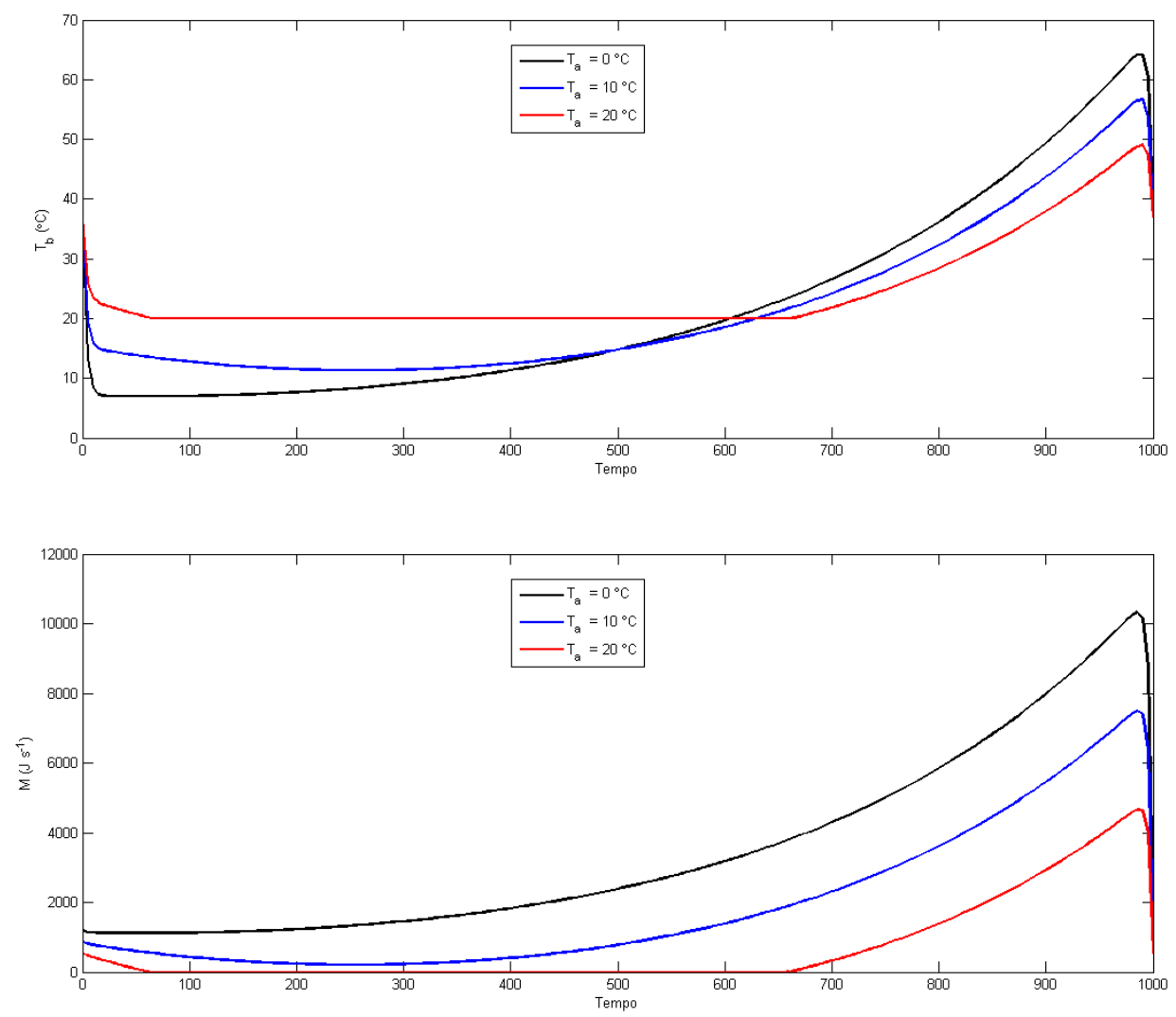

Fig. 6.2: Resultado de simulação de $T_{b}(t)$ e $\mathrm{M}(\mathrm{t})$, em 5.13 para as 3 situações de temperatura ambiente $T_{a}$ para os valores $\chi=160, h=0.2, K=0.5$ e $B=100$. (A) Este é o trajeto ao longo do tempo realizado pela temperatura corpórea, quando o controlador ótimo busca minimizar o esforço de controle dado pelo índice 5.9. (B) Respectiva taxa metabólica, resultado da minimização do mesmo índice, nas 3 situação de temperatura ambiente. Devemos ressaltar que, nesta situação, as condições iniciais e finais do sistema são conhecidas (dadas pela Tabela 6.2), assim o controlador atua de forma a levar o sistema de uma condição à outra, minimizando 5.9 .

De posse dos resultados obtidos podemos montar a Tabela 6.3 e comparar cada situação simulada frente aos índices que viemos utilizando. 


\begin{tabular}{|l|c|l|l|l|}
\hline & \multicolumn{2}{|c|}{$B=10$} & \multicolumn{2}{c|}{$B=100$} \\
\hline & IRAM & $J(u(t))$ & IRAM & $J(u(t))$ \\
\hline$T_{a}=0^{\circ} \mathrm{C}$ & 0.3149 & $1.135910^{6}$ & 2.9310 & $1.010510^{8}$ \\
\hline$T_{a}=10^{\circ} \mathrm{C}$ & 0.2062 & $6.545710^{5}$ & 2.1666 & $5.426110^{7}$ \\
\hline$T_{a}=20^{\circ} \mathrm{C}$ & 0.1388 & $3.197810^{5}$ & 1.2745 & $2.206310^{7}$ \\
\hline
\end{tabular}

Tabela 6.3: Índice de custo com a termorregulação $\mathrm{J}(\mathrm{u}(\mathrm{t})$ ) e índice relativo de área metabólica (IRAM) referentes às condições distintas de $\mathrm{T}_{\mathrm{a}} \mathrm{e} \mathrm{B}$. De uma forma geral, pode-se perceber que indivíduos menores tem seu redução metabólica justificada quando comparados aos indivíduos de massa maior.

Os resultados, apresentados na Tabela 6.3, mais uma vez sugerem a viabilidade da análise empregada, à medida que é capaz marcar as diferenças entre os indivíduos de massas corpóreas distintas. Vemos que para nenhuma situação de temperatura ambiente, na qual se encontre o indivíduo de massa $B=100$, a minimização como estabelecida parece ser uma estratégia viável para minimização do custo metabólico, uma vez que o custo com voltar a eutermia suplanta o custo de se manter em eutermia por todo o período (ver IRAM para qualquer situação de $\mathrm{T}_{\mathrm{a}}$ ). Isso sugere uma diferença entre as vantagens da ocorrência da depressão metabólica em indivíduos que pertencem a grupos de massas corpóreas tão distintas.

Neste sentido, através dos pesos $\mathrm{f}_{1}$ e $\mathrm{f}_{2}$, que correspondem aos forçamentos de temperatura corpórea e taxa metabólica, respectivamente, modificamos o índice 5.21 de maneira a alterar o balanço entre temperatura corpórea e taxa metabólica a serem considerados na minimização. Assim, analisamos algumas situações possíveis para o indivíduo de maior massa corpórea, apenas para a situação $T_{a}=0{ }^{\circ} \mathrm{C}$, por representar a condição ambiente de maior custo termorregulatório e de entrada em depressão metabólica, como podemos constatar na Tabela 6.3. Os resultados são apresentados na Tabela 6.4, abaixo. 


\begin{tabular}{|l|l|c|c|c|c|}
\hline $\mathrm{f}_{1}$ & $\mathrm{f}_{2}$ & $M_{f}$ & $T_{b_{f}}$ & $I R A M$ & $J(u(t))$ \\
\hline $10^{4}$ & $10^{4}$ & 1184 & 11.2291 & 0.8804 & $1.759910^{6}$ \\
\hline $10^{2}$ & $10^{8}$ & 1184 & 7.3789 & 0.5741 & $3.204810^{4}$ \\
\hline $10^{8}$ & $10^{2}$ & 1302.1 & 37 & 2.9004 & $9.599310^{7}$ \\
\hline $10^{2}$ & $10^{4}$ & 1184 & 7.3789 & 0.5741 & $3.204810^{4}$ \\
\hline $10^{4}$ & $10^{2}$ & 1199.6 & 11.3122 & 0.8832 & $1.749310^{6}$ \\
\hline
\end{tabular}

\footnotetext{
Tabela 6.4: Índice de custo com a termorregulação $\mathrm{J}(\mathrm{u}(\mathrm{t})$ ) e índice relativo de área metabólica (IRAM) referentes aos distintos forçamentos $\mathrm{f}_{1}$ e $\mathrm{f}_{2}$ do funcional 5.21 , para o mesmo indivíduo de massa corpórea $\mathrm{B}=100$. Os valores iniciais de temperatura corpórea e taxa metabólica inicial são dados por $\mathrm{M}_{\mathrm{i}}=1184 \mathrm{e}$ $\mathrm{T}_{\mathrm{b}_{\mathrm{i}}}=37$. Através dos valores de IRAM, pode-se perceber que para indivíduos de maior massa existe uma sensibilidade muito grande quanto ao forçamento referente à temperatura corpórea, $f_{1}$, isso porque para valores de $\mathrm{f}_{1}<10^{8}$ o indivíduo não é capaz de voltar ao estado de eutermia, ficando inclusive bastante abaixo do valor esperado para $\mathrm{T}_{\mathrm{b}}(\mathrm{t})$. $\mathrm{O}$ mesmo não ocorre para o forçamento referente à taxa metabólica.
}

Os resultados destas simulações, onde desacoplamos os forçamentos referentes à temperatura corpórea e taxa metabólica indicam, para o animal de maior massa, que o retorno à eutermia se faz sob custo elevado, basicamente, devido a uma priorização dada à manutenção da temperatura corpórea. Este resultado parece, em principio, não corresponder um fenômeno termorregulatório no sentido clássico, pois sugere um desacoplamento ao indicar que a eutermia pode ser "metabólica", porém não necessariamente térmica. A leitura que propomos é que, para esses indivíduos, o retorno da temperatura corpórea exige maior tempo que o da taxa metabólica, indicando a necessidade de uma análise temporal desacoplada entre estas variáveis, em linhas semelhantes ao que é sugerido por estudos calorimétricos (e.g., Webb, 1995; Tikuisis, 2003). Outra indicação obvia é que existem claras diferenças entre a depressão metabólica de pequenos e grandes endotermos, pois os últimos, como indicam os resultados na Tabela 6.3, "pagam um preço" muito alto para retornar à eutermia. 


\section{CONCLUSÕES}

Com os resultados deste trabalho, o que estamos sugerindo é que o set-point hipotalâmico seja um controle que surge como resultado de um processo de minimização, não um simples controle proporcional como propõem Hammel (1968) e Cabannac (1975) entre outros, que embora pareça justificar o fenômeno do ponto de vista térmico (como vimos na seção 4), ignora questões relacionadas ao metabolismo, a possíveis influencias de reservas energéticas e aos custos com a própria termorregulação. Porém, tão pouco deve ser visto de forma simplificada, como uma referência fixa, pré-determinada pelo/no sistema nervoso central. E, essa é uma grande confusão que encontramos pela literatura, o não entendimento das diferenças entre set-point e referência, que permeia toda a literatura especializada. Mais sobre essa confusão, sugerimos a leitura de Cabannac (2006).

O que queremos dizer com isso? O set-point hipotalâmico pode surgir no sistema termorregulatório, representando um controle para este sistema, como resultado da minimização de um índice que reúna características que se deseje preservar ou minimizar. Isso é possível, como vimos, desde que se saiba o que se deseja minimizar, porém com a liberdade de se definir um índice na forma 5.6, balanceando características de interesse, através de mudanças em $g(x(t), u(t), t)$ ou $h\left(x\left(t_{f}\right), u\left(t_{f}\right), t_{f}\right)$. Ou seja, o set-point pode atuar no sistema não apenas definindo onde a temperatura corpórea deve estar, mas também definido como ela deve chegar lá, levando em conta um balanço entre distintos critérios a serem considerados numa minimização. Isso é o que vimos ao longo da seção 5 , quando forçamos ganhos ao índice 5.18 (um balanço entre taxa metabólica e temperatura corpórea) que procurávamos minimizar.

Buscamos, assim, estabelecer um set-point que realiza aquilo que a literatura caracteriza por entrada em torpor (Westman \& Geiser, 2004; Geiser, 2004; Hainsworth, Collins \& Wolf, 1977), a partir de uma medida de desempenho que representa um custo com a própria termorregulação. Assim, uma vez definidas as condições iniciais de eutermia, o controlador ótimo $T_{s}(t)$ (set-point hipotalâmico) 
leva o sistema desta condição à outra, minimizando um índice de desempenho que força uma situação final para as variáveis dependentes, temperatura corpórea e taxa metabólica $\left(T_{b}(t)\right.$ e $\left.M(t)\right)$, e cujo resultado do ponto de vista metabólico é a própria depressão metabólica. Como exemplo de uma situação final a ser forçada, poderíamos considerar referências estruturais celulares de manutenção de tecidos e órgãos, como uma temperatura adequada de funcionamento.

Como vimos ao longo da seção 5, essas referências não são as mesmas para todas as situações de temperatura ambiente ou massa corpórea (seção 6). Assim, através do índice relativo de área metabólica (IRAM), definido na subseção 5.1, pôde-se ver o quanto se aumenta ou diminui, relativamente, o metabolismo total durante um período, devido à opção do controle ótimo em relação a se manter, durante todo o período, com a mesma taxa metabólica inicial.

Ainda na subseção 5.1, outra relação importante que analisamos se dá entre massa, temperatura ambiente e extensão do estado de depressão metabólica. Como pudemos observar a partir da Figura 5.1.1 B, e da redução de IRAM causada pelo aumento da extensão em depressão metabólica, a flexibilidade do aumento desta extensão sinaliza a viabilidade desta estratégia para redução do custo metabólico numa situação de baixa temperatura ambiente, para indivíduos cuja massa corpórea aumenta o custo com a depressão. Este resultado sugere a possibilidade de que padrões distintos de depressão metabólica podem, na verdade, ser resultado dessa diferenciação nas características metabólicas de indivíduos induzidas por sua massa corpórea. Isso poderia, por exemplo, ser o que define uma diferença entre as características fisiológicas daquilo que usualmente se define por torpor, entendido como um evento de curta duração e aquilo que se define por hibernação, um fenômeno de maior extensão.

As idéias desenvolvidas aqui sugerem, assim, estabelecer ferramentas que vão ao encontro da discussão proposta por Humphries e colaboradores (2003). Os autores analisam o paradigma atual que entende como maior benefício do torpor ser maximizar a duração das reservas, i.e., maior extensão da depressão metabólica (isto seria a "hibernação ótima") ao considerarem que "o reconhecimento da flexibilidade na estratégia energética da maioria dos hibernantes e as evidências 
que vêm se acumulando dos custos associados a tais estados põem em questão essa assunção se a "hibernação ótima" necessariamente envolve maximizar a profundidade e a duração dos surtos de torpor" (Humphries et al., 2003).

Como sugerem os resultados analisados na seção 5.1 para a temperatura ambiente $T_{a}=0^{\circ} \mathrm{C}$, expressos na Tabela 5.3, e as situações analisadas na seção 6 , expressas na Tabela 6.3, para indivíduos de distintas massas, a entrada em depressão metabólica não poderia ser sempre associada ao benefício da diminuição do gasto energético, como sugere o paradigma atual. Porque, se assim o fosse, então, por que nem todos os endotermos entram, corriqueiramente, em tais estados; e, mais ainda, por que os animais que o fazem parecem, mesmo assim, postergar e restringir os períodos de depressão? Mesmo a própria hibernação ocorre de maneira episódica, com períodos de torpor intercalados com eutermia (Deboer \& Tobler, 1994; Strijkstra \& Daan, 1997; Deboer \& Tobler, 2000), termina por aumentar a demanda energética total do animal. Essas são evidencias que se manter na condição de baixo metabolismo não é isento de riscos ou custos.

Desta forma, parece-nos bastante razoável supor que a teoria de controle ótimo surge, nesta direção, com um ferramental teórico propício para analisar como se dão possíveis minimizações dos gastos energéticos com a depressão metabólica, ou seja, como o sistema nervoso atuaria, estabelecendo um controle (set-point hipotalâmico) que minimizasse estes gastos à medida que se desse o processo de termorregulação. 


\section{CONSIDERAÇÕES FINAIS DO AUTOR}

Como bem lembra Poincaré (1995), não existem relações de causa e efeito, mas sim relações de causas e efeitos. Quando aquilo que não consideramos como causa, por algum motivo, não conta, supomos conhecer as relações entre as variáveis consideradas importantes (através do modelo); nesse momento, a visão, tão importante para o processo de construção dos modelos, se mostra ineficaz, pois boa parte das causas - vez por outra ditas perturbações - nos são, além de invisíveis, inimagináveis. Por isso, cabe muitas vezes à razão (ou será à imaginação?) e a seus métodos dedutivos ou inferenciais, fazendo uso de alguma linguagem, substituir, ou melhor, alargar a visão no processo de construção dos modelos e do convencimento (contabilizando seu papel político e histórico!) de que aquilo que se representa simbolicamente corresponde a uma natura. Assim, através dessa "visão" generalizada, por assim dizer, surge a morphè que se "escondia" por trás dos fenômenos. Muitas vezes ganha vida própria, desprende-se, e até perdemos a noção de que se tratava de uma representação. Então, cabe aí a pergunta: estamos falando de ciência ou de arte, ou de literatura, de criação, enfim? Os métodos se chocam, se confundem. Tudo passa pela linguagem, ou melhor, se submete a ela. Uma coisa é certa, não estamos falando apenas de descrição de fenômenos e suas relações possíveis, sua álgebra, mas de uma mistura que incorpora elementos para construção de um corpus volumoso, amalgamado, indissociável. E, ainda que para muitos seja difícil ver, e a muitos outros interesse que eles de fato não vejam, aquilo a que chamamos ciência faz, com certeza, parte da cultura humana, tanto quanto a culinária, a literatura ou a carpintaria. 


\section{BIBLIOGRAFIA}

Berger, R. J. \& Phillips, N. H. (1995). Energy conservation and sleep. Behav. Brain Res. 69: 65-73.

Berger, R. J. (1998). Does post-torpor EEG slow wave activity in ground squirrels reflect a 'sleep debt' or a thermoregulatory process? J. Sleep Res. 7: 69-72.

Bonnier, G. \& Cabanac, M. (1970). Regulation de la calcemie. Etude analogique. Rev. Eur. Et. Clin. Biol. 15: 551-557.

Bryson, A. E. \& Ho, Y. C. (1975). Applied Optimal Control, Hemisphere Pub. Corp. Washington.

Cabannac, M. (1975). Temperature regulation. Annu. Rev. Physiol. 37: 415 - 439.

Cabannac, M. (2006). Adjustable set point: to honor Harold T. Hammel. J. Appl. Physiol. 100: $1338-1346$.

Chaui-Berlinck, J. G., Navas, C. A., Monteiro, L. H. A. \& Bicudo, J. E. P. W. (2005). Control of metabolic rate is a hidden variable in allometric scaling of homeotherms. J. Exp. Biol. 208, 1709-1716.

Cooper, K. E. (2002). Some historical perspectives on thermoregulation. J. Appl. Physiol. 92:1717-1724.

Deboer, T. \& Tobler I. (1994). Sleep EEG after daily torpor in the Djungarian hamster: similarity to the effect of sleep deprivation. Neurosci. Lett. 166: 35-38.

Deboer, T. \& Tobler I. (2000). Slow waves in the sleep electroencephalogram after daily torpor are homeostatically regulated. Neuroreport. 11:881-885.

Freeman, D. A., Lewis, D. A., Kauffman, A. S., Blum, R. M. \& Dark, J. (2004). Reduced leptin concentrations are permissive for display of torpor in Siberian hamsters. Am. J. Physiol. Regul. Integr. Comp. Physiol. 287:R97-R103.

French, A. R. (2000). Interdependency of stored food and changes in body temperature during hibernation of the eastern chipmunk, Tamias striatus. J. Mammal. 81: 979-985.

Geiser, F. (2004). Metabolic rate and body temperature reduction during hibernation and daily torpor. Annu. Rev. Physiol. 66: 239-274. 
Geiser, F. (2000). Metabolic rate reduction during hibernation and daily torpor. Publicado em Life in the Cold: Evolution, Mechanisms, Adaptation and Application. Twelfth International Hibernation Symposium.

Geiser, F. (2004). Metabolic rate and body temperature reduction during hibernation and daily torpor. Annu. Rev. Physiol. 66: 239-274.

Graf, R., Krishna, S. \& Heller, H. C. (1989). Regulated nocturnal hypothermia induced in pigeons by food deprivation. Am. J. Physiol. 256: R733-R738.

Guppy, M., \& Withers, P. C. (1999). Metabolic depression in animals: physiological perspectives and biochemical generalizations. Biol. Rev. 74, 1-40.

Hainsworth, F. R. (1995) Optimal body temperatures with shutting: desert antelope ground squirrels. Anim. Behav. 49: $107-116$.

Hainsworth, F. R., Collins, B. G. \& Wolf, L. L. (1977). The function of torpor in hummingbirds. Physiol. Zool. 50: 215-222.

Hainsworth, F. R. (1978). Feeding: models of costs and benefits in energy regulation. Amer. Zool. 18: 701-714.

Hammel, H.T. (1968). Regulation of internal body temperature. Annu. Rev. Physiol. 30: $641-710$.

Hammel, H. T., D. C. Jackson, J. A. J., Stolwijk, J. D. H. \& Stromme,S. B. (1963). Temperature regulation by hypothalamic proportional control with an adjustable set point. J. Appl. Physiol. 18(6): 1146-1154.

Heldmaier, G., Ortmann, S. \& Elvert, R. (2004). Natural hypometabolism during hibernation and daily torpor in mammals. Respir. Physiol. \& Neurobiol. 141: 317329.

Heller, H. C. \& Ruby, N. F. (2004). Sleep and circadian rhythms in mammalian torpor. Annu. Rev. Physiol. 66: 275-289.

Hochachka, P. W. \& Somero, G. N. (2002). Biochemical Adaptation: Mechanism and Process in Physiological Evolution. Oxford University Press, New York.

Hoffman, K. \& Kunze, R. (1979) Álgebra Linear - 2a . Edição. Livros Técnicos e Científicos Editora, Rio de Janeiro, RJ.

Hurwitz, S., Fishman, S. A., Bar, M. P., Riesenfeld, G. \& Talpaz, H. (1983). Simulation of calcium homeostasis: modeling and parameter estimation, Am. J. Physiol. Regul. Integr. Comp. Physiol. 245: R664-R672. 
Humphries, M.M., Thomas, D. W., Kramer, D. L. (2003) The role of energy availability in mammalian hibernation: a cost-benefit approach. Physiol. \& Bioch. Zool. 76: $165-179$.

Jansky, L. (1995). Humoral thermogenesis and its role in maintaining energy balance. Physiol. Rev. 75: 237-251.

Kalman, R. E. (1970). Contributions to the Theory of Optimal Control, "Bol. Soc. Mat. Mex., 102:119

Kanosue, K., Romanovsky A. A., Hosono, T., Chen, X. M. \& Yoda, T. (1997) "Set point" revisited. In: Thermal Physiology 1997, edited by Nielsen-Johansen B and Nielsen R. København: August Krogh Institute, p. 39-43

Kirk, D. (1970). Optimal Control Theory. Prentice-Hall Inc., Englewood Cliffs, New Jersey.

Khoo, M. C. K. (1999) Physiological Control Systems: Analysis, Simulation, and Estimation. Wiley-IEEE Press.

Lane, M. A., Baer, D., Rumpler, W., Weindruch, R., Ingram, D., Tilmont, E., Cutler, R. \& Roth, G. (1996). Calorie restriction lowers body temperature in rhesus monkeys, consistent with a postulated anti-aging mechanism in rodents. Proc. Nat. Acad. Sci. USA 93: 4159-4164.

Mekjavic, I.B., Sundberg C.J., \& Linnarsson, D. (1991) Core temperature "nullzone." J. Appl. Physiol. 71: 1289-1295.

Mekjavic, Igor B., \& Ola Eiken. (2006) Contribution of thermal and nonthermal factors to the regulation of body temperature in humans. J. Appl. Physiol. 100: 2065-2072.

Mercer J. Glossary of terms for thermal physiology. (2001) Jpn. J. Physiol. 51: 245 280.

Monteiro, L. H. A. (2006). Sistemas Dinâmicos. 2a ed. Editora Livraria da Física. Nise, N. (2003) Control Systems Engineering, $4^{\text {th }}$ edition, Wiley.

Pianka, E. R. (2000). Evolutionary Ecology. 6a ed. Addison Wesley Longman.

Poincaré, H. (1995). O valor da ciência. Editora Contraponto.

Rodriguez-Gironés, M. A. (2002). Predicting body temperature of endotherms during shuttling. J. Ther. Biol. 27: $393-403$. 
Romanovsky, A. A., Ivanov, A. I., \& Shimansky, Y. P. (2002) Selected Contribution: Ambient temperature for experiments in rats: a new method for determining the zone of thermoneutrality. J. Appl. Physiol. 92: 2667 - 269.

Romanovsky, A. A. (2007). Thermoregulation: some concepts have changed. Functional architecture of the thermoregulatory system. Am. J. Physiol. Regul. Integr. Comp. Physiol. 292: R37-R46.

Romanovsky, A. A. (2004). Do fever and anapyrexia exist? Analysis of set pointbased definitions. Am. J. Physiol. Regul. Integr. Comp. Physiol. 287: R992R995.

Schmidit-Nielsen, K. (1997). Animal Physiology: adaptation and environment. 4th edition Cambridge University Press, Cambridge.

Smith, Donald R. (1998). Variational Methods in optimization Dover Publications Inc.,Mineola, New York.

Schmid, J. \& Speakman, J. R. (2000). Daily energy expenditure of the grey mouse lemur (Microcebus murinus): a small primate that uses torpor. J. Comp. Physiol. B 170: 633-641.

Song, X. \& Geiser, F. (1997). Daily torpor and energy expenditure in Sminthopsis macroura: interactions between food and water availability and temperature. Physiol. Zool. 70: 331-337.

Souza, S. C. R., Carvalho, J. E. Abe, A. S., Bicudo, J. E. P. W. \& Bianconcini, M. S. C. (2004). Seasonal metabolic depression, substrate utilisation and changes in scaling patterns during the first year cycle of tegu lizards (Tupinambis merianae). J. Exp. Biol. 207: 307-318.

Strijkstra, A. M. \& Daan, S. (1997). Ambient temperature during torpor affects NREM sleep EEG during arousal episodes in hibernating European ground squirrels. Neurosci. Lett. 221: 177-180.

Talmage, R. V., Lester, G. E., Hirsch, P. F. (2000). Parathyroid hormone and plasma calcium control: an editorial. J. Musculoskel. Neuron. Interact.; 1(2):121-126.

Tikuisis, P. (2003). Heat balance precedes stabilization of body temperatures during cold water immersion. J. Appl. Physiol. 95: 89-96.

Webb, P. (1995). The physiology of heat regulation. Am. J. Physiol. Regul. Integr. Comp. Physiol. 268: R838-R850. 
Westman, W. \& Geiser, F. (2004). The effect of metabolic fuel availability on thermoregulation and torpor in a marsupial hibernator. J. Comp. Physiol. B 174: 4957.

Withers, P. C. (1992). Comparative Animal Physiology. Saunders College Pub., Fort Worth 